Erster Beratungsgegenstand:

\title{
Das demokratische Prinzip im Grundgesetz
}

1. Bericht von Professor Dr. Werner von Simson, Freiburg Inhalt

Seite

A. Zum demokratischen Prinzip . . . . . . . . . . . . . . 4

I. Neuere Zweifel am demokratischen Prinzip . . . . . 4

II. Die Eindeutigkeit des Prinzips in negativer, ausgrenzender Hinsicht . . . . . . . . . . . 5

III. Der Bereich des Unbezweifelten in der positiven Ausgestaltung des Prinzips . . . . . . . . . . . 7

B. Zur Anwendung des demokratischen Prinzips . . . . . . 10

I. Die Entscheidung für das demokratische Prinzip . . . 11

II. Die verfassungstechnischen Mittel zur Verwirklichung des demokratischen Prinzips . . . . . . . . . . . . . 12

1. Die Vorabbestimmung des Willens . . . . . . . . 13

a) Die Willensausschließung . . . . . . . . . 13

b) Die positive Willensfestlegung . . . . . . . . 14

aa) Die „rechtsstaatliche und soziale“ Demokratie 15

bb) Die "freiheitliche" Demokratie . . . . . . 17

cc) Die „bundesstaatliche“ Demokratie ... . 20

dd) Die den Staat transzendierende Demokratie 21

c) Anhang: Zur Interpretierbarkeit der Vorabbestimmung .............. 21

2. Die Willensverteilung . . . . . . . . . . . 22

a) Die Aufteilung innerhalb staatlich-hoheitlicher

Instanzen . . . . . . . . . . . 22

aa) Die Verteilung auf Gesetzgeber und

Regierungs- und Verwaltungsorgane . . . . 22

bb) Die Verteilung auf kurz- und langfristig ausgerichtete Willensorgane . . . . . . 25

cc) Die Verteilung auf staatliche und zwischenstaatliche Institutionen . . . . . . . . 26

b) Die Aufteilung zwischen staatlich-hoheitlichen und nicht-hoheitlichen Instanzen . . . . . 28

3. Die Willensverschränkung . . . . . . . . . . 30

a) Die Verschränkung verschiedener Wahlmöglichkeiten 
aa) Die Verschränkung von zentralen und regionalen Entscheidungsebenen . . . .

bb) Die Verschränkung von demokratischen und undemokratischen Entscheidungsverfahren

cc) Die Verschränkung von Wählerwillen und Willen des Gewählten. . . . . . . . . . 31

dd) Die Verschränkung in der Mehrgleisigkeit des politischen Gesamtwollens

b) Einzelne im GG vorgenommene Willensverschränkungen . . . . . . . . . . . 33

aa) Die Verschränkung der Willensmöglichkeit verschiedener Organe . . . . . . . . . . . 33

bb) Verschränkungen des Willensgefüges . . . 34

III. Das demokratische Prinzip in der Verfassungswirklichkeit 35

1. Die Gefährdung durch mangelndes Demokratiebewußtsein und undemokratische Herrschaftsansprüche . . . . . . . . . . . . 35

2. Die von der Natur der modernen Aufgaben und Probleme ausgehende Bedrohung . . . . . . $\quad 35$

3. Die Entwicklungsfähigkeit des demokratischen Prinzips im GG . . . . . . . . . . .

\section{A. Zum demokratischen Prinzip*)}

Mir ist zumute wie einem Dorfkaplan, der beauftragt worden ist, vor dem Vatikanischen Konzil einen einstündigen Vortrag zu halten über das Thema: Die Bibel. Mein Trost ist, daß das vom Vorstand für den ersten Tag der diesjährigen Tagung bestimmte Thema seine einleitende clausula salvatoria in sich trägt. Es umfaßt, wollte man es voll ausschöpfen, so ungefähr den gesamten Bereich des geltenden deutschen Staatsrechts. So kann also nicht davon die Rede sein, vor der Staatsrechtslehrervereinigung das allseits Bekannte in oberflächlicher Skizzierung auszubreiten. Vielmehr muß das Referat dies alles voraussetzen, und Geistes- und Dogmengeschichte des Demokratiebegriffs müssen neben vielem anderen unerörtert bleiben.

I. Neuere Zweifel am demokratischen Prinzip

Aber gegen manches, was bis vor kurzem als selbstverständlich galt, erheben sich heute Zweifel. Teils stammen sie aus unseren eigenen Reihen, teils aus Nachbardisziplinen ${ }^{1}$ ). Auch mehr oder weniger radikale Zauberlehrlinge und Sonntagsjäger des Staatsrechts lassen sich hören und wissen einen Teil der

*) Die in eckige Klammern gesetzten Abschnitte wurden aus Zeitgründen nicht vorgetragen. Auf einen nach Vollständigkeit strebenden Zitierapparat wurde verzichtet.

1) Vor allem zählen hier die Politikwissenschaft und die Soziologie. 
öffentlichen Meinung zu gewinnen. Die Staatsrechtslehre muß $\mathrm{zu}$ all dem Stellung nehmen, und ich fasse das gestellte Thema so auf, daß wir unsere Meinungen über diese Stellungnahme austauschen wollen.

Zunächst beginnt dieser Zweifel - insofern kann ich ihn als vorwiegend von außen kommend klassifizieren - mit dem Begriff der Demokratie selbst. Die Schöpfer des Grundgesetzes - bestärkt durch Carlo Schmids magistrale Definition im Parlamentarischen Rat ${ }^{2}$ ) - gingen praktisch noch von einem eindeutigen Begriff aus. Inzwischen lesen wir bei Konrad Hesse ${ }^{3}$ ), es gebe kaum einen verfassungsrechtlichen Begriff, dem so unterschiedliche Deutungen gegeben würden, wie dem der Demokratie. Obwohl das demokratische Prinzip die verfassungsmäßige Ordnung des GG primär bestimme, bestehe darüber, was „Demokratie" sei, eine Fülle verschiedenster, oft gegensätzlicher Auffassungen. Die Politologen sagen ähnliches $\left.{ }^{4}\right)$. Die sogenannte neue - in Wahrheit ja recht betagte - Linke wirft der heutigen Demokratie des Westens vor, sie sei weder demokratisch, noch wolle sie es sein. Sie tue nur so, um ihr wahres antidemokratisches Wesen zu verschleiern ${ }^{5}$ ).

Hätten wir nun also unsere Sicherheit verloren was den Begriff eines demokratischen im Gegensatz zu einem nicht-demokratischen Staat anlangt?

\section{Die Eindeutigkeit des Prinzips in negativer, ausgrenzender Hinsicht}

In der verfassungsrechtlich wichtigsten, der negativen, ausgrenzenden Hinsicht besteht kein AnlaB zu Zweifel und Unsicherheit. Der die Minimalanforderungen beschreibende Grenzbegriff "Demokratie“ tritt deutlich hervor, wenn man sich ansieht, was die Diktaturbeflissenen in einem Staat abschaffen, sobald sie es können'). Dieser engere Begriff war nach

2) Parlamentarischer Rat, Plenum. Sitzung (8. 9. 1948), Stenographischer Bericht S. 13 ff.

3) K. Hesse, Grundzüge des Verfassungsrechts der Bundesrepublik Deutschland, 4. Aufl., 1970, S. 52.

4) F. Scharpf, Demokratietheorie zwischen Utopie und Anpassung, 1970 , S. 8; M. Hättich, Demokratie als Herrschaftsordnung, 1967, S. 11 ff., mit Hinweisen auf weitere Autoren, die den Demokratiebegriff als mehrdeutig bezeichnen (S. 13).

5) $M$. Hättich, Demokratie und Demokratismus. Zum Demokratieverständnis der "Neuen Linken“, in: Schenck (Hrsg.), Die Wiedertäufer der Wohlstandsgesellschaft, 1968, S. $124 \mathrm{ff}$; vgl. auch J. Agnoli/P. Brïckner, Die Transformation der Demokratie, 1968

o) S. z. B. R. Dubs (Hrsg.), Freiheitliche Demokratie und totalitäre Diktatur. Eine Gegenüberstellung am Beispiel der Schweiz und der Sowjetzone Deutschlands, Frauenfeld 1966. 
der nationalsozialistischen Zeit der zunächst bei weitem wesentlichste. Er zeigte, worauf es vor allem ankommt, und wo wir uns nicht irre machen lassen dürfen. Man versucht ja, uns heute $\mathrm{zu}$ verunsichern, wie der seiner Erfinder würdige Ausdruck lautet. Alle überhaupt existierenden Regierungssysteme nennen sich jetzt demokratisch. Man spricht von einer kollektiven im Gegensatz zur individualistischen ${ }^{7}$ ) und ebenso von einer totalitären Demokratie. Auch der terminus „autoritäre Demokratie ${ }^{\text {(8) }}$ wagt sich wieder hervor"). Demokratie soll dabei so viel heißen wie "legitimiert am wahren Volksinteresse“.

Aber das ist eine Vorwegnahme des entscheidenden Problems und damit eine Verfälschung des wahren Unterschiedes zwischen demokratischen und nicht-demokratischen Zielsetzungen. Der Unterschied besteht ganz offenbar in folgendem: Bei den östlichen, wie überhaupt bei allen dogmatisch fundierten Regierungssystemen ist das Volksinteresse vorbestimmt von Wissenden, und die Aufgabe besteht nicht in seiner Erkenntnis, sondern in seiner Verwirklichung. Kollektiv, autoritär heißt hier eindeutig. Die anderen, Nichtwissenden, haben sich zu fügen, sonst handeln sie gegen das Volksinteresse. Sie zählen nur, soweit sie den Wissenden Beifall spenden.

Nach der Zielsetzung demokratischer Regierungsformen dagegen ist die Definition des Volksinteresses, welches die Staatsmacht legitimiert, einem Prozeß der freien Diskussion, und die Bestimmung derjenigen, welche diese Macht ausüben, einem nach festgelegten Regeln stattfindenden Kampf um die politische Macht überlassen ${ }^{10}$ ), Regeln, die in der Hauptsache folgendes sichern sollen: die Freiheit der Meinungsäußerung, die Mitwirkung bei der Bildung des Staatswillens und bei der Kon-

7) $H$. Wheeler, Democracy in a Revolutionary Era, Santa Barbara 1970, S. 6.

8) R. Ahlberg, Akademische Lehrmeinungen und Studentenunruhen. Linker Irrationalismus in politologischen und sozlologischen Theorien, Freiburg i. Br. 1970, spricht (S. 17) von Karl Jaspers „totalitär-messianistischer Konzeption des 'Volkes'“. Vgl. auch L. Talmon, Die Ursprünge der totalitären Demokratie, 1961 (deutsche Ausgabe von: The Origins of Totalitarian Democracy, London 1955).

$\left.{ }^{9}\right)$ L. Romain-G. Schwarz (Hrsg.), Abschled von der autoritären Demokratie, 1970. Kritisch darin: Schwarz, S. $40 \mathrm{ff}$. Der Begriff ist ein anderer als der von W. Kägi, Rechtsstaat und Demokratie, in: Festschrift für Giacometti, Zürich 1953, S. 107 ff., widerlegte Begriff der dezisionistisch-totalitären Demokratie, nach welchem die Mehrheit der an der Entscheidung teilnehmenden stimmfähigen Bürger eo ipso recht hat.

10) "Competition for political leadership" als das wesentliche Merkmal der Demokratie wird besonders hervorgehoben von J.A.Schumpeter, Capitalism, Socialism and Democracy, London 1943 und 1961, S. $269 \mathrm{ff}$. 
trolle seiner Ausübung, die Bereitschaft, sich dabei überstimmen zu lassen, und das Recht der Minderheit, sich um die Macht zu bemühen ${ }^{11}$ ). Keines dieser Rechte kann effektiv sein ohne freie Meinungsäußerung ${ }^{12}$ ) und ohne da $\beta$ eine Wahl besteht zwischen den jeweils Regierenden und anderen, die an deren Stelle regieren könnten. Keines dieser Rechte gibt es, so verstanden, in einer Despotie oder sogenannten Volksrepublik. Aber es gibt sie in jeder Demokratie. Das ist der Prüfstein, auf den die wechselseitigen Behauptungen über demokratische oder nicht-demokratische Zustände aufgetragen werden müssen.

[Aber auch die Demokratie, welche diese Probe besteht, bleibt immer nur ein Entwurf. Wir können kaum mehr von ihr sagen, als was Hans Zacher ihr zuschreibt: daß sie jedenfalls das Herrschaftssystem ist, welches die kleinste auf die Dauer vernachlässigte Minderheit aufweist ${ }^{13}$ ). Sie ist die Regierungsform, in der immer aufs neue die miteinander konkurrierenden gesellschaftlichen Ansprüche auf ihren gegenseitigen Vorrang hin geprüft werden sollen.]

Was wir heute vorfinden ist also die Eindeutigkeit des demokratischen Prinzips nach dieser negativen Seite. Dem steht seine Vieldeutigkeit nach der Seite seiner weiteren Entfaltung gegenüber. Erst wo das ausgrenzende Gebot gewahrt und der Staat insoweit demokratisch ist, öffnet sich der Blick für die nach diesem Verzicht zur Wahl stehenden vielfältigen Verwirklichungsformen der positiven demokratischen Existenz. Und hier allein, nicht im Verhältnis zu pseudo-demokratischen Lehren, kann von einer Vieldeutigkeit des Demokratiebegriffs die Rede sein.

\section{Der Bereich des Unbezweifelten in der positiven} Ausgestaltung des Prinzips

Für die konkrete Existenz des Staates, und auch gerade für seine konkrete demokratische Legitimation, sind aber Elemente der Eindeutigkeit erforderlich, die sich aus der negativen Definition noch nicht ergeben. Nicht alle diese Elemente können einem aktuellen politischen Willen entsprechen. Vieles muß,

11) Der Wechsel zwischen regierenden Parteien, und also die praktische Aussicht der Minderheit, zur Mehrheit zu werden, ist in der englischen Auffassung für das Funktionieren der Demokratie notwendig. Denn nur so kann die Minderheit sich überstimmen lassen, ohne sich ausgeschlossen zu fühlen.

12) John Milton (Areopagitica): "Give me the liberty to know, to utter, and to argue freely according to conscience, above all liberties".

19) H. F. Zacher, Freiheitliche Demokratie, 1969, S. 20. 
so sehr es sich auch bezweifeln ließe, praktisch unbezweifelt bleiben. Ich nenne als Beispiel die Artikulation des pouvoir constituant durch die Landtage bei der Beschlußfassung über das GG. Vieles andere, so etwa die nähere Ausgestaltung des Wahlrechts, muß einfach so oder so entschieden und der weiteren, sonst alles zersplitternden Diskussion entzogen worden sein, wenn die demokratischen Forderungen der Freiheit und Gleichheit überhaupt irgendwie zur Geltung kommen und mit Ordnung und Leistung des politischen Gemeinwesens vereinbar sein sollen.

[Diese Elemente größerer Eindeutigkeit werden auf verschiedene Weise gewonnen. Es geschieht dies teils durch unbewußtes gemeinsames Verhalten ${ }^{14}$ ), teils durch vorab getroffene, das Tagesgeschehen bindende Entscheidungen. Die letzteren wieder entstehen zum einen Teil aus unbezweifelter konventioneller Ubung, zum anderen aus zwangsläufiger Fortsetzung früheren Geschehens ${ }^{15}$ ), schließlich aber auch aus dem, was uns hier besonders beschäftigt, nämlich aus einer von der Verfassung bewirkten Festlegung, einem bewußten Vorsatz also. Dieser Vorsatz wiederum kann sich nur zum Teil in konkreter Normsetzung auswirken. Für vieles muß er sich auf das Offenhalten von späteren, wandelbaren Möglichkeiten und auf den Entscheidungsmechanismus richten, durch den Bestimmtheit und Wandel herbeigeführt werden.]

Denn der demokratische Staat kann natürlich nicht alles widerlegbar oder offen lassen. Er kommt ohne Unterstellungen nicht aus, er kann nicht alles wissen, was er wissen müßte, um nur auf einwandfrei erkannten Wahrheiten zu beruhen. Aber seine Unterstellungen sind von anderer Art als die der dogmatisch fundierten Systeme. Er nimmt nicht in Anspruch, daß die Wissenschaft halt zu machen habe vor seinen Axiomen. Er will nicht mehr behaupten, als $\mathrm{da} B$ diese Unterstellungen die frei gebildete Meinung einer großen, wechselnden Mehrheit darstel-

14) F. A. von Hayek, Die Irrtümer des Konstruktivismus, 1970, S. 8 und passim, macht es sich besonders zur Aufgabe, zu zeigen, „daß die Menschen in ihrem Handeln stets nicht nur von ihrer Einsicht in Kausalzusammenhänge zwischen bekannten, konkreten Mitteln und bestimmten, angestrebten Zielen, sondern stets auch von Verhaltensregeln geleitet werden, deren sie sich selten bewuBt sind, die sie gar nicht absichtlich geschaffen haben, und deren Funktion und Bedeutung zu entdecken eine schwiergie und nur unvollkommen gelöste Aufgabe der Wissenschaft ist".

15) F. Scharpf, aaO. (s. Anm. 4) S. 61 weist nach Belegen von A.von Brïnneck darauf hin, daB in den öffentlichen Haushalten der Bundesrepublik „die politisch nicht disponiblen 'versteinerten' Ausgabepositionen etwa 90 Prozent des Gesamtvolumens ausmachen." 
len oder daß sie als nützliche Konvention, als eine Formel also, die um der Notwendigkeit eindeutigen Handelns willen die Diskussion zunächst einmal abschließt, unabhängig von ihrem objektiven Wahrheitswert akzeptiert werden.

Die wesentlichste derartige Unterstellung in der Demokratie betrifft das Formale. So wird z. B. unterstellt, die Mehrheit treffe eher das Richtige als die Minderheit $\left.{ }^{16}\right)$. Der oft gehörte Vorwurf der „Formaldemokratie“ ist deshalb nichts anderes, als der Vorwurf des Nichtdemokraten gegen die Demokratie. Jede Demokratie ist zunächst eine Formaldemokratie. Denn der Verzicht auf das einer demokratischen Zustimmung nicht weiter unterliegende Absolute ist, wie vielfach erkannt worden ist, eben nur möglich, wenn die Regeln, die über den jeweiligen Vorrang einer Meinung über die andere entscheiden, ihrerseits für absolut genommen werden. Ein Organismus ohne Regeln, das weiß auch die Biologie, geht an sich selbst zugrunde.

[Die besonderen Bedingungen, unter denen allein diese hochkomplizierte politische Lebensform mit den Anforderungen staatlicher Selbsterhaltung vereinbar ist, und die Fragen, die sich aus dem Verhältnis der Demokratien zu Staaten ergeben, die strafferer Befehlsformen bedürfen oder zu bedürfen glauben, kann ich hier nicht erörtern. Diese Fragen sind bis in die jüngste Zeit hinein in katastrophaler Weise leicht genommen worden $\left.{ }^{17}\right)$. Wir fangen erst an, $z u$ sehen, zu welchen Despotien der Versuch der Einführung von Freiheiten dort führt, wo deren Voraussetzungen nicht vorliegen. Wir müssen uns, in einem Zeitalter universaler Bedrohungen, auf die politischen Gebilde einrichten, die wir vorfinden, und nicht auf die, die wir uns an deren Stelle wünschten.]

Für die Unterscheidung, auf die es uns ankommt, bleibt es bei der klaren Alternative: Wo der Staat, sei es infolge nicht zu beseitigender Machtverhältnisse, sei es, weil er sonst seine $\mathrm{Da}-$ seinsbedingungen nicht erfüllen kann, nicht auskommt mit freiwillig akzeptierten, keinem materiellen Wahrheitsanspruch widersprechenden, der Diskussion und freien Meinungsbildung offenstehenden Unterstellungen, wo er also wissenschaftliche, d. h. der prinzipiellen Widerlegbarkeit unterliegende Aussagen für unwiderleglich erklären und deren Leugner einsperren, töten oder verbannen muß, da mag an sonstiger Gleichheit und

10) Das war wenigstens die Prämisse, von der aus Rousseau zu der Ansicht gelangte, der in der Minderheit Stimmende habe sich geirrt, da es sein wahrer Wille gewesen sein müsse, in der Mehrheit zu stimmen.

${ }^{17}$ ) Dies wird besonders deutlich in der Darstellung von J. K. Galbraith, Ambassador's Journal, London 1969. 
Freiheit gewährt sein was will, da mögen Leistungen der höchsten Art erbracht werden, aber da besteht keine Demokratie. Denn da kann der Staat eine ganz bestimmte Gleichheit, nämlich die Gleichheit der Erkenntnismöglichkeiten und des damit verbundenen Rechts auf Irrtum, und eine ganz bestimmte Freiheit, nämlich die Freiheit der objektiven Wahrheitsfindung, nicht dulden. Das ist die Beziehung dieses undemokratischen Herrschaftstypus zur Wahrheit.

Seine Beziehung zur Freiheit und Menschlichkeit kann ich nicht besser ausdrücken als durch das Wort Rilkes, wonach „eine Zeit, die die göttliche Güte der Vorsehung vorweg auszuteilen unternimmt, zugleich auch die ältesten Vorräte der Grausamkeit unter die Menschen reißt“18). Wir Älteren, die wir die Unmenschlichkeit - nicht als Versagen, sondern als Prinzip - mit Augen gesehen haben, können kaum fassen, wie schnell dieses apokalyptische Bild der Vorstellung unserer Zeit verblaßt ist.

\section{B. Zur Anwendung des demokratischen Prinzips}

Es erübrigt sich, vor dieser Versammlung die einzelnen Regelungen, mit denen das GG auf die soeben geschilderte Alternative reagiert, noch etwa nachzuzeichnen. Stattdessen will ich versuchen, das allgemein Bekannte in bestimmte methodische Kategorien einzuteilen und damit die Technik zu schildern, mittels derer das GG das demokratische Prinzip zu politischem Leben $\mathrm{zu}$ bringen sucht. In dieser methodischen, eigentlich dem Gebiet der allgemeinen Staatslehre zugehörigen Richtung besteht nämlich nach meiner Meinung ein Nachholbedarf. Wir brauchen dieses methodische Instrumentarium um so nötiger, als wir zunehmend in überstaatliche Verfassungsfragen verstrickt werden, die in neue Begriffe gefaßt werden müssen.

Die Theorie des demokratischen Gedankens selbst mag ausgiebig genug behandelt worden sein. Ich habe ihr jedenfalls, wie Sie gesehen haben, nichts hinzufügen können. Die Theorie der Anwendung dieses Prinzips steht dagegen in ihren Anfängen. Man kann sie heute, wenn ich recht sehe, in drei Felder aufteilen:

In dem einen wird gefragt, ob die hier definierte Freiheit den Preis wert sei, den sie kostet, ob wir also Demokratie haben sollten bzw. uns leisten könnten, oder nicht, und ob da etwa Graduierungen möglich seien (unten I).

18) Zitiert bei W. Haftmann, Skizzenbuch. Zur Kultur der Gegenwart, 1960 , S. 13, der hinzufügt: "Um 90 v. H. theoretisch zu beglücken, werden $10 \mathrm{v}$. H. praktisch erschlagen." 
Im zweiten Feld ist die Frage, ausgehend von der Bejahung der ersten, welche Mittel zu Gebote stehen, um den erwünschten Freiheitsgrad und die vorläufigen Unbestimmtheiten zu sichern, die er verlangt. Wie kann also versucht werden, das politische Leben mit seinen Kräften und ständig drängenden Impulsen auf den Vorsatz der Freiheitsgewährung im demokratischen, wahrheitssuchenden Sinne festzulegen (unten II)?

Im dritten Felde schließlich stellt sich die Frage nach den wirklichen Folgen des derart Betriebenen, die Frage, die wir gewohnt sind, als die nach der Verfassungswirklichkeit zu bezeichnen (unten III).

\section{Die Entscheidung für das demokratische Prinzip}

Die erste Frage möchte ich aus unserem Thema ausklammern. Den Schöpfern des GG hat sie sich gar nicht erst gestellt. Sie durften ihr pouvoir constituant ja nur unter der Voraussetzung und ausdrücklichen Bedingung ausüben, daß sie einen demokratischen Staat gründeten. Darüber hinaus beschränkt sich, im Gegensatz zu Weimar, auch heute noch die grundsätzliche Ablehnung dieser politischen Lebensform auf eine unbedeutende Minderheit.

[Ein Teil davon zieht die einzig in Betracht kommende Alternative, die Zugehörigkeit zum kommunistischen Machtsystem in einer seiner Ausprägungen, vor. Ein anderer übt sogenannte theoretische Kritik, die in ihrer intelligenteren Schicht das Vorliegen der kommunistischen Alternative erkennt und sie ablehnt. Sie hat sich daher für die Abkehr von allen weltlichen Versuchungen entschieden $\left.{ }^{14}\right)$. Ihre weniger nachdenklichen Gefolgsleute können eine ernst zu nehmende dritte Möglichkeit nicht einmal andeutungsweise aufzeigen und halten das zum Teil auch für unter ihrer Würde. Für das weitaus überwiegende Bewußtsein unserer Zeit ist jedenfalls der demokratische Staat als möglich, ja als nötig erkannt und damit unserem staatsrechtlichen Denken vorgegeben. Diese Entscheidung ist nicht mehr, wie uns Carl Schmitt und Hans Kelsen im Interesse einer realeren Erfassung der damals in Betracht kommenden Möglichkeiten belehren mochten, beliebig und für die Geltung des Rechtes irrelevant ${ }^{20}$ ). Sie ist Vorbedingung für eine Qualität des Rechts, die wir heute mit seinem normativen Geltungsanspruch identifizieren.]

10) Vgl. G. Rohrmoser, Das Elend der kritischen Theorie. Theodor W. Adorno, Herbert Marcuse, Jürgen Habermas, 1970, S. $103 \mathrm{ff}$.; C. Graf von Krockow, Die Entscheidung, 1958, S. 92 Anm. 206.

${ }^{20}$ ) Statt vieler vgl. $H$. Ehmkes Gleichsetzung von $C$. Schmitt und H. Kelsen in: Grenzen der Verfassungsänderung, 1953, S. $33 \mathrm{ff}$. 
II. Die verfassungstechnischen Mittel zur Verwirklichung des demokratischen Prinzips

Begeben wir uns also getrost auf das zweite Feld, dessen Behandlung den Hauptteil dieses Berichts bildet. In diesem Felde stellt sich die Frage nach den Mitteln, mit denen das demokratische Prinzip in die Staatswirklichkeit zu übertragen ist. Hier sucht die Staatstheorie, die wir damit auch die demokratische Theorie nennen können, jetzt ihren eigentlichen Standort.

Die Demokratie ist ein Vorsatz. Aber wie führt man einen solchen Vorsatz in das politische Leben ein, so daß er zugleich das Essentielle gegenüber abweichenden späteren Willenslagen sichert und doch für das übrige den Willen frei läßt?

Die Kategorien, in die ich diese Mittel aufteilen möchte, sind: erstens die Ausschließung bestimmter Willensmöglichkeiten und die Festlegung des Willens auf bestimmte Ziele, zusammenzufassen als die Vorabbestimmung des Willens (unten 1), zweitens die Willensverteilung (unten 2), und drittens die Willensverschränkung (unten 3). Es handelt sich also darum, daß zunächst bestimmte Dinge als Möglichkeit politischen Wollens in dem derart verfaßten Staat überhaupt ausgeschlossen, andere dem Tageswillen durch die Verfassung vorgegeben oder doch aufgetragen werden; da $\beta$ ferner die Möglichkeit des verbleibenden politischen Wollens auf verschiedene Willenssubjekte oder auf verschiedene Verfahren der Willensbildung verteilt wird; und daß schließlich die derart verteilten Willensmöglichkeiten untereinander verschränkt, $d$. h. voneinander abhängig gemacht, vorformuliert und auf bestimmte Alternativen reduziert werden, zwischen denen das zuständige Willenssubjekt allein wählen $\mathrm{kann}^{21}$ ). Alle drei Mittel dienen der Stabilisierung vorgefaßter oder von besonderen Bedingungen abhängiger Entschlüsse gegenüber dem auf aktueller Majorität beruhenden Willen. Sie stellen also eine Modifikation des einfachen demokratischen Prinzips dar.

21) Der Einwand von $H$. Ehmke (VVDStRL 24, S. 94 f.), die Frage der Organisation der Lenkungs-, Leitungs-, Koordinierungs- und Führungsfunktion im Staat komme zu kurz, wenn man davon ausgehe, "die ganze Politik (bestehe) offenbar einfach in Willensbildung", scheint mir nicht gegen die Auffassung zu sprechen, wonach die verfassungsrechtliche Sicherung politischer Fundamentalentscheidungen in der Tat durch die hier unterschiedenen Formen der Willensbeeinflussung erfolgt. Das politische Geschehen wird damit nicht voll erfaßt, aber in Grenzen verwiesen (verfaßt). 
Wie setzt das GG diese Mittel ein?

1. Die Vorabbestimmung des Willens

a) Die Willensausschließung

Nehmen wir zunächst die Vorabbestimmung des Willens. Von dieser gehe ich zuerst auf die Willensausschließung ein.

Im GG ist das, was von seinem Staat überhaupt nicht gewollt werden kann, was also durch kein Tätigwerden eines verfassungsmäßigen Organs zum Staatswillen zu erheben ist, bekanntlich in Art. 79 III aufgezählt. Damit wird die Identifizierung bestimmter, für unangreifbar erklärter Verfassungszustände mit dem Gesamtbestand des konkret verfaßten Staates ausgesprochen. Ich übergehe die hierin liegende Problematik, sowohl was den Umfang dieses Katalogs als auch was die Legitimation zu derartigen Festlegungen betrifft. Sie ist uns allen geläufig. Wichtig ist mir hier nur die damit ausgesprochene Abkehr vom Positivismus sowohl der einfachen als auch der verfassungsändernden Gesetzgebung. Ein ein für allemal geltender positiver Verfassungswille beschränkt die Möglichkeit abweichender konstitutioneller und subkonstitutioneller Rechtsetzung.

$[\mathrm{Da} B$ dies bei uns durch einen Rechtssatz, und nicht, wie bei anderen Demokratien, durch das sichere Bewußtsein der Bürger erfolgt, die dem Staat bei Verletzung bestimmter Grundsätze die Gefolgschaft versagen würden, ist gut zu erklären. Denn gerade dem rechtlichen Deutschen fällt es unendlich schwer, das eigene Urteil über Eid und Gesetz zu stellen. Stein, York und die Göttinger Sieben, auch die Männer des Widerstands gegen Hitler, sind Ausnahmen. Heute besteht jedenfalls, neben dem inneren, ein äußeres Gesetz, vermöge dessen der Staat es zu seiner Bedingung und zugleich zu seiner Rechtfertigung macht, $\mathrm{da} B$ er für das Gebiet des ihm nicht zugänglichen, dessen was $\mathrm{zu}$ wollen ihm nicht erlaubt ist, jede mögliche Staatsmacht konsumiert und ausschaltet.]

Die negative Funktion der Verfassung betrifft zunächst die Abhängigkeit der Staatsmacht von demokratischer Legitimation, sodann die grundrechtlichen und anderen Freiheiten, schließlich das Ausklammern unmenschlicher Möglichkeiten aus dem rechtlich legitimierbaren Staatshandeln. Dieser Verzicht beansprucht jetzt unter den staatsbegründenden Faktoren den vielleicht höchsten Rang, höher noch als den der Legitimation durch eine Ordnung und Leistung, die auf diese Dinge keine Rücksicht nähme. Nicht was der Staat alles kann, sondern was er nicht können darf, bindet heute viele Bürger an ihren Staat. Und das Widerstandsrecht des Art. 20 IV richtet sich genau- 
so gegen die von der öffentlichen Gewalt unternommenen, wie gegen private Angriffe auf die verfassungsmäßige Ordnung. Zugleich ist, in einem die Demokratie mehr und mehr faktisch unterbauenden Sinne, dieses Nichtkönnen zur Grundbedingung für die überstaatliche, immer lebenswichtiger werdende Gruppenzugehörigkeit der Demokratien untereinander geworden. Ubi libertas nicht nur, sondern ubicumque libertas, ibidem patria.

Auch andere, im GG selbst nicht als unveränderlich bezeichnete Grundsätze nehmen daran teil. Ich nenne nur den in Art. 26 I verbotenen Angriffskrieg. Die Verfassungswirklichkeit geht hier über den Verfassungstext hinaus. Die neuere Zeit neigt sogar dazu, und zwar nicht nur bei uns, das Gewissen, oder was dafür ausgegeben wird, schon in mehr und mehr formloser, eines Anerkennungsverfahrens nicht mehr bedürftiger Weise zur Geltung gegenüber dem Staatswillen kommen zu lassen. Plebiszitäre Erscheinungen, vom GG so ängstlich vermieden, treten auf, und ihre Unterdrückung wird politisch nicht leicht genommen. Kennzeichnend hierfür ist die neuere Behandlung des Demonstrationsrechts, und die Protestbewegung gegen den Krieg in Vietnam. Es sind Zeichen im guten, hoffnungsvollen, aber auch im bedrohlichen, dilettantisch irrenden oder bewußt zerstörerischen Sinne: Chancen und Gefahren der Demokratie.

b) Die positive Willensfestlegung

Soviel zur Willensausschließung. Die Frage der positiven Willensfestlegung ist zweifellos eine Frage des Aufbaus der Freiheit in der Gesellschaft, die Frage also zunächst, welche Entscheidungen als Grundbestand des ganzen Zusammenlebens vorweggenommen und damit der weiteren Diskussion, dem Wettbewerb der Meinungen und Uberzeugungskräfte, der Veränderlichkeit je nach Zustimmung oder Ablehnung entzogen bleiben sollen. In welcher Hinsicht soll, um den fruchtbaren Begriff Herbert Marcuses ${ }^{22}$ ) hier anzuwenden, der Staat eindimensional, d.h. ohne Wahl bleiben, und in welcher anderen soll, gewissermaßen als Lohn und Sinn dieser Eindeutigkeit, die Ausbildung mehrerer Dimensionen und die Wahl zwischen diesen möglich, ja erforderlich sein?

Nach meiner Ansicht nimmt das GG zu dieser Frage - neben dem Bundesstaatsprinzip - Stellung durch die Eigenschaftswörter, mit denen es die Demokratie versieht. Rechtsstaatlich und sozial muß sie sein. Insoweit bleibt es bei einer Dimension. Aber solange sie dieses ist, soll und muß sie frei-

22) H. Marcuse, Der eindimensionale Mensch, 1969. 
heitlich sein, und das heißt, daß mehrere Dimensionen, und die Wahl zwischen diesen, zu ihrem Wesen gehören. Lassen Sie uns unter diesem Gesichtspunkt einen kurzen Blick auf die Begriffsgruppe rechtsstaatlich und sozial auf der einen, und auf die Freiheitlichkeit auf der anderen Seite werfen.

aa) Die "rechtsstaatliche und soziale" Demokratie

Auf der Bonner Tagung 1953 sind die Begriffe sozial und rechtsstaatlich, und ihr Verhältnis zueinander, erörtert wor$\operatorname{den}^{23}$ ). Es handelt sich hier um ein Grundthema des deutschen Staatsrechts. Als praktisch unbestritten kann heute gelten, daß die Verbürgungen der Rechtsstaatlichkeit nicht so weit reichen, unsoziale Zustände zu verteidigen, die sich ohne diese Verbürgungen beseitigen lassen würden. Auch daß das Wort sozial eine verfassungsrechtlich gebotene Auslegungsdirektive für die Rechtsanwendung ist, wird allgemein anerkannt.

[Die weiteren Verwirklichungen des Sozialen aber werden teils angesehen als einfache rechtliche Gegebenheiten innerhalb des verfassungsrechtlich Möglichen, aber nicht Gewährleisteten $^{24}$ ), teils mit dem höheren Anspruch ausgestattet, sie entsprächen einer verfassungsrechtlichen Verpflichtung des Gesetzgebers, die bisher nur teilweise erfüllt worden sei, und die insbesondere die Auslegung der Grundrechte beherrschen müs$\left.\mathrm{se}^{25}\right)$.]

Darüber hinaus fragt es sich: wieviel von dem, was sozial ist, steht im GG, und wieviel ist der freiwilligen Verwirklichung überlassen? Ich folge der gegenwärtig auch wohl überwiegend gebilligten Meinung von Otto Bachof, wonach der grundsätzliche Akzent auf der Freiwilligkeit liegt $\left.{ }^{26}\right)$. Sozial heißt danach, wenn ich es richtig deute, nicht nur, daß die soziale Leistung erbracht, sondern auch, daß sie in freiwilliger Verantwortung erbracht wird.

[Ein schönes Wort aus Mommsens Römischer Geschichte mag dies erhellen: „Nach dem gleichen Naturgesetz" heißt es dort,

$\left.{ }^{23}\right)$ Bericht von E. Forsthoff, Mitbericht von O. Bachof, Begriff und Wesen des sozialen Rechtsstaates, in: VVDStRL 12, S. $8 \mathrm{ff}$. und $34 \mathrm{ff}$.

24) So auch W. Abendroth, Zum Begriff des demokratischen und sozialen Rechtsstaats im GG der BRD, in: Festschrift für Bergstraesser, Diskussionsbeitrag, 1954, S. 284; ders., in: VVDStRL 12, S. 89; ders., Obrigkeitsstaat oder soziale Demokratie? in: Gewerkschaftliche Monatshefte, Juni 1959, S. 349. Dazu M. Hättich, aaO. (s. Anm. 4) S. 5, bes. Anm. 5.

25) In dieser Richtung wieder: $H$. Scholler, Die Interpretation des Gleichheitssatzes als Willkürverbot oder als Gebot der Chancengleichheit, 1969.

26) VVDStRL 12, S. 81, Leitsatz 7. 
"weshalb der geringste Organismus unendlich mehr ist als die kunstvollste Maschine, ist jede noch so mangelhafte Verfassung, die der freien Selbstbestimmung einer Mehrzahl von Bürgern Spielraum läßt, unendlich mehr, als der genialste und humanste Absolutismus; denn jene ist der Entwicklung fähig, also lebendig, dieser ist, was er ist, also tot".]

Aber in einer Hinsicht ist dieses Bild zu ergänzen, und" es erlebt hier die berühmte normative Kraft des Faktischen eine Revitalisierung. Das eigene Handeln des Staates fügt der Rechtsstaatlichkeit materielle Inhalte zu. Was einmal in sozialer Hinsicht freiwillig gewollt war und verwirklicht worden ist, ist nunmehr, vielleicht nicht in allen, aber doch in allen wesentlichen Stücken, der Freiwilligkeit entzogen. Konnte der Zustand vor Erlaß des Bundessozialhilfegesetzes allenfalls für verfassungsmäßig angesehen werden, weil das soziale Geben, wie das BVerfG anerkannte, das Vorhandensein von Mitteln voraussetzt, über die nur in politischer, nicht in richterlicher Verantwortung verfügt werden $\mathbf{k a n n}^{27}$ ), so würde die ersatzlose Aufhebung dieses Gesetzes wohl kaum diese Probe bestehen. Und so geht es mit manchem anderen. Hat sich einmal gezeigt, daß ein bislang der Verfassung nicht genügender Zustand nicht mehr die Einrede der Unvermeidlichkeit für sich hat, so wird die Beseitigung dieses Zustandes zum positiven Verfassungsgebot $\left.^{28}\right)$.

Eine weitere Bedeutung dessen, was das GG mit dem Wort sozial hat festlegen wollen, tritt mehr und mehr in den Vordergrund, die Tatsache nämlich, um mich einer Formulierung Hans Peter Ipsens ${ }^{29}$ ) zu bedienen, „daß dem verfaßten Träger der Verantwortlichkeit für die rational organisierte Selbsterhaltung von Menschen eines Territoriums ${ }^{30}$ ) heute obliegt, gesellschaftliche Konflikte im Innern weithin durch öffentliche Wirtschafts- und Sozialpolitik auszugleichen und zu neutralisieren“. Das heißt: der Staat darf solche Konflikte heute nicht

27) BVerfGE 1, 105; 8, 329.

29) „Eine Mauer", sagt Wallenstein, „aus meinen eigenen Werken baut sich auf, die mir die Umkehr türmend hemmt" (Wallensteins Tod, I 4).

${ }^{20}$ ) Verfassungsperspektiven der Europäischen Gemeinschaften 1970 , S. 5.

30) Wenn H. P. Ipsen, aaO. (s. Anm. 29) S. 2 einer Formulierung Arnold Gehlens folgend, den letzten Sinn des Staates letzten Endes nur als rational organisierte Selbsterhaltung eines geschichtlich irgendwie zustandegekommenen Zusammenhangs von Territorium und Bevölkerung verstehen zu können glaubt, so unterschätzt er die Notwendigkeit des im Staat bewahrten Irrationalen, ohne das wir, wie F. A. von Hayek, aaO. (s. Anm. 14) erläutert hat, nicht auskommen. 
ungelöst bestehen lassen, indem er die einseitige Majorisierung zuläßt, wo die Berücksichtigung der Minorität geboten ist. Er muß, darauf kommt es hinaus, dem Schwachen eine die Härten der Mehrheitsentscheidung ausgleichende Hilfe geben ${ }^{31}$ ). Soviel zu den Begriffen sozial und rechtsstaatlich.

bb) Die „freiheitliche“ Demokratie

Damit ist angedeutet, welche Inhalte das GG, soweit das demokratische Prinzip in Frage kommt, als mit sich selbst identisch, als unveränderlich im Rahmen seines Bestehens in Anspruch nimmt. $\mathrm{Da} B$ es nicht mehr ist als dies, das eben wird durch das Wort freiheitlich ausgedrückt. Es bedeutet in diesem Zusammenhang, daß jede konkretere inhaltliche Ausformung des Staates, die den Anforderungen dieser Unveränderlichkeit entspricht, legitim ist im Sinne der Demokratiepostulate des $G^{32}$ ). In weiterer als in dieser Hinsicht ist der nach dem GG zulässige politische Wille nicht gebunden, soweit die Wahrung des demokratischen Prinzips in Frage kommt. Zwischen den möglichen Formen und Inhalten der Demokratie kann in diesem Rahmen die jeweilige Gegenwart frei wählen. Das bedeutet zugleich, daß diese Wahl in der eigenen Verantwortung dieser Gegenwart liegt.

Und hier finden wir denn auch den wahren Kern der Vorwürfe, welche - teils gut-, teils weniger gutgläubig - gegen die Freiheitlichkeit, also die mangelnde Bestimmtheit des GG in bezug auf die konkrete Ausformung des Staats- und Gesellschaftsbildes erhoben werden. Nicht, daß die gewünschten $\mathrm{Zu}$ stände nach dem GG ausgeschlossen seien, ist das wahre gravamen, sondern daß zu ihrer Herbeiführung die Zustimmung einer Mehrheit erforderlich wäre. Die Mehrheit ist danach nicht einsichtig genug, um das für alle Erwünschte selbst zu erkennen und zu wollen. Das GG hätte ihr diesen Entscheidungsprozeß abnehmen und von den Möglichkeiten demokratischer Existenz diejenige als die einzig zulässige festlegen sollen, die heute von einer erleuchteten Minderheit als solche erkannt wird.

s1) Dieser Gedanke wird eindringlich von W. Abendroth, Diskussionsbeitrag, in: VVDStRL 12 , S. $86 \mathrm{ff}$. vertreten.

s2) Mit Recht - Dürig nennt es selbstverständlich - beschränkt man aber wohl die Unveränderlichkeit der Grundsätze des Art. 1 und 20 auf eben das Grundsätzliche ihrer Aussage, so daß ausdehnende Interpretationen, wie z. B. das ausdrücklich auch auf Art. 20 gestützte Verbot der Finanzierung allgemeiner Parteizwecke aus staatlichen Haushaltsmitteln (BVerfGE 20, 56 ff.) nicht daran teilnehmen. Auch die Einführung des Abs. 4 in Art. 20 begegnet methodischen Bedenken, zumal sich über dessen Beurteilung unter dem Gesichtspunkt der Rechtsstaatlichkeit durchaus streiten läßt. 
Wir brauchen gar nicht zu untersuchen, ob diesen Kritikern ${ }^{33}$ ) wirklich solche überlegenen Geistes- und Wertungskräfte zukommen. Denn auch dann müßten wir daran festhalten, daß innerhalb der genannten Grenzen, die das Hervorgehen undemokratischer Resultate aus demokratischen Prozessen verhindern sollen, die Auswahl der Lebensform eben nicht nach objektiven, vorweg entscheidenden Kriterien erfolgen soll, sondern danach, was eine bestimmte Zeit mit den in ihr Lebenden sich als richtig vorstellt. Und gerade dieses Recht, sich sein Glück selbst vorzustellen, sich die zum Glück der anderen zu erbringenden Opfer selbst zuzumuten, vor allem aber auch, über diese Dinge abweichend von anderen denken zu dürfen, kann eine Demokratie ihren Bürgern nicht vorenthalten, und auch, anders gesehen, nicht ersparen wollen. Die Möglichkeit näherer Anpassung der allgemeinen Vorsätze an das jeweils Mögliche und Erträgliche, die Freiheit der Entscheidung bei dieser Anpassung, die Wandelbarkeit und Aufnahmefähigkeit jedes gegebenen Zustandes, die Verantwortung schließlich für Gelingen und Fehlschlagen des Ganzen, gehören in das Blickfeld und die Entscheidungsgewalt der lebenden Zeit. Wer anderes für richtig hält, nenne es wie er will. Aber er nenne es nicht Demokratie.

Zwei Fragen, die sich aus dieser Freiheitlichkeit und Ausbaubedürftigkeit des grundgesetzlichen Staatsbildes ergeben, sollen wenigstens erwähnt werden. Einmal die Verteidigung der Demokratie gegen den Mißbrauch ihrer Freiheiten. Ich muß ihre Erörterung, mit all der in ihr liegenden Zweifelhaftigkeit, hier beiseite lassen.

[Hier wählt das GG jedenfalls einen Mittelweg: es läßt den Widerstand des Einzelnen zu, wenn der Staat versagt. Es erlaubt das Parteiverbot und die Aufhebung des verfassungsrechtlichen Schutzes bei der Ausübung bestimmter Grundrechte. Aber es unterstellt die Einleitung dieser Maßnahmen, außer vielleicht in ganz eindeutigen Fällen, der abwägenden Beurteilung durch die Regierung oder durch eines der beiden Gesetzgebungsorgane, und weist die ausschließliche Sachkompetenz dem BVerfG zu. Darin kommt zum Ausdruck, daß die Verteidigungsrechte Einschränkungen des demokratischen Gedankens

33) Z.B. R. P. Wolff, Das Elend des Liberalismus (übers. von $E$. Balser), 1970. Auch Winfried Martini, Apologet Salazars im Sinne von Dostojeuskis Großinquisitor, hält die Freiheitlichkeit des GG für verfehlt. Diese Mahnungen sind nicht überflüssig, sondern müssen ständig neu bedacht werden. Sie laufen im Grunde auf eine Einschätzung der Menschen in einem bestimmten Volk, und auf dessen Eignung zur Demokratie hinaus. 
sind, wenn auch um seiner Erhaltung willen. Sie sollen verhindern, daß der demokratische Staat, wie Hegel sagte, stirbt an der Furcht zu sterben ${ }^{34}$ ).]

Ebenso wichtig ist die zweite Frage, wie nämlich zu verhindern ist, daß die rechtsstaatliche Verfassung, die, wie Ernst Forsthoff festgestellt hat, in relativ hohem Maße an den gesellschaftlichen status quo gebunden ist ${ }^{35}$ ), diesen in undemokratischer Weise verfestigt. Es wird ja heute mit besonderer Intensität der Vorwurf erhoben, nicht alle sozialen und politischen Konflikte seien in der Wirklichkeit unseres Staates der freien Auseinandersetzung anheimgestellt. Bestimmte interessengebundene Entscheidungen, so heißt es, seien in Wahrheit vom GG vorweggenommen und der demokratischen Veränderlichkeit entzogen worden. Es soll sich dabei keineswegs um nebensächliche Entscheidungen handeln. Vielmehr sind diese vorwegnehmenden Zementierungen, glaubt man der sogenannten kritischen Theorie, nachgerade für alles denkbare Ubel, von der Ausbeutung ahnungslos Unterdrückter bis zur sexuellen Perversion, verantwortlich zu machen, und zwar, das ist die größte Gemeinheit, ohne daß es jemand merkt, außer eben den Schreibtischtätern der Menschheitsbefreiung.

Sieht man sich aber die umfangreiche, zum Teil leidenschaftlich entrüstete Literatur zu dieser Frage daraufhin an, um welche Entscheidungen es sich da handeln soll, so bleibt im Grunde keine einzige positive Regelung sichtbar, auf die sich dieser Vorwurf stützen könnte. Nicht nur die vom damaligen Minister Höcherl apostrophierten Beamten des Bundesinnenministeriums, sondern auch manche Kritiker unserer Verfassungszustände scheinen gelegentlich ohne das GG unterm Arm herumzulaufen. Eine angebliche Wurzel allen undemokratischen Ubels etwa, das Privateigentum an den sogenannten Produktionsmitteln, widerlegt gerade diese Kritik: es ist im GG ja gar nicht zementiert. Art. 15 läßt seine Vergesellschaftung ausdrücklich zu. Er macht sie nur von einer lästigen $\mathrm{Be}-$ dingung abhängig: daß nämlich eine Mehrheit - es braucht noch nicht einmal eine verfassungsändernde zu sein - sich dafür ausspricht. Nicht. daß das GG diesen heilsamen Schritt verhindere, sondern daß es die freiwillige Zustimmung einer

34) Utber Ansichten wie die Otto Strassers (Politische Studien, Heft 172 [1967], S. 138), wonach jedes Verbot undemokratischer Aktivitäten der Demokratie widerspreche, kann man sich, wenn man Lenins und Hitlers entsprechende Vernichtungsstrategien kennt, getrost hinwegsetzen.

35) VVDStRL 12, S. 15. 
Mehrheit zu seiner Voraussetzung mache, ist also der wahre Vorwurf. Man muß bei uns wahrhaftig zweifeln, ob nicht die Gefahr der mißverstandenen Demokratie größer ist als die der A.blehnung demokratischer Zustände.

cc) Die „bundesstaatliche“ Demokratie

Ein formales Element der durch das GG vorgeschriebenen Eindeutigkeit ist die Verfassung des Staates als Bundesstaat.

[Mit welchem Recht gehört sie zum unaufhebbaren Bestand? Die historische Legitimation ist verblaßt, sie betrifft nur zum geringen Teil überhaupt die heutigen Länder und ihre zu großen Teilen zugewanderte Bevölkerung. Von der Seite der Leistung her lassen sich gewichtige Einwendungen hören $\left.{ }^{36}\right)$. Beide Argumente lassen es möglich erscheinen, daß sich, wie der Bundestagsabgeordnete Hans Dichgans annimmt ${ }^{37}$ ) oder den Meinungsforschern in den Mund legt, bei einer Volksabstimmung über "Föderalismus oder Einheitsstaat" 70-80 \% der Stimmen für den Einheitsstaat aussprechen würden.]

Die Umwandlung des Bundes in einen Einheitsstaat ist aber nicht nur der Tagesmeinung, sondern überhaupt jeder innerhalb des GG zulässigen Entscheidung entzogen. Das geschieht nicht nur, weil der grundgesetzlich verfaßte Staat ohne das Bestehen von Ländern inoperabel sein würde. Vielmehr bildet der Föderalismus heute einen eigenen Weg der demokratischen Verwurzelung und Legitimation, ein zusätzliches Schema der Gewaltentrennung nämlich, ein Aufrechterhalten engerer, regionale Mehrheitsverhältnisse honorierender, vom Einzelnen her überschaubarer und persönlich vertrauter Verbände, eine Möglichkeit divergierender, der Entfremdung steuernder Handhabung, auf die kaum zu verzichten ist. Diese regionale Bündelung des politischen Wollens hat einen eigenen demokratischen Wert ${ }^{38}$ ). Daß Leistungseinbußen der Preis dafür sind, sollte nicht gesagt werden, ohne daß in Erwägung gezogen wird, wie sehr die demokratische Legitimation, die Bewahrung der Lebensnähe politischen Handelns, ihrerseits ein für Freiheit und Verantwortung entscheidendes Leistungserfordernis sind. Wir haben es bei der Bundesstaatlichkeit mit Fragen zu tun, die in vielem noch ungelöst vor uns stehen. Ich muß auch sie hier aus verständlichen Gründen unerörtert lassen.

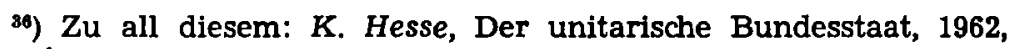
passim.

37) Vom GG zur Verfassung, 1970, S. 121.

38) Vgl. H. Zacher, aaO. (s. Anm. 13) S. 180; sowie H. Dichgans, aaO. (s. Anm. 37) S. 121 ff. 


\section{dd) Die den Staat transzendierende Demokratie}

Ich schließe die Behandlung der Willensfestlegungen mit dem Hinweis auf eine über den Staat hinausreichende Willensfestlegung. In Art. 25 GG erhalten die allgemeinen Regeln des Völkerrechts direkten übergesetzlichen Rang. In der Praxis nehmen sie sogar am Bestand des von verfassungswegen Unveränderlichen teil. Ähnliches dürfte, von einigen Einschränkungen abgesehen, für die Zugehörigkeit zur Europäischen Konvention zum Schutz der Menschenrechte und Grundfreiheiten gelten. Von den Europäischen Gemeinschaften wird noch die Rede sein.

\section{c) Anhang: Zur Interpretierbarkeit der Vorabbestimmung}

Abschließend zur Vorabbestimmung des Willens läßt sich sagen: die ein für allemal getroffenen, der weiteren demokratischen Diskussion entzogenen Vorabentscheidungen betreffen im wesentlichen die allgemeine, nur in Form der Ausgrenzungssätze konkretisierte Wertfeststellung. Jede denkbare Form, die dieser Wertfeststellung gerecht wird, bleibt von der entsprechenden Entscheidung der insoweit den Staat hervorbringenden, wandelbaren Gesellschaft abhängig, und zwar in der Abstufung von verfassungsändernden, von Zustimmungsund von einfachen Gesetzen.

[Der Versuch, einzelne Ausformungsvorstellungen in den $\mathrm{Be}-$ reich des ein für allemal Entschiedenen zu verlagern und sich dadurch von dem Erfordernis der Zustimmung einer gegenwärtigen Mehrheit zu dispensieren, wird trotzdem immer aufs neue unternommen. Jeder möchte seiner Meinung Verfassungsrang geben. Der eine will das ungeschmälerte Privateigentum und das Recht zur Monopolbildung zum Bestandteil der Menschenwürde oder der mit ihr identischen Freiheit erheben ${ }^{39}$ ), der andere möchte den Gleichheitssatz als konkreten Leistungsauftrag an den Staat ${ }^{40}$ ), ja an Private ${ }^{41}$ ) verstanden wissen $^{42}$ ). Alles dies ist immer der Versuch, eine bestimmte Meinung vor abweichenden Meinungen einer späteren Zeit in

s9) E. R. Huber, Deutsche Verfassungsgeschichte, Bd. IV, 1969, S. 978.

40) H. Scholler, aaO. (s. Anm. 25) S. 103.

41) Vgl. H. C. Nipperdey, Die Würde des Menschen, in: NaumannNipperdey-Scheuner (Hrsg.), Die Grundrechte, Bd. II, 1954, S. 18.

42) Auch die lange Geschichte der nordamerikanischen Demokratie bietet in dieser Hinsicht Beispiel über Beispiel. Hier wurde abwechselnd die rücksichtslose wirtschaftliche Betätigung (als economic due process), die Rassentrennung, die Prohibition, und dann auch wieder die Monopolkontrolle, die Integrierung der Rassen, der freie Alkoholgebrauch in Generalklauseln der Verfassung hineininterpretiert oder durch Ergänzung in die Verfassung hineingeschrieben. 
Schutz zu nehmen, und auf diese Weise ein Stück Wahlfreiheit der anderen auszuschalten. Damit geht dann zugleich ein Stück aktueller Legitimation der jeweils bestehenden Zustände verloren.]

\section{Die Willensverteilung}

Damit kommen wir nun zu der Frage der Willensverteilung als eines Mittels zur Ausführung des demokratischen Vorsatzes. Sie wird in der Staatslehre gewöhnlich erörtert als die Verteilung der Möglichkeiten staatlichen Handelns, also als die Gewaltentrennung in all ihren vielfach diskutierten Varianten. $\mathrm{Ob}$ diese der Einschränkung der Herrschaft ${ }^{43}$ ) oder ihrer politischen Kontrolle, oder ob sie der Beteiligung an der Herrschaft und ihrer Verantwortung dient, ob wir hierbei von zwei, drei, vier ${ }^{44}$ ) oder gar sechs ${ }^{45}$ ) Gewalten sprechen sollten, ob die Trennung nach Machthabern oder nach Funktionen und damit verbundenen Verfahren vorzunehmen sei, und wie es schließlich mit der Gewaltenvereinigung ${ }^{40}$ ) oder doch der wechselseitigen Durchdringung der Gewalten stehe, das alles ist seit Jahrzehnten in und außerhalb unseres Kreises erörtert worden. Ich muß den Stand der Diskussion hier voraussetzen und mich auf zwei hauptsächliche Hinweise beschränken. Sie haben es erstens zu tun mit der Aufteilung staatlich-hoheitlichen Wollens: nämlich mit dem Verhältnis von Gesetzgebung und Verwaltung, von gegenwarts- und zukunftsbezogenen Entscheidungen und von nationalem und übernationalem Willen, und zweitens mit der Verteilung der Willensmöglichkeiten zwischen hoheitlich-eindeutigem und nicht-hoheitlich pluralistischem Handeln.

a) Die Aufteilung innerhalb staatlich-hoheitlicher Instanzen

aa) Die Verteilung auf Gesetzgeber und Regierungs- und Verwaltungsorgane

Ich beginne mit der Frage der Aufteilung staatlich-hoheitlichen Wollens. Hier ist in der neueren Diskussion vor allem

43) Montesquieu: „Le pouvoir arrête le pouvoir".

44) Vgl. zum Ganzen $K$. Loewenstein, Das Gleichgewicht zwischen Legislative und Exekutive: Eine vergleichende verfassungsrechtliche Untersuchung, in $\mathrm{H}$. Rausch (Hrsg.), Zur heutigen Problematik der Gewaltentrennung, 1969, S. $40 \mathrm{ff}$; ders., Die neue Dreiteilung der Staatsfunktionen, ebd., S. 272 ff.; ders. Verfassungslehre 1959, S. 14 f., S. 39 ff.; ders., Nachtrag zur Verfassungslehre, 1969, S. 423.

$\left.{ }^{45}\right) R$. Tugwell, Draft of a Proposed Constitution of the United Republics of America, Santa Barbara 1970, S. 39.

46) Vgl. die zahlreichen Nachweise in den verschiedenen Arbeiten K. Loewensteins, aaO. (s. Anm. 44); K. Hesse, aaO. (s. Anm. 3), S. $192 \mathrm{ff}$. 
die Verteilung der Entscheidung auf den Gesetzgeber einerseits und auf die Regierungs- und Verwaltungsorgane andererseits in den Vordergrund der Erwägung getreten. Wieviel von dem konkreten Verwaltungshandeln soll in einem normativen Prozeß vorentschieden, wieviel der fallweisen Verwaltungsentscheidung überlassen sein?

In Amerika ist diese Zuständigkeitsfrage vornehmlich unter dem Gesichtspunkt erörtert worden, wieviel Entscheidungsfreiheit die Tagesmeinung im Namen des demokratischen Prinzips gegenüber der Verfassung beanspruchen könne. Fritz Scharpf hat die Frage erneut aufgegriffen im Hinblick auf die Partizipation weiter Kreise an dem demokratischen Staatsleben. Er spricht von den „politischen Kosten des Rechtsstaats ${ }^{\prime 47}$ ), und zwar indem er den Normierungsgrad des Verwaltungshandelns im amerikanischen und im deutschen Verfassungsleben vergleicht ${ }^{48}$ ). Den größeren $Z$ wang zur vorwegnehmenden Normierung, den das deutsche Rechtsstaatsmodell voraussetzt, findet er bedenklich. Denn der Bestand an Informationen und an Beeinflussungsmöglichkeiten, der in die Entscheidung eingehe, und die politische Verantwortlichkeit des Entscheidenden erführen eine wesentliche Einbuße durch die gesetzliche Festlegung.

[Seine erste Einwendung geht dahin, dieser Normierungszwang vermindere die Qualität und Quantität der für die Entscheidung im demokratischen Sinne erheblichen Information, nämlich die Information über das Ausmaß der Zustimmung, welche die konkrete Entscheidung findet. Das zweite Bedenken von Scharpf ist, daß der Zwang zur vorwegnehmenden Normierung zu einer restriktiven Auswahl unter den Interessen und Gruppen führe, die das Entscheidungsprogramm politisch beeinflussen können. Schließlich glaubt Scharpf voraussetzen zu können, daß die vorwegnehmende Normierung des Verwaltungsprogramms die Effektivität politischer Verwaltungskontrollen vermindern und den Spielraum für eine selbstän-

47) F. Scharpf, Die politischen Kosten des Rechtsstaats, 1970.

48) Die amerikanischen "Großen" bis zu den zwanziger Jahren dieses Jahrhunderts, insbesondere Justice $O$. W. Holmes $j r$. und Judge Learned Hand waren noch sehr darauf bedacht, daß die Verfassung wesentlich in streitbar-verantwortlicher Wirkung und damit auch in der Entscheidungssphäre jeder lebenden Generation liege. Eine neuere Richtung, für die vielleicht Judge Charles Wyzanski jr. oder Paul Freund maßgeblich eintreten, wollte dem Verfassungsgeist und dessen richterlicher Auslegung das letzte Wort geben. Heute scheint das Gewicht wieder mehr auf die politische Entscheidung der Gegenwart gelegt zu werden. 
dige Politik der Verwaltung erweitern würde, beides Folgen, die unter dem Gesichtspunkt der Demokratie bedenklich erscheinen müßten. Innerhalb dieses Modells, so sagt Scharpf, bleibt es für die Exekutivbürokratie ohne politische Folgen, wenn eine Fehlkalkulation stattfindet, denn nicht die Bürokratie, sondern der politisch schwer zu fassende Gesetzgeber hat sie zu vertreten.]

Die Arbeiten von Hans Peter Ipsen ${ }^{49}$ ) und Joseph H. Kaiser ${ }^{50}$ ) würden, wenn ich sie recht interpretiere - und fürchterlich ist jedenfalls der erstere in seinem Zorn, wenn man ihn nicht richtig interpretiert - die Argumente selbst, auf die sich diese Bedenken stützen, nicht bestreiten. Aber sie würden, im Gegensatz zu Scharpf, die gerügten Folgen gerade insoweit billigen, als sie zu einer pauschalen Ermächtigung und zur Freistellung der Verwaltung von detaillierter politischer Kontrolle beitragen.

Ich will zu diesen verschiedenen Ansichten hier nicht selbst Stellung nehmen, sondern mich auf die Rolle des Berichterstatters beschränken, nicht aus Angst, sondern aus Zeitmangel. Das GG überläßt die genauere Bestimmung des Normierungsgrades, indem es unbestimmte oder doch nur nach der negativ-ausgrenzenden Seite hin bestimmte Verfassungsbegriffe verwendet, in hohem Maße der Verfassungsauslegung ${ }^{51}$ ). Sie muß ihren Weg finden zwischen dem Postulat demokratischer Entscheidungsnähe und politisch bestimmter Kontrolle, wie Scharpf es in den Vordergrund stellt, und dem Planungs- und Leistungsspielraum, auf den die moderne Verwaltung angewiesen ist, und den Kaiser und Ipsen, im Einzelnen nicht immer einig, ihr zu vindizieren suchen.

49) AaO. (s. Anm. 29) S. 14 ff.; ders., Aktuelle Fragen des europäischen Gemeinschaftsrechts, 1965.

so) Vgl. seinen Bericht: Bewahrung und Veränderung demokratischer und rechtsstaatlicher Verfassungsstruktur in den internationalen Gemeinschaften, in: VVDStRL 23, S. 1 ff.

51) Es ist weithin eine Frage der eigenen Einschätzung durch das BVerfG, wieweit es sich für befugt hält, eine Frage als durch das GG entschieden oder als offengelassen zu bezeichnen. Bei diesem Typus der richterlichen Einschätzung wird, wie die Rechtsprechung des Supreme Court der USA z. B. zur Frage der racial equality zeigt, die Verfassungsentscheidung als eine eventuelle, zunächst offen bleibende, aber für den Fall des Eintritts bestimmter Verhältnisse bindende aufgefaßt - eine Auslegungstechnik, die der theologischen Dogmatik, wie mir scheint, ganz geläufig ist, und die im Staatsrecht, wie oben schon angedeutet, $\mathrm{zu}$ der Erscheinung der praktischen Unumkehrbarkeit einmal erreichter Erfüllung von Verfassungsaufträgen führt. 
Ich möchte diesen Erwägungen noch eine weitere hinzufügen, die sich aus der zunehmenden Komplexität und Reichweite der notwendigen politischen Entschlüsse ergibt.

Die Verlagerung solcher Entschlüsse auf eine prinzipielle, der demokratischen Tagesdiskussion nicht weiter zugängliche Ebene kann ein sehr taugliches Mittel sein zur Verfestigung labiler und sonst nicht stabilisierbarer politischer Willenskonstellationen $^{52}$ ). Bei den unerläßlichen Aufgaben der Zusammenfügung hoch komplexer politisch-wirtschaftlicher Gefüge zu immer größeren, aber auch immer entfernteren und diffuseren Entscheidungseinheiten sind so viele Einzelübereinstimmungen zu gleicher Zeit erforderlich, daß keinerlei Wahrscheinlichkeit ihr simultanes Eintreten erhoffen lassen könnte, sollten alle diese Ubereinstimmungen jedesmal von der politischen Tagesmeinung und -verantwortung all der vielen $\mathrm{Be}-$ teiligten abhängen. Da ist ein „corriger la probabilité“ durch stabilisierende Willensfestlegungen unentbehrlich, Festlegungen, die zu gegenseitigen subjektiven Rechten und damit zu richterlicher Prüfung führen ${ }^{53}$ ). Ein Opfer an unmittelbarer demokratischer Legitimation ist erforderlich zugunsten einer anderen, immer wichtiger werdenden Legitimation: der Legitimation an der Leistung, die für alles andere erst den Boden hergibt. Es bleibt uns vielfach nichts anderes übrig, als, wie Max Frisch einmal treffend sagt, die Freiheit zu bewirtschaften, so sehr sie auch ihren eigenen, von allen Zwecken unabhängigen Wert hat.

Das GG, zunächst nur auf die Wiederherstellung der Freiheit selbst bedacht, begnügt sich, wie gesagt, damit, diese Frage offen zu lassen. Es bleibt hier ein verfassungsrechtlicher Leerraum auszufüllen. Diese Aufgabe hat sowohl eine zeitliche wie eine räumliche Dimension. Die zeitliche Dimension betrifft die Willensverteilung zum Zwecke der Bewahrung permanenter Güter, die räumliche die Willensverteilung zum Zwecke der Schaffung handlungsfähiger Organe in übernationalen Räumen. In beiden Richtungen läßt es das GG an eigenen Regelungen fehlen.

bb) Die Verteilung auf kurz- und langfristig ausgerichtete Willensorgane

52) Vgl. hierzu W. von Simson, Der politische Wille als Gegenstand der Europäischen Gemeinschaftsverträge, in: Festschrift für Riese, 1964, S. $83 \mathrm{ff}$.

53) Dies gilt besonders im Europäischen Gemeinschaftsrecht, in welchem der Gerichtshof der Gemeinschaften das politische Handeln der Staaten an ihren vertraglichen Verpflichtungen, auf die Klage des Betroffenen hin, zu messen befugt ist. 
Weder im Text des GG, noch in der Auslegungspraxis spiegelt sich, um mit der Bewahrung zu beginnen, der Gedanke wieder, daß bestimmte Güter ein Besitz nicht nur der gegenwärtigen, sondern auch kommender Generationen sind, und hiernach gerade im demokratischen Verständnis auch nicht zur alleinigen Disposition einer einzelnen Generation stehen dürfen. Und doch ist es ja eigentlich eine typische Verfassungsaufgabe, Sachwalter der permanenten Werte gegenüber den Tagesinteressen zu sein. Landschaft, Wasser, Luft, Bodenschätze sind nicht frei verfügbare, sondern anvertraute Güter. Das GG schweigt hier, im Gegensatz zu manchen Landesverfassungen. Die bayerische Verfassung geht weiter. Aber auch sie verkündet in ihrem Art. 141 nur ein Programm und schafft keine besondere, für diese Verantwortung zuständige Willensinstanz. Es scheint aber, oder es ist wenigstens zu hoffen, daß sich allmählich ein überparteilicher, auch über der Tagespolitik stehender permanenter Konsens hinsichtlich der drängendsten Bewahrungsprogramme bildet, so daß der mangelnde Verfassungssatz hier zunächst jedenfalls durch die Verfassungswirklichkeit ersetzt wird. Auch völkerrechtliche Verträge können, wie hier nur andeutend bemerkt sei, dabei eine wichtige Rolle spielen $^{54}$ ).

cc) Die Verteilung auf staatliche und zwischenstaatliche Institutionen

Dieselben zielbezogenen Notwendigkeiten oder Abwandlungen demokratischer Legitimation begegnen uns dann auch auf dem Gebiet der Entfaltung. Es müssen, kurz gesagt, heute vielfach Dinge gewollt werden, die ein einzelner Staat für sich allein nicht mehr wollen kann. Dieser Fragenkomplex hat den Gegenstand einer Diskussion auf der Berliner Tagung 1957 gebildet, und Karl Carstens hat aus nächster Nähe der prak-

54) So wurde etwa die jüngste Diskussion über eine Neuordnung des Meeresvölkerrechts u. a. durch die Erfahrung angestoßen, daß das bestehende Rechtsgefüge gegenüber einigen neuartigen, bald vielleicht schon irreparablen Gefährdungen des Meeresraumes versagt. Zu Spezialfragen aus diesem Kreis regelungsbedürftiger, umwelt- und fischereipolitischer Probleme vgl. z. B. E. Böhme, Tankerunfälle auf hoher See, 1970; N. Pelzer, Rechtsprobleme der Beseitigung radioaktiver Abfälle in das Meer, 1970. Zum Schutz des gefährdeten marinen „Erbteils der Menschheit" und der langfristigen gemeinsamen meerespolitischen Interessen der Völkerrechtsgemeinschaft werden seit $1966 \mathrm{z}$. T. sehr weitgehende materiell- und organisationsrechtliche Neuregelungen vorgeschlagen. Vgl. etwa $E$. Mann Borgese, The Ocean Regime. A Suggested Statute for the Peaceful Uses of the High Seas and the Sea-Bed Beyond the Limits of National Jurisdiction, Santa Barbara 1968; W. Graf Vitzthum, Pacem in Maribus, AöR 96 (1971) S. $100 \mathrm{ff}$. 
tischen Erfahrung dazu Stellung genommen ${ }^{55}$ ). Was er damals gesagt hat, trifft auch heute noch zu. Die pauschale Ubertragung eines ganzen, immer wichtiger werdenden Zusammenhangs von Willensentscheidungen auf zwischenstaatliche Organe ist notwendig, und zwar ohne daß, oder jedenfalls doch bevor, diese Organe Staatlichkeit gewinnen. Wie können diese Organe demokratisch legitimiert, wie für die Einhaltung von Verfassungsgeboten verantwortlich gemacht werden?

Die Staats- und Europarechtler sind hier geteilter Meinung. Homerisches Pathos belebt die Äußerungen der Streitenden. Man hält sich gegenseitig verfassungsrechtlichen Leichtsinn $\left.(R u p p)^{56}\right)$ und Unkenntnis des Europarechts (Ipsen $)^{57}$ ) vor. Sie sehen, wie das Problem der Staatsrechtslehre zu Herzen geht.

Das GG folgt der Mahnung Napoleons: Une constitution doit être courte et obscure. Es überläßt diese Frage der Verfassungsauslegung, die die politische Entwicklung in Rechnung zu stellen hat. Und in der Tat ließ sich damals nicht und läßt sich auch heute nicht festlegen, in welchem Maße sich die Probleme des Freiheits- und Gleichheitsschutzes und der demokratischen Beteiligung und Mitverantwortung aus dem staatlichen Leben heraus in zwischenstaatliche Bezirke verlagern werden, und wieweit es überhaupt möglich ist, hier von einzelstaatlicher Regelung her das Heft in der Hand zu behalten.

[Das GG begnügt sich damit, die deutschen Verfassungsanforderungen kein Hindernis sein zu lassen, weil eben das Bestehen auf solchen Anforderungen mit dem Einbringen staatlicher Handlungsbefugnisse in überstaatlich-gemeinsame Regie nicht zu vereinbaren ist. Aber damit wird das Problem des Verfassungsschutzes aufgeworfen, nicht schon gelöst.]

Im Augenblick ruht der Verfassungsschutz in diesem Bereich auf zwei Säulen: der sachlich begrenzten Eingriffskompetenz der bisherigen zwischenstaatlichen Einrichtungen, und der verfassungsrechtlichen Homogenität der beteiligten Staaten. Insofern ist, wie Karl Carstens damals festgestellt, und wie Hans Peter Ipsen kürzlich wieder bestätigt hat ${ }^{58}$ ), bisher noch alles gut gegangen. Aber ich bin doch, mich hierin gegen Hamburg auf die bayerische Seite von Hans Zacher schlagend, dessen An$\left.\operatorname{sich}^{50}\right)$, „daß die Verfügbarkeit über die Kernelemente des re-

55) VVDStRL 16, S. 133.

58) NJW 1970, S. 353 ff., 354

57) AaO. (s. Anm. 29) S. 1 ff., 17.

58) AaO. (s. Anm. 29) S. 19 ff.

59) AaO. (s. Anm. 13) S. 221; vgl. auch allgemein G. Zieger, Das Grundrechtsproblem in den europäischen Gemeinschaften, Tübingen 1970. 
publikanischen, demokratischen und sozialen Rechtsstaats, auch soweit zwischenstaatliche Einrichtungen in Frage kommen, doch schließlich irgendwo enden muß“. Darin, daß die bisherigen Schritte verfassungsrechtlich vertretbar sind, will ich Ipsen zustimmen. Aber unsere verfassungsrechtliche Verantwortung, für die das GG ja nicht konstituierend, sondern nur exemplifizierend ist, begleitet auch die aus dem Bereich des GG entlassenen Entscheidungsbereiche. Die Gemeinschaften streben nach Ausdehnung, auch über den Kreis demokratisch gesicherter Staatswesen hinaus. Der, wenigstens indirekt, den heimischen Parlamenten verantwortliche Ministerrat mag nicht immer das maßgebliche Organ, die Eingriffskompetenz der Gemeinschaften nicht immer auf grundrechtsunempfindliche Unternehmen beschränkt bleiben. Auch die Besetzung des Gerichtshofes kann sich, als Folge politischer Entwicklungen, verändern.

Dies alles legt die Forderung nahe, daß, je nach dem Grade der fortschreitenden Vergemeinschaftung, die Zustimmung des Bundes zu weiteren Kompetenzübertragungen und Kompetenzerrichtungen nicht bedingungslos erfolgen kann, ohne Rücksicht also auf die Verfassung, in der wir auch außerhalb unseres Staates leben wollen. Soviel, denke ich doch, müssen wir auf diesem Gebiet in das GG hineinlesen.

b) Die Aufteilung zwischen staatlich-hoheitlichen und nichthoheitlichen Instanzen

Ist im Vorhergehenden schon deutlich geworden, daß die Willensverteilung über den Staatswillen und seine getrennten Gewalten hinausgeht, so gilt das aber nicht nur für die Beteiligung fremdhoheitlicher Willensträger an den für den Staat relevanten Entscheidungen. Ein weiteres, für die demokratische Willensverteilung wesentliches Gebiet betrifft, wenn man so sagen darf, die Gewaltenteilung zwischen dem Staat und nichthoheitlichen Instanzen. Die klassische Gewaltentrennungslehre hatte es ja mit der Teilung der hoheitlichen Gewalt innerhalb ihrer selbst zu tun. Für den freiheitlichen demokratischen Staat ist es aber gerade kennzeichnend, daß das Wollen und Handeln des vom Staat umfaßten Lebens nicht von diesem allein wahrgenommen wird. Das Thema der Willensverteilung zwischen dem eindeutig entscheidenden Staat und den pluralistisch aufeinander wirkenden Kräften ist, soweit diese politisch wirksam organisiert sind, also vornehmlich als Verbände auftreten, auf der Würzburger Tagung $\left.1965^{80}\right)$, und auch

60) Bericht von G. Leibholz, Mitbericht von G. Winkler, Staat und Verbände, in: VVDStRL 24, S. 5 ff., 34 ff. 
sonst, ziemlich ausgiebig erörtert worden. Werner Weber ${ }^{\text {(1) }}$ ) hat ihm auch in der Gewaltenteilungslehre Hausrecht verschafft.

Ich beschränke mich hier auf die Bemerkung, daß der Akzent dieser Diskussion, und damit auch der Umfang der in Betracht kommenden Interessen, sich mehr und mehr zu verschieben scheint. Die Diskussion hatte vorwiegend unter dem Gesichtspunkt begonnen, daß die demokratische Willensbildung allein in den Verfassungsorganen zu Hause sei und durch das Tätigwerden und die Einflußnahme von außerstaatlichen Gruppen und Verbänden feudalisiert und gefährdet werden könne. Joseph $H$. Kaiser ${ }^{62}$ ) erläuterte dann im Einzelnen, inwieweit diese Erscheinungen einen Beitrag leisten zur sachgerechten, informierten, und - was das demokratisch wichtigste ist - gegensätzlichen, bei den Verfassungsorganen um den Vorrang der Berücksichtigung kämpfenden Meinungsbildung, und damit zur demokratischen Legitimation des politischen Handelns. Neuerdings wird das Problem, unter dem Einfluß soziologischer und politologischer Modelltheorien, in einem noch umfassenderen Zusammenhang gesehen als früher. Die Aufrechterhaltung zentraler Entscheidungsfähigkeit einerseits, die pluralistische Einflußnahme organisierter Interessen andererseits, dazu aber die Partizipation bisher nicht geweckter oder erkannter Interessen, und damit die Gewinnung dieser Bedürfnisse und Ziele Einzelner für ein volleres demokratisches Leben und gegen unerkannte Manipulationen sind das Ziel. Die Schaffung geeigneter Kanäle und Filterungssysteme, in sich autonomer, von außen her aber koordinierbarer Subsysteme der Meinungsbildung, Informationsweitergabe, Wahlausübung sind die Mittel. Was uns gegenwärtig von der Politikwissenschaft angeboten wird, enthält neben anderem eine empirische Fortentwicklung von Wilhelm Hennis' Darstellung des Amtsgedankens als der Essenz des Demokratiebegriffs ${ }^{63}$ ). Sie wird zusammengefaßt von Fritz Scharpf ${ }^{64}$ ) in dem Versuch einer, wie er es nennt, komplexen Demokratietheorie. Man spürt das Eindringen industrieller Organisationsprinzipien in die politische Wissenschaft.

[Der Pluralismus soll hiernach nicht beschränkt bleiben auf eine Interessenartikulation, die auf der zentralen Entscheidungsebene um die Entscheidung ringt. Es sollen möglichst

61) W. Weber, Die Teilung der Gewalten als Gegenwartsproblem, in: Festschrift für C. Schmitt, 1959, S. 265.

(2) Die Repräsentation organisierter Interessen, 1956.

o3) Amtsgedanke und Demokratiebegriff, in: Staatsverfassung und Kirchenordnung, Festgabe für Smend, 1962, S. $51 \mathrm{ff}$.

64) AaO. (s. Anm. 4). 
alle Probleme, die nicht von zentraler Bedeutung sind, in engeren, miteinander konkurrierenden Verarbeitungs- und Entscheidungsbereichen gelöst und miteinander in Einklang gebracht werden. Die zentrale Entscheidungsinstanz würde bei solchen Problemen nur eingreifen, wenn unter den Subsystemen keine Einigung erfolgt, oder wenn sie aus anderen Gründen Anlaß hat, zu intervenieren oder zu kontrollieren.]

Wieviel von solchen Gedanken ist im GG verwirklicht?

\section{Die Willensverschränkung}

Mit dieser Frage kommen wir zu der Willensverschränkung, dem eigentlichen technischen Weg, auf dem sich die Notwendigkeit vorausschauender, vorausschätzender, einheitlich vorgehender Willensbildung vereinen läßt mit der Kontrolle durch einen egalitären, in sich also nicht prinzipiell unterschiedenen Volkswillen, mit der Aufnahme eines Höchstmaßes von Informationen, mit der Berücksichtigung möglichst vieler, auch organisationsunfähiger Interessen und Bedürfnisse, mit der Bewahrung anvertrauter Werte, und schließlich mit der Freiheit und Verantwortlichkeit des Einzelnen.

\section{a) Die Verschränkung verschiedener Wahlmöglichkeiten}

Ich möchte es als die Aufgabe der Willensverschränkung bezeichnen, in dem Dilemma zwischen zentraler, ungehemmter Willensbildung und egalitärer Freiheit und Verantwortung Wahlmöglichkeiten mit verwertbaren Ergebnissen zu schaffen. Hierzu bedarf es eines Entwurfs der zur Verfügung gestellten Wahlmöglichkeiten. Eine Wahl, welche die höchste Spitze zwischen Millionen verschiedener Einzelvorstellungen träfe, wäre ebensowenig sinnvoll, wie eine Wahl des Einzelnen zwischen unzähligen, von ihm in kaum einer Hinsicht übersehbaren Möglichkeiten politischen Handelns. In beiden Richtungen bedarf es verschränkender Festlegungen. In beiden Richtungen stellt das GG selbst, als Gesamtverfassung, eine Willensverschränkung dar, und zugleich nimmt es, innerhalb seiner Geltung, einige solcher Festlegungen vor, die jetzt näher zu erörtern sind.

aa) Die Verschränkung von zentralen und regionalen Entscheidungsebenen

Zunächst ist hier die Aufteilung in zentrale und regionale Problembereiche, also in Bundes-, Länder- und Gemeindezuständigkeiten zu nennen. Parallel hierzu geht die Aufteilung in die Gesetzgebungszuständigkeit und die Verwaltungszuständigkeit bei der Ausführung der Bundesgesetze. Die jeweils kompetente Instanz kann, auf das Ganze bezogen, nur beschränkt 
in eigener Willensausübung handeln. Sie muß den Willen einer anderen Instanz in ihre Willensbildung inkorporieren oder für sie Raum lassen.

bb) Die Verschränkung von demokratischen und undemokratischen Entscheidungsverfahren

Ferner erwähne ich die vom demokratischen Entscheidungsverfahren ausgenommenen Sachbereiche. Für diese überläßt das GG die Willensbildung der auf sich bezogenen Gruppe, z. B. den Parteien, den Glaubensgemeinschaften, der Familie, den wissenschaftlichen Institutionen, oder gar dem einzelnen, weil die erwünschte Vielfältigkeit oder die Qualität der Entscheidung von dieser Autonomie abhängt und in demokratisch egalitären Legitimierungsprozessen nicht hervorzubringen ist. Das Einbeziehen solcher zum Teil undemokratisch gewonnener Resultate in den demokratischen Prozeß, und andererseits die Verhinderung undemokratischer Gewalt- und Schrankenbildung bei Entstehung und Ubernahme dieser Resultate, nicht aber die um keinen Qualitätsverlust bekümmerte Gleichschaltung, ist hier die demokratische Aufgabe. Das hat Wilhelm $H_{e n n i s^{65}}$ in seiner Analyse des Begriffs der Demokratisierung, und das hat kürzlich Edith Eucken-Erdsiek in ihrer großen Apologie der Freiheit - das Buch heißt „Die Macht der Minderheit" - mit gleicher Lebendigkeit dargetan ${ }^{68}$ ).

Für diese Gewinnung von Resultaten unterhalb der zentralen Entscheidungsebene läßt das GG den nötigen Raum. Hans Zacher ${ }^{67}$ ) spricht dem „Gruppenpluralismus“ den verfassungsrechtlichen Nutzen zu, „die übermäßige Geschlossenheit des parteidemokratisch-parlamentarischen Herrschaftsbetriebs aufzulockern".

cc) Die Verschränkung von Wählerwillen und Willen des Gewählten

Als wichtigste, die politische Willensverschränkung betreffende Institution aber müssen wir die Wahl des repräsentativen gegenüber dem reinen Versammlungs- oder Volksabstimmungstyp der Demokratie ansehen. $\mathrm{Daß}$ von einem inhaltlich aus dem Volkswillen hervorgehenden Regierungswillen in politischen, über die Dimension der Schweiz hinausgehenden Räumen nicht die Rede sein kann, ist nicht ernsthaft zu bestreiten, und auch die gelegentlich wieder auftauchende Sehnsucht nach der Räteverfassung ändert daran nichts.

65) W. Hennis, Demokratisierung. Zur Problematik eines Begriffs, 1970 .

${ }^{66}$ ) E. Eucken-Erdsiek, Die Macht der Minderheit, 1970.

67) AaO. (s. Anm. 13) S. 125. 
Bei uns jedenfalls erfolgt die Ausübung der Staatsgewalt durch Betrauung von besonderen Organen und durch Bestellung und Kontrolle dieser Organe ${ }^{68}$ ). Der einzelne übt seinen Willen in Form einer Wahl aus. Die demokratische Aufgabe besteht darin, das politische Leben, die Sachkenntnis, den Uberblick, den zusammengefaßten Herrschaftswillen, die Entscheidung, und wie sonst man die Lebens- und Geschehenskräfte geschichtlicher Existenz beschreiben mag, Kräfte, die dem Einzelnen gar nicht zugänglich sein können, in eine Form zu bringen, in der eine Wahl möglich ist. Nur wenn eine solche Form gefunden wird, und nur in dem Maße, in welchem sie, gemessen an den Ordnungs- und Leistungserfordernissen der Zeit, überhaupt gefunden werden kann, ist es denkbar, daß die Staatsgewalt in irgend einem Sinne vom Volke ausgeht.

dd) Die Verschränkung in der Mehrgleisigkeit des politischen Gesamtwollens

Der Staatswille insgesamt wird auf diese Weise in ein "sic et non", in ein: so ist es, und auf diese bestimmte Weise könnte es auch anders sein, verwandelt, und ob es so oder anders ist, das allein bestimmt, wo die Verfassung nicht Sätze enthält, die alle Möglichkeiten binden, ein egalitärer Volkswille. Die Bestimmung dessen aber, was als sic und was als non in Frage kommt, vertraut das GG den Parteien an. Deren demokratische Aufgabe ist es, den Prozeß der Vorformung des Staatswillens pluralistisch oder zum mindesten dualistisch zu gestalten. Wenn der Einzelne überhaupt etwas soll wollen, wenn er überhaupt jemanden soll verantwortlich machen, wenn auf ihn und das, was er glaubt, überhaupt eine Rücksicht soll genommen werden können, dann geht das nur in der Form einer Wahlmöglichkeit bei der Herrschaftsbetrauung. Herrschaft als Amt ist Ilerrschaft mit der Möglichkeit der Ablösung. Und diese Möglichkeit ist nicht nur um der Kontrolle, sondern mehr noch um der Verantwortung willen wesentlich. Die Verantwortungslosigkeit des einzelnen moralischen Bewußtseins in bezug auf das Staatshandeln erscheint ja immer da, wo der Einzelne sagen kann oder muß: Ich kann doch gar nichts ändern! Nur wo er die Herrschaft abberufen und sie durch eine andere ersetzen kann, kann er etwas ändern und ist verantwortlich, wenn er es nicht tut. Und daher kommen die moralischen Kräfte einer Nation auch erst zum Tragen, wenn die regierende Partei fürchten muß, die andere, die Opposition, könnte ihr die Mißachtung dieser Kräfte entgegenhalten und damit die öffentliche

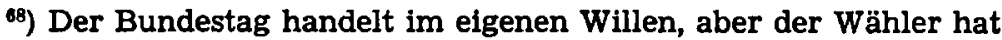
ihn zum Wollenden gemacht. 
Meinung für sich in Bewegung setzen. Die Herrschaft des Apparats, ohne die nicht auszukommen ist, wird also relativiert durch die Existenz eines Alternativapparats, oder doch eines alternativ zur Verfügung stehenden Bedieners der Apparatur $\left.^{80}\right)$. In der Wahl zwischen diesen Alternativen ist Mitsprache und Verantwortung des einzelnen gebunden.

b) Einzelne im GG vorgenommene Willensverschränkungen

aa) Die Verschränkung der Willensmöglichkeit verschiedener Organe

Ich brauche, vor dieser Versammlung, die im GG mit diesem Ziel vorgenommenen Willensverschränkungen nicht im Einzelnen zu schildern. Das Schema ist klar. In Gemeinden, in denen Ubersichtlichkeit und Nähe der Probleme eine direkte Entscheidung einzelner erlauben, ist keine Betrauung gewählter Organe vorgeschrieben (Art. 28 I S. 3). Sonst aber wird auch auf dieser untersten politischen Stufe eine Vertretung tätig, und das GG bestimmt, daß bei deren Bestellung dieselben Grundsätze gelten, wie bei der Bundestagswahl. Daß die Wahl nicht eine Beauftragung, sondern eine Betrauung ist, wird in Art. 38 I noch einmal ausdrücklich bestätigt. Hier wird also der Gewählte aus der Vinkulierung mit dem Wählerwillen entlassen. Der Wähler kann nur die Betrauung, nicht das Handeln des Betrauten bestimmen. Und der Betraute, so sehr er auch von einer Richtung im Gegensatz zu einer anderen bestellt ist, gilt von der Bestellung $a^{70}$ ) als Vertreter aller, die für oder gegen ihn gestimmt haben, oder die der Wahl ferngeblieben sind. Hier sollen auch die Anliegen aufgehoben sein, für die kein organisierter Wille eintritt, und die bei direkter Kontrolle des Gewählten durch den Wähler nicht zu ihrem Recht kämen.

Ein ebenso wichtiger Grund für die ausschließende Verschränkung des Wählerwillens ist aber, daß politische Dinge sich nur nach ihren Resultaten beurteilen lassen. Bis dahin beruhen sie auf Einschätzungen, die gar nicht auf eine dem Wähler zugängliche Formel zu bringen sind. Alle vier Jahre werden dem Wähler die Resultate unterbreitet. Nach diesen allein kann, nach diesen allein darf er urteilen. Das setzt voraus, daß während dieser Zeit der Wählerwille die Regierung zunächst einmal in Ruhe läßt, damit es zu den positiven oder negativen Resultaten kommen kann.

Die Verschränkung findet aber nicht nur im Verhältnis des Wählerwillens oder des Gruppenwillens zu umfassenderen Or-

(99) Diese Alternative bestand auch während der Großen Koalition.

70) Nicht vorher: s. H. Trautmann, JZ 1970, S. $405 \mathrm{ff}$. 
ganen, also in der Diktion des BVerfG nach oben hin statt, sondern auch in umgekehrter Richtung. Das tritt in Erscheinung bei der Duldung und Förderung der öffentlichen Meinung, ja der Offentlichkeit überhaupt, durch die so viel apostrophierten Herrschenden, aber auch, wo die Regierung bei bestimmten Willensäußerungen an den Weg der Gesetzgebung gebunden ist, oder wo bestimmte Zustimmungserfordernisse an die Ausübung des Regierungs- oder Gesetzgebungswillens gestellt werden.

Schließlich sei als Beispiel noch die Autonomie der Tarifpartner erwähnt, deren unverschränkte, d. h. nicht in einen vom Staat gesetzten Handlungsspielraum gebundene Betätigung zum ernsten Problem wird. Es genügt, zu erwähnen, daß eine Lohnerhöhung von $10 \%$ zu einem Kaufkraftimpuls von DM 25 Mrd. oder, wie mir Herr Hettlage sagte, zu einer Preissteigerung von 2-3\% führen kann.

bb) Verschränkungen des Willensgefüges

Neben diesen Willensverschränkungen zwischen verschiedenen Organen, die also z. T. nur zusammen wollen können, gibt es Verschränkungen inhaltlicher Art. Der Bundestag kann den Kanzler abberufen, aber nur, wenn er einen neuen wählt. Er, oder der Bundesrat, können, wenn zwei Drittel der Mitglieder es wollen, den Bundespräsidenten wegen Verfassungsverletzung zur Rechenschaft ziehen. Aber nur seine gesamte Stellung, nicht eine einzelne Handlung, kann in Frage gestellt werden. Es kann also das betreffende Organ das Ganze, aber nicht das Einzelne, das Große, aber nicht das Kleine wollen. Das ist eine demokratisch höchst bedeutsame und sachgemäße Konfiguration der Willensbildung. Die mit dem Amt betraute Stelle bleibt kritisierbar, aber nicht lenkbar. Denn sie ist verantwortlich, solange sie betraut ist. Und die Kritik der derart verantwortlichen Instanz ist kein Weisungsrecht, sondern eine Kritik im Nachhinein, so wie wir es in dem Verhältnis zwischen Wähler und Bundestag und zwischen Bundestag und Regierung ${ }^{71}$ ) gefunden haben.

\footnotetext{
71) Vgl. BVerfGE 1, S. 394 zur Verteilung der Funktionen zwischen Regierung und Parlament: „Art. 59 Abs. 2 GG (hat) dem Bundestag kein Recht gegeben, in den Zuständigkeitsbereich der Regierung einzugreifen. Der Bundestag bleibt auf die allgemeinen verfassungsmäßigen Kontrollmöglichkeiten beschränkt. Er regiert und verwaltet nicht selbst, sondern er kontrolliert die Regierung. Mißbilligt er deren Politik, so kann er dem Bundeskanzler das Mißtrauen aussprechen (Art. 67 GG) und dadurch die Regierung stürzen. Er kann aber nicht selbst die Politik führen."
} 


\section{Das demokratische Prinzip in der Verfassungswirklichkeit}

Der dritte und letzte Aspekt unserer Betrachtung der Anwendung des demokratischen Prinzips betrifft die Verfassungswirklichkeit. Ihr kann ich nur noch ein kurzes Wort widmen. Lange Zeit war das konstitutionelle Denken durch die Vorstellung beherrscht, daß durch ein System der Vorabbestimmung des Willens, der Willensverteilung und der Willensverschränkung ein für allemal die Freiheits- und Gleichheitssicherungen in ein funktionierendes, ein automatisches Gleichgewicht enthaltendes Verhältnis zu bringen seien. Diese Vorstellung wird in neuerer Zeit als unzureichend erkannt, und zwar wird die Wirksamkeit der grundgesetzlichen Postulate heute von zwei Seiten her in Frage gestellt.

1. Die Gefährdung durch mangelndes Demokratiebewußtsein und undemokratische Herrschaftsansprüche

Es geschieht dies einmal von einem mangelnden Demokratiebewußtsein und der Entwicklung undemokratischer Herrschaftsansprüche her. So werden demokratische Parolen eingesetzt, um Andersdenkende auszuschalten. Man lernt, Abstimmungsvorgänge $\mathrm{zu}$ inszenieren, Drohungen und Störungen demokratisch zu rechtfertigen, Ressentiments und Benachteiligungen anderer hochzuspielen und als Kampfmittel für die Förderung eigener Herrschaftsansprüche einzusetzen. All dies begegnet einer gefährlichen Kritik- und Teilnahmslosigkeit, und nicht selten auch Feigheit.

Auf der anderen Seite entstehen Monopole, und zwar sowohl wirtschaftlicher als auch meinungsbildender Art. Diese Monopole sind weder im GG vorgesehen noch werden sie durch das herrschende System begünstigt. Sie entstehen, weil sich keine Gegenkräfte bilden, weil also das demokratische Recht, sich ihnen gegenüber im entgegengesetzten Sinne hervorzutun, von den Berechtigten nicht wahrgenommen wird. Das GG ist hier nicht zu tadeln. Eine Verfassung kann Pluralität ermöglichen und fördern, aber nicht selbst hervorbringen.

2. Die von der Natur der modernen Aufgaben und Probleme ausgehende Bedrohung

Die zweite Bedrohung geht von der Natur der modernen Aufgaben und Probleme aus. Nicht nur das GG nimmt insofern eine Willenseinschränkung vor, sondern der Drang der tatsächlichen Entwicklung, der Bevölkerungsexplosion, der Technologie, insbesondere der Waffen- und Nachrichtentechnik, und der wissenschaftlich-technischen Bedrohungen tut dasselbe. 
Ein großer Teil der Entscheidungen - und das gilt auch für Entscheidungen des Privatunternehmers - sind heute gar keine eigentlichen Entscheidungen mehr. Sie sind Schlußfolgerungen aus ermittelten oder für richtig gehaltenen Tatsachen und aus Konstellationen, die unterhalb jeder bewußten Entscheidungsebene durch spontanes, vielfältiges, zunächst unkontrollierbares Handeln und Geschehen herbeigeführt worden $\sin \mathrm{d}^{\mathbf{2}}$ ).

Lassen Sie mich nur ein Beispiel geben. Wenn die Informationen, die zum Eingreifen der Amerikaner in Vietnam führten, zutrafen, so gab es kaum eine andere Entscheidungsmöglichkeit. Die wahre Entscheidung lag also in der Einschätzung der Sachlage, nicht in den Folgerungen.

Erreichen diese Tatbestände den Zustand, in dem sie für umfassendere, vom Einzelnen her gar nicht intentionierte Entscheidungen erheblich werden, so bleibt dann nur noch die Wahl zwischen wenigen Alternativen, wenn überhaupt noch eine Wahl bleibt. Es wird nun immer mehr die Aufgabe bürokratischer Informations- und Planungsstäbe, von oben vorentscheidend in dieses Geschehen einzugreifen, und es andererseits von unten, nach übergeordneten entscheidenden Stellen hin, in die Form klarer Alternativmöglichkeiten $\mathrm{zu}$ bringen. Anders als auf diese Weise kann in den riesigen, hochkomplexen Entscheidungsbereichen unserer Zeit überhaupt nicht mehr regiert und entschieden werden. Der Entscheidende muß fast austauschbar sein, und alles zu Entscheidende muß auf die Form zwingender Schlußfolgerungen gebracht werden ${ }^{73}$ ).

Die Persönlichkeit, die den Entscheidungen nicht mehr gewachsen sein kann, muß also durch ein System, einen Apparat ersetzt werden. Das bedeutet aber eine zunehmende Entscheidungsmacht der Bürokratie. Wer kontrolliert sie, wer teilt ihre Verantwortung? Das GG schweigt zu diesem Problem. Es ist das wichtigste Problem, vor dem das Verfassungsrecht heute steht. Aber seine verfassungspolitische Lösung führt über das Thema dieses Berichts hinaus. Der Weg, der sich anbietet, ist der der Schaffung gegeneinander argumentierender Bürokratien, sei es der Ministerien, der Parteien, der Gesetzgebungsorgane oder der Verbände, schließlich auch der Presse. Diese sind es, die durch ihre Ubereinstimmung eine neue Art der Legitimierung von Regierungsentscheidungen verfügbar und zum Teil notwendig machen, und die durch ihren Widerspruch

72) Hierzu F. A. von Hayek, aaO. (s. Anm. 14).

73) Hierzu $H$. Wheeler, The Rise and Fall of Liberal Democracy, Santa Barbara 1969. 
auch in diesem Felde der Willensbildung eine Kontrolle, d. h. das Abberufen einer Herrschaft, ermöglichen können. Die Schaffung einer vielfältig bewegten Offentlichkeit und eines vielfältig verteilten Sachverstands in dieser Offentlichkeit kann allein das demokratische Prinzip am Leben erhalten.

3. Die Entwicklungsfähigkeit des demokratischen Prinzips im GG

Neue Formen der Partizipation und Kontrolle müssen sicherlich gefunden werden, wenn Demokratie und Freiheit sich retten sollen. Das GG konnte insofern noch keine Regelungen enthalten. Die Zeit scheint auch heute noch nicht reif, um Vorschläge für konkrete Bestimmungen zu machen, die in das GG aufzunehmen wären ${ }^{74}$ ). Es muß uns genügen, da $\beta$ das $G G$ offen ist für neue Ausformungen des demokratischen Prinzips.

74) Nach meiner Ansicht würden allerdings weder die von $H$. Dichgans, aaO. (s. Anm. 37), noch etwa die von $H$. Lindemann, Das antiquierte Grundgesetz, 1966, vorgeschlagenen Verfassungsänderungen von irgendeiner grundsätzlichen, diesem Problem gerecht werdenden Bedeutung sein, so wichtig auch sonst die von diesen Autoren angestellten Erörterungen sein mögen. 


\section{Leitsätze des Berichterstatters über:}

\section{Das demokratische Prinzip im Grundgesetz}

\section{A. Zum demokratischen Prinzip}

1. Der Demokratiebegriff, der zur Zeit der Ablösung des Hitlerregimes für eindeutig galt, wird heute vielfach in Zweifel gezogen. Er wird von vielen nicht mehr als das Schema zur Firmöglichung eines variierenden Ausgleichs zwischen einander widersprechenden, um den Vorrang ringenden Meinungen und Interessen verstanden. Vielmehr soll er zur Legitimierung einzelner und zur Diskreditierung anderer Meinungen eingesetzt werden. Man spricht in diesem Sinne von kollektiver, totalitärer und autoritärer Demokratie.

2. Das aber ist ein Widerspruch zu dem eigentlichen Sinn der Demokratie: das Richtig- oder Falschsein einzelner nicht allgemein anerkannter Meinungen offenzuhalten, und die Vielfalt und Widersprüchlichkeit nebeneinander bestehender Auffassungen mittels eines formalen, den jeweiligen Vorrang bestimmenden Ausgleichsmechanismus zu bewahren und mit den Bedürfnissen einheitlicher Staatslenkung zu vereinbaren.

3. In Hinsicht dieser materiellen Unentschiedenheit ist das demokratische Prinzip eindeutig, und vor Verfälschungen zu bewahren. Im Hinblick auf seine konkrete Verwirklichung ist es vieldeutig. Denn seine aktuelle Bestimmtheit ist nicht von vornherein festgelegt, sondern einem Proze $\beta$ der Herstellung von Eindeutigkeit überlassen. Diese positive Eindeutigkeit muß immer aufs neue hergestellt und als Ergebnis demokratischer Konkurrenz gerechtfertigt werden.

4. Allerdings enthält auch die Staatswirklichkeit der Demokratie Elemente des Unbezweifelten, ohne deren Hinnahme kein Staatsleben möglich wäre. Sie unterscheiden sich von den Axiomen dogmatisch fundierter Herrschaftssysteme jedoch dadurch, daß sie nicht als unwiderlegliche Wahrheiten, sondern nur als nützliche Konventionen aufgefaßt werden, die lediglich solange unentbehrlich sind, als nicht andere, wahrheitsnähere, sie ersetzen können. 


\section{B. Zur Anwendung des demokratischen Prinzips}

Die Theorie des demokratischen Gedankens ist ausreichend entwickelt. Die Theorie seiner Anwendung steht in ihren Anfängen. Sie läßt sich in drei Felder aufteilen:

- die Frage, mit welchen Kosten der demokratische Staatstypus erkauft wird, und ob angesichts heutiger Leistungsansprüche und Uberlebensgefahren dieser Preis zu verantworten ist (unten I);

- die Frage, ausgehend von der Bejahung der vorigen, welche verfassungstechnischen Mittel zu Gebote stehen, um das demokratische Prinzip mit den Freiheiten und vorläufigen Unbestimmtheiten, die es dem Staatsleben auferlegt, in die Staatswirklichkeit einzuführen und zu sichern (unten II);

- die Frage nach den wirklichen Folgen des derart Betriebenen in den uns heute erkennbaren Verhältnissen (unten III).

I.

Die erste Frage hat sich den Schöpfern des GG nicht gestellt. Sie durften ihr pouvoir constituant nur unter der Voraussetzung und Bedingung ausüben, da $\beta$ sie einen demokratischen Staat errichteten. Die Frage stellt sich aber auch heute nicht. Für die Bundesrepublik gäbe es in der gegenwärtigen Situation politischer, durch entgegengesetzte Grundanschauungen zusammengehaltener Großformen nur die Alternativen einer Zugehörigkeit zum kommunistischen Machtsystem in einer seiner Ausprägungen, oder ein Sichverlieren in vagen ideologischen Konzepten, deren Verwirklichungsfähigkeit nicht ersichtlich ist. Beide Alternativen werden von dem überwiegenden verfassungstragenden Bewußtsein der Bundesrepublik abgelehnt.

\section{II.}

Die zweite Frage, d.h. die Frage nach den Mitteln, mit denen das demokratische Prinzip in die Staatswirklichkeit übertragen werden kann, führt zur Unterscheidung von drei Mitteln:

- die Ausschließung bestimmter Willensmöglichkeiten des Staates, und die Festlegung seines Willens auf bestimmte Ziele; zusammenzufassen als die Vorabbestimmung des Staatswillens (unten 1);

- die Willensverteilung, d.h. die Verteilung des verbleibenden politischen Wollens auf verschiedene Willenssubjekte 
oder auf verschiedene Verfahren der Willensbildung (unten 2);

- die Willensverschränkung; durch sie werden verschiedene Willensmöglichkeiten von einander abhängig gemacht, vorformuliert und auf bestimmte Alternativen reduziert; nur zwischen ihnen kann das zuständige Willenssubjekt dann wählen (unten 3).

1. Die Vorabbestimmung des Staatswillens betrifft

a) in der Willensausschließung (dem ersten ihrer beiden Elemente) folgende Dinge:

- die Unabänderlichkeit gewisser Strukturprinzipien des Staates, insbesondere der demokratischen Legitimation der Staatsmacht;

- die Unantastbarkeit gewisser Werte und ihres Zurgeltungkommens im Staat;

- die Aufrechterhaltung der Verantwortung des Einzelnen für das Staatshandeln, mit der Folge, daß sich der Einzelne aus Gewissensgründen dem Staat versagen kann.

b) Die Willensfestlegung (das andere Element der Vorabbestimmung) ist eine Frage des Aufbaus der Freiheit in der Gesellschaft. Das GG nimmt zu dieser Frage durch die Eigenschaftswörter rechtsstaatlich, sozial und freiheitlich Stellung, mit denen es die Demokratie versieht.

aa) Gewisse Grundentscheidungen unterliegen nicht dem Wandel der Tagesmeinung, sondern sind jedem aktuellen Wollen vorgegeben. Die Kontrolle des aktuellen Staatswillens an dem Maßstab dieser Vorsätze erfolgt durch das Bundesverfassungsgericht. Wesentliche Vorsätze dieser Art sind das Sozialstaatsprinzip und die Rechtsstaatlichkeit. Auch das Bundesstaatsprinzip gehört hierher.

Das konkrete Verfassungsgebot dieser Willensfestlegungen ist ausgrenzend und korrigierend. Ihre positive Ausgestaltung jedoch ist nicht in die Verfassungsregelung einbezogen. Sie bleibt - das ist eine wesentliche Bedeutung des dem demokratischen Prinzip hinzugefügten Begriffs ,freiheitlich" - der Zustimmung der Tagesmeinung und damit der Verantwortung der lebenden Zeit überlassen. Insofern ist das GG ein Entwurf, der der Verwirklichung bedarf.

bb) Wohl aber nimmt das einmal Verwirklichte, jedenfalls in seinem wesentlichen Gehalt, an dem Schutz der Verfassungsregelung teil. Das Verfassungsgebot, zunächst bedingt durch 
die Einrede der Unausführbarkeit, wird durch die Tatsache der einmal geglückten Ausführung zur konkret bindenden Norm.

cc) Die Verfassung des Staates als Bundesstaat, ein formales Element der Willensfestlegung, ist erforderlich, weil eine Anzahl von Verfassungsorganen davon abhängen und sonst durch andere ersetzt werden müßten.

Sie hat aber auch einen eigenen demokratisch-legitimierenden Wert: Durch regionale Bündelung des politischen Wollens im ganzen und der politischen Zuständigkeit im einzelnen leistet sie einen Beitrag zur Verwurzelung des politischen Handelns in einer teilnehmenden und zur Kontrolle fähigen Uberzeugung.

2. Die Willensverteilung, ein weiteres Mittel der Ubertragung des demokratischen Prinzips in die Staatswirklichkeit, ist nicht länger nur eine Frage der Verteilung staatlich-hoheitlichen Wollens (unten a) in funktioneller (unten aa)), zeitlicher (unten $b b$ ) und räumlicher (unten cc) Hinsicht, sondern auch einer Frage der Verteilung der Willensmöglichkeiten zwischen hoheitlich-eindeutigem und nicht-hoheitlich pluralistischem Handeln (unten b).

a) Für das hoheitliche Handeln ist der neueren Diskussion vor allem

aa) die Verteilung der Entscheidung auf den Gesetzgeber und die - im Gegensatz zu diesem direkt politisch beeinflußbaren und politisch haftenden - Regierungs- und Verwaltungsorgane in den Vordergrund getreten. Das Problem stellt sich insbesondere da, wo der Gesetzgeber sich auf pauschale und auslegungsbedürftige Aussagen beschränkt und auf diese Weise die politisch nicht verantwortliche Rechtsprechung zur Entscheidung beruft, oder wo er die Verwaltung durch generelle Ermächtigungen von eigener Verantwortung, allerdings auch von politischer Pression, freistellt.

Hier stehen sich die Postulate demokratischer Legitimation und ungehemmter Aktionsfähigkeit gegenüber. Das GG überläßt die genauere Bestimmung des Normierungsgrades, an den die Verwaltung gebunden sein soll, in weitem Maße der Rechtsprechung.

Hierbei ist auch folgender Gesichtspunkt zu berücksichtigen: Die zunehmende Komplexität der Entscheidungszusammenhänge bringt die Gefahr mit sich, daß die zur Entscheidung notwendigen politischen Ubereinstimmungen nicht mehr mit ausreichender Wahrscheinlichkeit zur gleichen Zeit herbeizuführen sind. Deshalb bedarf es der stabilisierenden Festlegung 
einzelner Willenskonstellationen, die nur in dieser Festlegung in weitere, im Wege der Ubereinstimmung herzustellende $\mathrm{Zu}$ sammenhänge eingebracht werden können. Hinter diesem $\mathrm{Er}$ fordernis müssen die Anforderungen detaillierter demokratischer Legitimation zurücktreten.

bb) Die im GG vorgenommenen Willensverteilungen ignorieren den Umstand, daß gewisse Werte der Verfügung durch eine einzelne politische Generation entzogen und der Verantwortung eines zeitlich übergreifenden Willens überlassen bleiben sollten. Ein solches an zeitlicher Permanenz legitimiertes Willensorgan, wie es andere Verfassungen, jedenfalls im Prinzip, kennen, fehlt im GG. Zum Ausgleich bildet sich, insbesondere was die Bewahrung von Landschaft, Wasser, Luft und Bodenschätzen angeht, ein praktischer Konsens hinsichtlich langfristiger Programme und Verbote, der auch in internationale Bezirke hineinwirkt.

cc) In der Ausdehnung auf zwischenstaatliche, nur gemeinsam zu lösende Probleme beschränkt sich das GG auf die Ermächtigung des Gesetzgebers zur Einbringung von Hoheitsrechten in gemeinsame Ausübung durch zwischenstaatliche Institutionen. Darunter wird jetzt allgemein auch die gemeinsame Begründung von neuen, das Gebiet der Geltung des GG einschließenden Hoheitsrechten verstanden.

Die Frage der Sicherung demokratischer Rechte in diesen überstaatlichen Zusammenhängen ist in den gegenwärtigen Verhältnissen noch nicht drängend. Sie verdient aber Aufmerksamkeit im Hinblick auf die Ausdehnung der Befugnisse zwischenstaatlicher Einrichtungen und hinsichtlich der Ausdehnung des Mitgliederkreises auf demokratisch weniger gefestigte Staaten.

- Das GG enthält keine ausdrücklichen Kautelen in dieser Hinsicht. Es entspringt aber einer fundamentalen Uberzeugung, die es uns zur Pflicht macht, bei neu entstehenden Herrschaftstypen auf eine demokratische Bindung zu achten, wenn auch dabei dieses Konzept gewisse Modifikationen erfahren müßte.

b) Die Willensverteilung betrifft aber nicht nur die Verteilung des Willens zwischen den getrennten staatlichen und zwischenstaatlichen Gewalten, sondern auch die Willensverteilung zwischen hoheitlichen Gewalten und nichthoheitlichen Gruppen und Verbänden. Denn auch deren Entscheidungen sind für das Staatsleben relevant. Die aus dieser Form der Willensverteilung resultierende Konkordanz zwischen der Auf- 
rechterhaltung zentraler Entscheidungsfähigkeit einerseits und der Partizipation und Kontrolle organisierter Interessen andererseits kann ein volleres demokratisches Leben ermöglichen.

3. Die Willensverschränkung ist das verfassungstechnische Mittel, die Willensmöglichkeiten des nach der Willensverteilung Zuständigen von vornherein auf gewisse Alternativen festzulegen. Es handelt sich darum, in dem Spannungsfeld zwischen Staatsleistung und Verhinderung des Machtmißbrauchs, zwischen Eindeutigkeit des Willens und allgemeiner Partizipation und Kontrolle, zwischen Vertragsbindung und Planung einer- und freier, offengehaltener Entwicklung andererseits den geometrischen Ort zu bestimmen. Es müssen Wahl und Entscheidungsmöglichkeiten eröffnet und zugleich muß sichergestellt werden, daß deren Ergebnisse im Rahmen der politischen Gesamtverantwortung verwertbar sind. Im Wege der Willensverschränkung werden zu diesem Zweck bestimmte, diesen Anforderungen genügende Möglichkeiten formuliert und zur Wahl gestellt.

Die Auswahl dieser Möglichkeiten ist, wie bereits bei der Willensverteilung angedeutet, zum Teil im GG selbst erfolgt, zum Teil ist sie den politischen Parteien und anderen beschränkt autonomen Gruppen überlassen.

a) Im GG sind zunächst Aufteilungen zwischen Bundes-, Länder- und Gemeindezuständigkeiten, sowie Grad und Umfang des Einflusses dieser Zuständigkeiten aufeinander festgelegt. Die Länder wirken bei der Bundesgesetzgebung mit und führen grundsätzlich die Gesetze aus. Der Bund gewährleistet bestimmte Verfassungs-, Ordnungs- und Leistungsverhältnisse in den Ländern. So mu $\beta$ der Wille des einen den Willen des anderen in der vorgeschriebenen Weise inkorporieren oder für ihn Raum lassen.

b) Andere Bereiche sind von den allgemeinen demokratischen Verfahren ausgenommen und eigenständigen Entscheidungsträgern zugewiesen. Bei diesen ist zum Teil ein innerdemokratisches Verfahren vorgeschrieben - z. B. bei den Parteien und in Körperschaften des öffentlichen Rechts mit genossenschaftlicher Struktur - teils wird aber auch anerkannt, daß für die spezifische Art des hier in Frage kommenden Resultats der demokratische Prozeß nicht das geeignete Vehikel ist. Es werden dann die undemokratisch gewonnenen Ergebnisse als solche in den demokratischen Gesamtproze $\beta$ eingebracht. Kirchen, Wissenschaften, Bundeswehr, die Resultate von Arbeits- und Lohnkämpfen, aber auch die Wahrung über- 
politischer Interessen, wie die Währungspflege durch die Bundesbank, sind Beispiele.

c) Die wichtigste Willensverschränkung betrifft die allgemeine Einrichtung der Mehr- oder doch der Zweigleisigkeit des politischen Gesamtwollens. Dieses Gesamtwollen wird mehr und mehr komplex und kann praktisch nur noch im Wege der Delegation ausgeübt werden. Es ist in so hohem Maße auf Vorausschätzung zukünftiger Entwicklungen angewiesen, daß auch seine Kontrolle nicht mehr im Wege der Weisung, sondern nur noch im Wege nachträglicher Kritik möglich ist.

Diese wird durch die Willensverschränkung auf Pauschalmöglichkeiten reduziert. Der Wähler kann die Staatsführung im ganzen ersetzen, aber kaum noch im einzelnen beeinflussen. Nur die gesamte Stellung des Bundespräsidenten, nur die gesamte Existenz einer politischen Partei, nicht einzelne Handlungen unterliegen der Korrektur durch andere Verfassungsorgane.

\section{III.}

In der Verfassungswirklichkeit, dem dritten Feld der Anwendung des demokratischen Prinzips, wird die Wirksamkeit der grundgesetzlichen Postulate heute von zwei Seiten her in Frage gestellt.

1. Es geschieht dies einmal von einem mangelnden Demokratiebewußtsein und der Entwicklung undemokratischer Herrschaftsansprüche her.

a) So werden demokratische Parolen eingesetzt, um Andersdenkende auszuschalten. Man lernt, Abstimmungsvorgänge zu inszenieren, Drohungen und Störungen demokratisch zu rechtfertigen, Ressentiments und Benachteiligungen Anderer hochzuspielen und als Kampfmittel für die Förderung eigener Herrschaftsansprüche einzusetzen. All dies begegnet einer gefährlichen Kritik- und Teilnahmslosigkeit.

b) Auf der anderen Seite entstehen Monopole, und zwar souohl wirtschaftlicher als auch meinungsbildender Art. Diese Monopole sind weder im GG vorgesehen noch werden sie durch das herrschende System begünstigt. Sie entstehen, weil sich keine Gegenkräfte bilden, weil also das demokratische Recht, sich ihnen gegenüber im entgegengesetzten Sinne hervorzutun, von den Berechtigten nicht wahrgenommen wird.

Das GG ist hier nicht zu tadeln. Eine Verfassung kann Pluralität ermöglichen und fördern, aber nicht selbst hervorbringen. 
2. Die zweite Bedrohung geht von der Natur der modernen Aufgaben und Probleme aus. Nicht nur das GG nimmt insofern eine Willenseinschränkung vor, sondern der Drang der tatsächlichen Entwicklung, der Bevölkerungsexplosion, der Technologie, insbesondere der Waffen- und Nachrichtentechnik, und der wissenschaftlich-technischen Bedrohungen tut dasselbe.

Die politischen Entscheidungen werden immer mehr zu zwangsläufigen Folgerungen aus ermittelten oder für richtig gehaltenen Daten. Der politische Entscheidungsproze $\beta$ wird zum Proze $\beta$ der Tatsachenermittlung und -aufbereitung.

Neue Formen der Partizipation und Kontrolle müssen gefunden werden, wenn Demokratie und Freiheit sich retten sollen. Das GG kann insofern noch keine Regelungen enthalten. Die Zeit scheint noch nicht reif, um Vorschläge für konkrete Regelungen zu machen, die in das GG aufzunehmen wären. Es muß uns genügen, daß das $G G$ offen ist für neue Ausformungen des demokratischen Prinzips. 


\section{Das demokratische Prinzip im Grundgesetz}

2. Mitbericht von Professor Dr. Martin Kriele, Köln

Seite

I. Einleitung . . . . . . . . . . . . . . . . 46

II. Zum Typus „parlamentarische Demokratie“ . . . . . . . 49

1. Herrschaft des Volkes und Herrschaft des Rechts . . . 49

2. Zur Umdeutung der Volksherrschaft in Volkssouveränität $\mathbf{5 3}$

3. Zur Umdeutung der Repräsentation in Diskussion . . . 56

III. Art. 20 II GG und Volkssouveränität . . . . . . . . . 58

1. pouvoir constituant . . . . . . . . . . . 58

2. Trägerschaft und Ausübung der Staatsgewalt . . . . 60

3. Gleichheit . . . . . . . . . . . . . . 61

4. Vorrang der Parlamente . . . . . . . . . . . 63

5. Staatsbürgerliche Einflußrechte . . . . . . . . 65

6. Offentlichkeit . . . . . . . . . . . 67

IV. Art. 20 II GG und Repräsentation . . . . . . . . . . . . 68

1. Das Ethos der Repräsentation . . . . . . . . . . 68

2. Parteien . . . . . . . . . . . . 69

3. Fraktionen . . . . . . . . . . . . . 70

4. Mandatsverlust bei Parteiwechsel . . . . . . . . . 71

5. Konventionalregeln . . . . . . . . . . . . 73

V. "Demokratisierung" der Gesellschaft . . . . . . . . . 74

1. Politische oder verfassungsrechtliche Frage? . . . . . . 74

2. Funktionale und politische Organisationen . . . . . . 75

3. Politische Organisationen . . . . . . . . . . 76

4. Hochschulen . . . . . . . . . . . . 78

5. Wirtschaft ............... . 79

\section{Einleitung}

Die juristische Interpretation des demokratischen Prinzips im Grundgesetz muß einsetzen bei Art. 20 II 1: „Alle Staatsgewalt geht vom Volke aus"1). Dieser Grundsatz ist in zahlreichen Einzelbestimmungen konkretisiert, insbesondere in den

1) Zu den diesbezüglichen Erörterungen im Parlamentarischen Rat vgl. JöR (NF) Bd. 1, S. $195 \mathrm{ff}$. 
Vorschriften über Repräsentation des Volkes, über Budgetrecht, Parteien, Wahlen, Abstimmungen, Petitionen, Freiheit der Meinung, der Presse, der Versammlung, der Vereinigung, sowie in einer großen Zahl von Gesetzes- und Geschäftsordnungsregeln. Das demokratische Prinzip des Art. 20 II 1 ist bisher nur in sehr wenigen Fällen unmittelbar zur Begründung richterlicher Entscheidungen herangezogen worden ${ }^{2}$ ) und wird auch wahrscheinlich selten relevant werden; denn es lebt hauptsächlich in seinen Konkretisierungen.

Daraus folgt aber nicht, daß im Rahmen unseres Themas alle diese konkretisierenden Vorschriften zu interpretieren seien. Das wäre nicht nur eine zeitliche und sachliche Uberforderung. Es wäre auch juristisch deshalb problematisch, weil Art. 79 III, der das demokratische Prinzip der legalen Verfassungsänderung entzieht, mit diesem Verbot nicht seine Ausgestaltungen im einzelnen, sondern eben nur das Prinzip meinen $\mathrm{kann}^{3}$ ). Die Hauptfrage läßt sich deshalb so stellen: Was ist in den verschiedenen Konkretisierungen des Demokratieprinzips das essentiell Demokratische, gewissermaßen der demokratische Wesensgehalt, der in Art. 20 II eingeht?

Andererseits kann Art. 20 II nicht ohne Bezugnahme auf die Konkretisierungen ausgelegt werden ${ }^{4}$ ). Vielmehr muß das demokratische Prinzip aus seinem systematischen Zusammenhang heraus unter Berücksichtigung der genetischen Auslegung interpretiert werden. Der Rückgriff auf den Typus „pariamentarische Demokratie " westlicher Prägung ${ }^{\overline{5}}$ ) und die Gründe, die seine Entwicklung bedingten, ist zum Verständnis der ratio legis unerläßlich.

Zum Typus parlamentarische Demokratie gehen die Demokratietheorien von sehr unterschiedlichen Kennzeichnungen aus. Parlamentarische Demokratie, heißt es, sei die Staatsform der

2) Vgl. vor allem BVerfGE 1, 14, 33; 11, 310, 321.

${ }^{3}$ So auch W. O. Schmitt-Glaeser, Der Begriff der freiheitlich demokratischen Grundordnung und Art. 79 Abs. 3 des GG, DOV 1965, S. 433, 437; zur Interpretation des Art. 79 Abs. 3 GG als „Schranke gegenüber einer Allmacht der Mehrheit" Hamann-Lenz, Das Grundgesetz für die Bundesrepublik, Deutschland, 3. Aufl., 1970, Anm. A. 1 , S. 538.

4) Vgl. auch $K$. Hesse, Grundzüge des Verfassungsrechts der Bundesrepublik Deutschland, 4. Aufl. 1970, S. 52 ff.

5) Zur Abgrenzung von der "Sozialistischen Demokratie“ vgl. $K$. von Beyme, Stichwort "Demokratie" in: Sowjetsystem und demokratische Gesellschaft, Bd. 1, 1966, Sp. 1139 ff. mit weiteren zahlreichen Literaturangaben. 
Identität von Regierenden und Regierten ${ }^{0}$ ), der Gleichheit ${ }^{7}$ ), der Mehrheitsherrschaft ${ }^{8}$ ), der Toleranz ${ }^{9}$ ), des Pluralismus ${ }^{10}$ ), der Konkurrenz der Machteliten ${ }^{11}$ ), der Interessenbalance ${ }^{12}$ ), der Komplexität ${ }^{13}$ ), des Kompromisses ${ }^{14}$ ) oder der Partnerschaft ${ }^{15}$ ). Alles das sind Aspekte, die ganz oder teilweise richtig sind. Keine dieser Theorien erklärt aber alles, was zum demokratischen Verfassungssystem des Grundgesetzes gehört. Und umgekehrt: jede dieser Theorien müßte konsequenterweise zu wenigstens einigen Folgerungen führen, die mit dem demokratischen Verfassungssystem des GG unvereinbar sind. Kurz: keine dieser Theorien bezeichnet den gemeinsamen Nenner, auf den die verschiedenen Rechtsinstitute, in denen sich das demokratische Prinzip im GG konkretisiert, gebracht werden können. Eine kritische Auseinandersetzung ist an dieser Stelle nicht möglich; doch bieten sich im Zuge des folgenden Inter-

-) In der rousseauistischen Tradition vor allem C. Schmitt, Verfassungslehre, Neudruck 1954, S. 234; neuerdings spricht man auch von "Partizipation", vgl. dazu F. Scharpf, Demokratietheorie zwischen Utopie und Ánpassung, 1970, S. 54 ff. m. w. Nachw.; hierher gehört auch die Definition von Abraham Lincoln, Demokratie sei "Government of the people, by the people, for the people".

7) G. Leibholz, Strukturprobleme der modernen Demokratie, 2. Aufl. 1964, S. 135, 137, 147, 152 f.; derselbe, Die Gleichheit vor dem Gesetz, 2. Aufl. 1959, S. 16 ff.; K. Hesse, VVDStRL 17 (1959), S. 17.

8) Hierzu: Elias Berg. Democracy and the Majority Principle - A Study in Twelve Contemporary Political Theories, Göteborg, 1965.

ๆ) Vgl. Schüle, Festgabe für Smend, 1952, S. 335, 338; zur juristischen Ausprägung des Begriffs Toleranz vgl. auch F. Werner, Recht und Toleranz, in: Verhandlungen des 24. Deutschen Juristentages, 1963, Bd. 2, S. $138 \mathrm{ff}$; $U$. Eisenhardt, Der Begriff der Toleranz Im öffentlichen Recht, JZ 1968, S. 214 ff.

10) A. F. Bentley, The Process of Government, 1908; R. A. Dahl, Pluralist Democracy in the U.S., 1967; zu dieser Richtung vgl. $F$. Scharpf, aaO. (Anm. 6), S. 29 ff.

11) J. A. Schumpeter, Kapitalismus, Sozialismus und Demokratie, 1950, S. $427 \mathrm{ff}$. (wegen weiterer amerikanischer Literatur vgl. $F$. Scharpf, aaO., Anm. 6, S. 33 ff.); $R$. Dahrendorf, Gesellschaft und Demokratie in Deutschland, 1964, S. 41; in einem etwas ánderen Sinne: S. M. Lipset, Political Man, 1960, S. 402 (Demokratie als „permanent insecurity for those in governing position").

12) H. Lasky, A Grammar of Politics, 6. Aufl. 1937; B. Crick, Eine Lanze für die Politik, 1966; vgl. jetzt $F$. K. Fromme, Der Demokratiebegriff des Grundgesetzes, DOV 1970, S. 518.

1s) Vgl. N. Luhmann, Komplexität und Demokratie, Politische Vierteljahreszeitschrift 10 (1969), S. 314 ff., F. Scharpf, aaO. (Anm. 6), S. $66 \mathrm{~m}$. w. Nachw.

14) Z.B. W. Trillhaas, Stichwort „Kompromiß“ in: Ev. Staatslexikon, Sp. 1113 ff.; J. Messner, Das Naturrecht, 4. Aufl. 1958, S. 721 ff.; P. Furth, Der Kompromiß als Wesensmerkmal der Demokratie, in: Die Kirche in der Welt 7 (1954), S. 89 ff.

15) L. Roos, Demokratie als Lebensform, 1969, S. $246 \mathrm{ff}$. 
pretationsversuchs Gelegenheiten, beispielhaft einige Gesichtspunkte aufzugreifen.

Die Frage drängt sich auf: kann es überhaupt einen gemeinsamen Nenner für so entgegengesetzte Prinzipien wie Volksherrschaft und Repräsentation geben, denen ähnlich polare Begriffspaare entsprechen: Parlamentssouveränität und Verfassungsbindung, Mehrheitsprinzip und Minderheitenschutz, Gleichheit und Freiheit? Ist das GG nicht aus Kompromissen zwischen im Grunde unvereinbaren Ideen gebildet? Werden Verfassungsauslegung und Verfassungskonflikte nicht letztlich davon bestimmt, welcher dieser Ideen man aus gesinnungsmäßiger Zuneigung das größere Gewicht zumißt? Oder entsteht dieser Anschein nur, wenn man zuvor einseitige Aspekte verabsolutiert und mit logischer Konsequenz ins Extrem treibt, statt sie dialektisch $z u$ relativieren und aufeinander $\mathrm{zu}$ beziehen?

Wenn es einen gemeinsamen Nenner gibt, so muß man ihn in der Geschichte der demokratischen Institutionen suchen (nicht also in der Geschichte der demokratischen Theorien, in denen die Ideenantagonismen schon angelegt sind). So wesentlich sich das Grundgesetz vom englischen Verfassungsrecht unterscheidet, so ist doch ein Blick in die Geschichte des englischen Parlamentarismus deshalb von Bedeutung, weil die englischen Institutionen in eigenständiger und kontinuierlicher Entwicklung den Typus der parlamentarischen Demokratie geprägt haben. Es ist in diesem Zusammenhang freilich nicht möglich, und nach den Ausführungen Herrn von Simsons auch nicht nötig, mehr zu tun, als einige Gesichtspunkte hervorzuheben.

\section{Zum Typus „parlamentarische Demokratie“}

1. Herrschaft des Volkes und Herrschaft des Rechts.

Meine Ausgangsthese ist folgende:

Herrschaft des Volkes im Sinne der parlamentarischen Demokratie ist identisch mit Herrschaft des Rechts (im Sinne der rule of law, nicht des Rechtsstaats). Herrschaft des Rechts ${ }^{10}$ )

10) Vgl. dazu etwa $H$. Kelsen, Reine Rechtslehre, 2. Aufl., 1960, S. 334 und öfter; $H$. Krabbe, Die Lehre der Rechtssouveränität, Groningen 1906 (hierzu P. Häberle, Zur gegenwärtigen Diskussion um das Problem der Souveränität, AöR 92 (1967), S. 259 ff., 263). Zum unterschiedlichen Inhalt des Begriffs Rechtssouveränität bei Krabbe und Kelsen siehe G. E. Langemeijer, Betrachtungen zum Begriff der Souveränität, in: Die moderne Demokratie und ihr Recht, Festschrift für Leibholz, 1966, Bd. 2, S. 91 ff. Siehe ferner die Bemerkung von Ch. F. Menger (Moderner Staat und Rechtspre-

4 Veröffentl. Dt. Staatsrechtslehrer, Heft 29 
darf nicht im Sinne des traditionellen deutschen Rechtsstaatsbegriffs des 19 . Jh. gedeutet werden ${ }^{17}$ ), weil in diesem Rechtsstaatsbegriff die Verknüpfung der materiellen Rechtsidee mit ihren institutionellen Realisierungsbedingungen fehlte. Er erschöpfte sich in Gesetzlichkeit und reduzierte den Gedanken der materialen Gerechtigkeit auf den moralischen Appell, der sich letztlich auch an einen absoluten Souverän richten kann ${ }^{18}$ ).

Herrschaft des Rechts ist eher im Sinne der rule of law zu deuten ${ }^{10}$ ). Diese geht davon aus, daß sich das Recht dialektisch nach prozessualen Regeln aus den im Volk gemachten Erfahrungen der Unzulänglichkeit des schon bestehenden Rechts verwirklicht. Parlamentarische Demokratie ist geschichtlich und theoretisch $\mathrm{zu}$ begreifen aus der Ubertragung des Gedankens des gerichtlichen Prozesses auf den politischen Prozeß der Gesetzgebung. Sie entstand aus der Suche nach den verhältnismäßig günstigsten institutionellen Bedingungen für die Verwirklichung des Naturrechts im positiven Recht.

Das englische Parlament hat seine geschichtliche Wurzel bekanntlich in der curia regis, einem Organ, das ursprünglich

chung, 1968, S. 25), das GG weise insofern „dualistische“ Züge auf, als es dem demokratischen Prinizp der Volkssouveränität das materiell-rechtsstaatliche Prinzip der "Souveränität" des Rechts gegenüberstellte; hiergegen $U$. Scheuner, Das Grundgesetz in der Entwicklung zweier Jahrzehnte, AöR 95 (1970), S. $353 \mathrm{ff}$., $383 \mathrm{f}$.

${ }^{17}$ ) Zur Vorgeschichte des „klassischen“ Rechtsstaatsbegriffs vgl. $U$. Scheuner, Die neuere Entwicklung des Rechtsstaats in Deutschland, in: Hundert Jahre deutsches Rechtsleben, Festschrift zum hundertjährigen Bestehen des Deutschen Juristentages 1860-1960. S. $229 \mathrm{f}$; $E$. W. Böckenförde, Entstehung und Wandel des Rechtsstaatsbegriffs, in: Festschrift für Adolf Arndt, 1969, S. 53 ff., 55 ff., 59; zur geistesgeschichtlichen Grundlage des „liberalen" Rechtsstaates nunmehr Ch. Heinze, Autonome und heteronome Verteilung, 1970, S. $18 \mathrm{ff}$.; zum "materialen“ Rechtsstaatsbegriff vgl. $H$. Heller, VVDStRL Bd. 4, S. 115.

18) Nach Kant ist zwar die repräsentative Republik „die einzig bleibende Staatsverfassung, wo das Gesetz selbstherrschend ist und an keiner bestimmten Person hängt" (Metaphysik der Sitten, § 52, Ausg. Vorländer 1922, S. 170); aber auch in der absoluten Monarchie ist nach Kant der Zustand allgemein verpflichtender Gesetzlichkeit (also eine abstrakte Rechtsstaatlichkeit) gegeben. Diese darf nicht revolutionär beseitigt werden, der Übergang zur Republik wird der reformerischen Weisheit des Monarchen anheim gegeben.

19) F. Neumann, (Demokratischer und autoritärer Staat, 1967, S. 108) meint sogar etwas zugespitzt, die englische Lehre der "Rule of Law" und der deutsche Rechtsstaat "haben nichts gemein". Zur Rule of Law siehe Sir Alfred Denning, The changing Law, 1953, S. 5 ff.; Sir Carlton Kemp Allen, Law and Order, 2nd Ed., 1955, S. 22; Sir Iver Jennings, The Law and the Constitution, 5. Aufl. 1963, S. 42 ff.; derselbe in: Jennings-Ritter, Das britische Regierungssystem, 1970, S. 107 ff., 119 ff. 
u. a. Rechtsprechungs- und Rechtsfortbildungsfunktion hatte. Seine Gesetzgebungsfunktion wurde seit dem 17. Jh. verstanden als Rechtsfortbildung in größeren Zusammenhängen, unabhängig von Präjudizien. Der Gesetzgeber war Beschleuniger, Richtpunktsetzer und Ordner der Rechtsfortbildung $\left.{ }^{20}\right)$.

Das Common Law gab es als Richterrecht vor den Gesetzen; Recht entsteht überhaupt zunächst als Richterrecht ${ }^{21}$ ). Die politische Gewalt zwingt den Austrag der Macht-, Interessenund Ansichtsgegensätze in eine prozessual geregelte Meinungskontroverse, die in eine verbindliche Dezision mündet. Der Anfang der Rechtsgewinnung ist, daß jemand im Volk eine situationsbedingte Unrechtserfahrung macht und klagt. In einer Welt, in der sein Fall nicht gesetzlich vorentschieden ist, behauptet er eine Normhypothese z. B. von der Art: "so etwas braucht man sich nicht gefallen zu lassen". Gegenstand der Kontroverse ist die Frage, ob es gerechtfertigt wäre, die Normhypothese durch Entscheidung zur Norm zu machen und zwar durch präjudizielle Wirkung der ratio decidendi im Richterrecht oder durch Gesetz.

Rechtfertigen bedeutet, wie Chief Justice Hale schrieb: die in Frage kommenden Normalternativen vergleichen, die voraussichtlichen Konsequenzen für das praktische, menschliche, wirtschaftliche, soziale Leben abschätzen und diejenigen wählen, die bei unparteiischer Abwägung der begünstigenden und benachteiligenden Wirkungen die relativ geringsten Nachteile und größten Vorteile mit sich bringt ${ }^{22}$ ).

Die Möglichkeit, trotz der erheblichen Meinungsverschiedenheiten zu argumentieren und begründet $\mathrm{zu}$ entscheiden, beruht auf einem Urteilsvermögen und Gerechtigkeitssinn, von dem man annahm, daß er den Menschen, wenn auch in verschiedenen Graden der Begabung und Entwicklung gemeinsam sei, und den man deshalb als sensus communis oder „common sense $^{\text {" }}$ voraussetzte ${ }^{23}$ ). Die zugeordnete Dogmatik verstand sich als prudentia und nicht als scientia. Ihre Kernbegriffe waren, wie Kluxen für das englische 18. Jahrhundert gezeigt hat: circumstances, conveniency, opportunity, expediency, probabili-

20) Matthew Hale, Consideration Touching the Amendment or Alteration of Laws, ed. by Francis Hargrave (Collecteana juridica, 1791, S. 253-289; vgl. dazu $M$. Kriele, Die Herausforderung des Verfassungsstaates, Hobbes und die englischen Juristen, 1970, S. $18 \mathrm{ff}$.

21) Eingehender: $M$. Kriele, Theorie der Rechtsgewinnung, 1967, insbesondere $S .60 \mathrm{f}$.

$\left.{ }^{22}\right)$ M. Kriele, aaO., S. $162 \mathrm{f}$., $198 \mathrm{ff}$.

23) Gadamer, Wahrheit und Methode, 2. Aufl., S. $16 \mathrm{ff}$. 
ty $\left.{ }^{24}\right)$. Fortschritte in der Einsicht wurden nicht durch Deduktion, sondern durch situationsbedingte Erfahrung gewonnen, durch "challenge and answer", durch "trial and error".

Man ging davon aus, da $B$ politische Meinungsverschiedenheiten zum größten Teil (nicht alle) prinzipiell diskutierbar, aber so komplex sind, daß sie auf verbindliche Dezisionen angewiesen sind, deren Richtigkeit dann aber wieder in Frage gestellt werden kann. Rechtlicher Fortschritt ist ein unendlicher Pro$z e \beta$ von Diskussion und Dezision ${ }^{25}$ ).

In dem Maße, in dem die sozialen Verhältnisse komplexer werden, werden sie regelungsbedürftiger und gewinnt die parlamentarische Gesetzgebung mehr und mehr an thergewicht über richterliche Rechtsbildung. Damit wird auch der Entscheidungsproze $\beta$ komplexer. Die diffuse Vielfalt von Anregungen und Ansichten zwingt zur Abfilterung des Relevantesten und Vordringlichsten. Volksherrschaft durch Parlamentarismus bedeutet deshalb in einer ersten vorläufigen Kennzeichnung dreierlei:

Einmal: Ansto $B$ zum parlamentarischen Entscheidungsproze $\beta$ geben die im Volk gemachten situationsbedingten Erfahrungen der Entscheidungsbedürftigkeit und der öffentlichen Relevanz einer Sache. Gegenstand der Diskussion sind Selektion und zeitliche und rechtliche Prioritätenordnung, also die Fragen, welche Sachen entscheidungsbedürftig, welche von ihnen vordringlich sind und welche Entscheidung gerechtfertigt wäre. Die von den Repräsentanten getroffene Entscheidung über Relevanz und Priorität muB sich vor dem common sense der Wähler rechtfertigen. Der demokratische Legitimationszirkel ist also ein ständiger Rechtfertigungsprozeß. Die Wahl gewährleistet, daß sich die Bewertung der Relevanzen und Prioritäten im Großen und Ganzen im Einklang mit dem common sense hält.

Zum anderen: der grundlegende Satz des juristischen Ethos ist: audiatur et altera pars (oder, wie es deutschrechtlich hieß: Eenes Mannes Rede ist keenes Mannes Rede, man muß sie hören alle beede). Sind drei an der Sache beteiligt, so müssen sie alle drei zu Worte kommen, sind hundert beteiligt, so alle hundert, sind es alle, so müssen eben alle zu Gehör kommen. Da das praktisch nicht möglich ist, drängt dieses Ethos zwangsläufig zu Organisationsformen, die eine Repräsentation aller ermöglichen.

24) K. Kluxen (Hrsg.) Parlamentarismus, 1967, S. 99, 103.

25) Dazu näher M. Kriele, aaO., S. $191 \mathrm{ff}$. 
Und schließlich: Das Problem der Repräsentation entsteht daraus, da $B$ im politischen Prozeß, im Unterschied zum juristischen, Plädierende und Entscheidende identisch sein müssen. Nicht schiedsrichterliche Führung, sondern Entscheidung durch Mehrheit. Die Rolle des Königs als eines möglichen pouvoir neutre wurde im Lauf der Geschichte mehr und mehr zurückgedrängt. Das scheint auf den ersten Blick dem Grundsatz zu widersprechen: niemand kann Richter in eigener Sache sein. Madison ${ }^{29}$ ) entwickelt im "Federalist" das Prinzip der Mehrheitsentscheidung aber gerade aus diesem Satz, und das im Ergebnis zu Recht. Denn im politischen Prozeß ist eine neutrale Instanz unmöglich. Jeder denkbare Schiedsrichter ist, so sehr ihn sein Amt aus der Gesellschaft heraushebt, doch zugleich Mitglied der Gesellschaft, als solches in Interessen, Ideologien, Traditionen verstrickt und also notwendigerweise $\operatorname{Partei}^{27}$ ).

Im Proze $\beta$ des politischen Meinungskampfes gibt es nur gewissermaßen nautische Positionen ${ }^{28}$ ). Alles ist in Bewegung. Auch der festgehaltene Standpunkt ändert seine Funktion durch die Bewegung der Umwelt. Jede denkbare Position ist dialektisch einseitig. Niemand kann je sagen, seine Ansicht sei absolut vernünftig. Es gibt nur Grade von Vertretbarkeit und Plausibilität. Dafür gibt es aber keinen anderen Maßstab als den der möglichst breiten und dauerhaften Zustimmung. Es ist wie in der juristischen Dogmatik: daß ständige Rechtsprechung und herrschende Ansicht vernünftiger sind als die Mindermeinung, die nicht $\mathrm{zu}$ überzeugen vermag, ist nicht sicher, aber wahrscheinlicher als die gegenteilige Annahme.

Aus diesen historischen Prämissen entwickelten sich die Institutionen der parlamentarischen Demokratie mit einer gewissen Zwangsläufigkeit. Deutungsprobleme der Demokratie entstehen meistens aus einer Auflösung dieses dialektischen $\mathrm{Zu}-$ sammenhangs von Volksherrschaft und Repräsentation. Volksherrschaft wurde umgedeutet in Volkssouveränität, Repräsentation in Wahrheitsfindung durch Diskussion.

2. Zur Umdeutung der Volksherrschaft in Volkssouveränität. Die auf Rousseau und die Verfassung von 1793 zurückgehende Idee von der Volkssouveränität deutet die notwendige Identität

26) James Madison, The Utility of the Union as a Safeguard against Domestic Faction and Insurrection, in Hamilton, Madison, Jay, The Federalist Papers (No. 10), The New American Liberary, 1961, S. 79.

27) So für den absoluten Monarchen N. Elias, Uber den Prozeß der Zivilation, Bd. 2, 1962, S. 222 ff., insbesondere S. 239-241.

28) Odo Marquard, Skeptische Methode im Blick auf Kant, S. 54. 
von Plädierenden und Entscheidenden um in Identität von Herrschenden und Beherrschten. Entscheidend soll der unmittelbare Volkswille und nicht die dialektisch erarbeitete Meinung über das Gerechtfertigte sein. Diese Theorie gibt es in zwei idealtypischen Varianten, je nachdem ob der Volkswille empirisch - so wie er ist (volonté de tous) - oder hypothetisch so wie er sein sollte (volonté générale) - verstanden wird ${ }^{20}$ ).

Soll der hypothetische Volkswille zur Geltung gebracht werden, so ist die Bezugnahme auf den Volkswillen eigentlich entbehrlich. Statt zu sagen, was man will, sagt man, was das Volk wollen würde, wenn es seine wahren Interessen objektiv erkennte. Die Frage ist dann nur, wer darüber zu entscheiden hat, was der wahre Volkswille ist. Will man den empirischen Volkswillen dennoch nicht völlig ignorieren, so muß man darauf bedacht sein, den empirischen Volkswillen dem hypothetischen anzupassen: Erziehungsdiktatur. Dialektik geht, ebenso wie Humanität, im alles rechtfertigenden Zweck auf und damit verloren.

Wird im Namen des demokratischen Prinzips die unmittelbare Realisierung des empirischen Volkswillens gefordert, so kann das auf ein Rätesystem ${ }^{30}$ ) hinauslaufen ${ }^{31}$ ), das in der Regel gekennzeichnet ist durch:

imperatives Mandat,

Abberufbarkeit der Gewählten,

Allzuständigkeit des Rats und

meist auch mittelbare Wahl, die von der Basisgruppe über Lokal- und Regionalräte zum Zentralrat führt.

Alle diese Elemente stehen mit den in Art. 20, 38, und 39 GG niedergelegten Grundsätzen im Widerspruch.

29) Dazu $D$. Schindler, Uber die Bildung des Staatswillens in der Demokratie, 1921, S. 31-51. Zur Entwicklung einer totalitären Demokratiekonzeption aus rousseauistischen Ansätzen vgl. I. Fetscher, Rousseaus politische Philosophie, 2. Aufl. 1968, S. 259 ff.; J. L. Talmon, The Rise of Totalitarien Democracy, 1952, dazu F. Scharpf, aaO. (Anm. 6), S. 26.

30) Vgl. hierzu J. Agnoli - P. Brückner, Die Transformation der Demokratie, 1968; F. Naschold, Organisation und Demokratie, 1969, S. 24 ff.; K. $v$. Beyme, Die parlamentarischen Regierungssysteme in Europa, 1970, S. 470 ff.

s1) Aber nicht notwendigerweise, vgl. Ivo Krbek, Repräsentation nach der Doktrin der Volkssouveränität, in: Die moderne Demokratie und ihr Recht (Leibholz-Festschrift) Bd. 2, 1966, S. 69 ff. Der Standpunkt des Verfassers ist nicht nur durch die Terminologie („konkrete" gleich unmittelbare, „abstrakte" gleich repräsentative Demokratie) dem hier Vorgetragenen entgegengesetzt. 
Die „Volkssouveränität“ läßt sich freilich auch dem parteienstaatlichen Parlamentarismus unterschieben und interessiert uns vor allem in dieser Gestalt ${ }^{32}$ ). Parlamentarische Demokratie gilt dann, wie es Hans Maier ausgedrückt hat, als ein „defizienter Modus unmittelbarer Volksherrschaft “s39). Ansätze zu solchem Denken finden sich gelegentlich auch bei angelsächsischen Theoretikern $\left.{ }^{34}\right)$. Der Wirklichkeit der parlamentarischen Institutionen, die von der rule of law ausgehen, sind sie ursprünglich aber fremd. Rousseau ersetzte den souveränen König Hobbes'scher Prägung durch das souveräne Volk, das im Paralament organisiert wird ${ }^{35}$ ). Im angelsächsischen Rechtsdenken konnte es aber keinen Souverän geben $\left.{ }^{38}\right)$. Auch der Monarch hatte nur die ihm durch das Recht zugewiesenen Kompetenzen. Souveränitätsanmaßung im 17. Jahrhundert führte zu Revolution und Bürgerkrieg, aber nicht, wie in der französischen Revolution, mit dem Ziel, königliche Souveränität durch Volkssouveränität zu ersetzen, sondern mit dem Ziel, wieder allgemeinen Respekt für die Rechts- und Kompetenzordnung zu erzwingen ${ }^{37}$ ).

32) z. B. G. Leibholz, Zum Begriff und Wesen der Demokratie, in: Strukturprobleme der modernen Demokratie, 1964, S. 142 ff.; dazu ausführlich L. Roos, aaO. (Anm. 15), S. 42 ff. Wir haben dann, zugespitzt ausgedrückt, angelsächsische Institutionen mit französischer Ideologie; aus dieser Spannung entstehen zahlreiche Probleme. Vgl. dazu E. Fraenkel, Deutschland und die westlichen Demokratien, 4. Aufl. 1968, S. 81 ff. Beispiel für eine solche Unterschiebung: W. Abendroth, Das Grundgesetz, eine Einführung in seine politischen Probleme, 1966, S. 78 ff.

33) H. Maier, Politische Wissenschaft in Deutschland, 1969, S. 186; ähnlich $H$. Kelsen, Vom Wert und Wesen der Demokratie, 1929, S. 24 f. (abgedruckt in: Lenk-Neumann, Theorie und Soziologie der politischen Parteien, 1968, S. 132, 139).

34) Vgl. dazu F. Nuscheler, Walter Bagehot und die englische Verfassungstheorie, Heidelberger politische Schriften, Bd. 2, 1969; K. Streifthau, Die Souveränität des Parlaments, 1963, S. 28 ff. (über Bentham) und S. 43 ff. (über J, Austin).

35) W. Kägi, Rechtsstaat und Demokratie, in: Festschrift für Giacometti, 1953, S. 109 f.

36) Auch die kontinentale Staatslehre bemüht sich immer wieder, vom abstrakten "Souverän" zur dialektisch verstandenen, d. h. in die institutionelle Ordnung integrierten und diese respektierenden "Souveränität" zu kommen. Hegel spricht in diesem Sinne von "Idealität" der Souveränität (Rechtsphilosophie, \$§ 278 f.), M. Hauriou bestimmt Souveränität geradezu als „Selbstbeherrschung“, Précis de Droit Constitutionel, 1923, S. 159. Auf der Basis der Scheelerschen Philosophie kommt E. Denninger, Rechtsperson und Solidarität, 1968, S. 273 ff., 280 ff. zu ähnlichen Formulierungen.

37) $M$. Kriele, Die Herausforderung des Verfassungsstaates Hobbes und englische Juristen, 1970, vor allem die Abschnitte 5 und 7. 


\section{Zur Umdeutung der Repräsentation in Diskussion.}

In der parlamentarischen Demokratie ist Staatswillensbildung Meinungsbildung, die in eine verbindliche Dezision mündet. Meinungen werden freilich nur idealiter durch Vernunft, die blo $B$ das Interesse des Ganzen und die gerechte Abwägung partikularer Interessen im Auge hat, bestimmt. Meinungen sind unvermeidlich selbst durch Willensrichtungen motiviert.

Deshalb lassen die Theoretiker der Volkssouveränität den Staatswillen unmittelbar aus den Einzelwillen hervorgehen und erklären die Vermittlungsstation der Meinungsbildung für eine sowohl überflüssige als auch illusorische Annahme.

Dieser Vulgärvoluntarismus gewinnt seine Gängigkeit aus der Polemik gegen einen rationalistischen Repräsentationsbegriff. Seine klassische Formulierung fand er bei Carl Schmitt. Schmitt hat die geistesgeschichtliche Grundlage des Parlamentarismus durch die Begriffe Diskussion und Offentlichkeit gekennzeichnet $\left.{ }^{38}\right)$. Diskussion deutete er so, als sei der Austausch von Argumenten zwischen den Parlamentariern gemeint. Was durch öffentliche Diskussion bewirkt werden solle, sagt Schmitt, "war nicht weniger als Wahrheit und Gerechtigkeit selbst" ${ }^{\text {(38) }}$ ). Diesem Idealbild stellt Schmitt die desillusionierende Realität gegenüber ${ }^{40}$ ): nicht vernünftig diskutierende Abgeordnete, sondern ideologisch festgelegte Fraktionen, der einzelne Abgeordnete durch Fraktionszwang gebunden.

Der Wirklichkeit des Parlamentarismus lag aber trotz des Anscheins, den die von Schmitt zusammengestellten Zitate vermitteln, niemals dieser Diskussionsbegriff zugrunde. $\mathrm{Daß}$ politische und soziale Fundamentalgegensätze nicht ausgetragen werden können, indem man sich einmal in Ruhe zusammensetzt und Argumente austauscht, das war auch schon im 17., 18. und 19. Jahrhundert so und ist übrigens auch den theoreti-

98) C. Schmitt, Die geistesgeschichtliche Lage des heutigen Parlamentarismus, 2. Aufl. 1926, S. $37 \mathrm{f}$.

30) C. Schmitt, aaO. (Anm. 38), S. 61. Diese Ansicht wird heute nicht mehr ernsthaft vertreten (vgl. Th. Ellwein, Politische Verhaltenslehre, 1964, S. 78 f.; $H$. Krïger, Allgemeine Staatlehre, 1964, S. $444-$ "Wunderglaube“ $\rightarrow$ ); trotzdem knüpft die „linke“ Parlamentarismuskritik (in Nachfolge von C. Schmitt) noch immer germ hier an, vgl. J. Agnoli - P. Briickner, aaO. (Anm. 30), S. $7 \mathrm{ff}$., $55 \mathrm{ff}$.; dazu F. Scharpf, aaO. (Anm. 6) S. 23 f.

10) Ahnlich (Parlamentarismus als technisch-rationales System ohne Integrationskraft), $\boldsymbol{R}$. Smend, Verfassung und Verfassungsrecht, 1928, S. $36 \mathrm{ff}$; dazu W. Bauer, Wertrelativismus und Wertbestimmtheit im Kampf um die Weimarer Demokratie, 1968, S. 291 if. (dessen Urteil über die Smend'sche Integrationslehre insgesamt zu einseitig ausgefallen ist). 
sierenden Beobachtern der Wirklichkeit des englischen Parlaments im allgemeinen nicht entgangen. Das ideologiekritische Denken war, von Bacon vorgeprägt, von Mandeville, Shaftesbury und Hume ausgebildet, schon im frühen 18. Jahrhundert Gemeingut der politischen Offentlichkeit Englands, hauptsächlich in der Gestalt der Rückführung von "reason" auf „passion“, "appetite“, „interest"“1).

Das bedeutet aber nicht, daß Argumente überhaupt politisch funktionslos, daß sie bloß Derivate von Residuen oder Spiegelungen von Klasseninteressen seien, wie es die radikale „Ideologieentlarvung " verschiedener Couleur beschreibt ${ }^{42}$ ). Das ist das andere und ebenso falsche Extrem.

Meinungen sind untrennbar verknüpft mit Interessen, mit Machtfragen, mit Autoritäten, mit Traditionen, die man oft nur geistes- und religionsgeschichtlich verstehen kann. Freiwillige Optionen für politische Gruppen oder Parteien kann man heute im Zeitalter der Tiefenpsychologie aus individual-, gruppen-, alterspsychologischen und anderen Strukturen und Konstellationen erklären. Politische Meinungen sind wie die Spitzen von Eisbergen, was sie letztlich bestimmt, bleibt unter der Oberfläche des Bewußtseins. Das Argument aber bleibt über der Oberfläche und kann sie deshalb nicht unmittelbar bewegen.

Was politische Meinungen ändern kann, sind tiefreichende Erfahrungen. Die Sicht des Vierzigjährigen unterscheidet sich meist sehr von der des Zwanzigjährigen. Die Sicht der päpstlichen Sozialenzykliken und der sozialistischen Parteiprogramme von heute unterscheidet sich wesentlich von der von vor fünfzig oder hundert Jahren. Doch führen im politischen Bereich gleiche Erlebnisse zu ganz unterschiedlichen Erfahrungen. Das erklärt sich daraus, daß die komplexen wirtschaftlichen, sozialen, geschichtlichen und anderen Zusammenhänge nur durch theoretische Interpretationsschemata erklärt werden können. Erfahrung entsteht durch ein Hin- und Herwandern des Blicks zwischen Erlebnis oder Information einerseits und theoretischem Erklärungsschema andererseits. Die Interpretationsschemata bilden den Kitt für Gruppensolidarität. Nehmen die in der Gruppe geltenden Autoritäten neue Erfahrungsgesichtspunkte auf und vertreten sie, so prägen sie die Gruppenmeinung allmählich um.

11) Siehe K. Kluxen, Das Problem der politischen Opposition, Entwicklung und Wesen der englischen Zweiparteienpolitik im 18. Jahrhundert, 1956, vor allem das 5. Kap.; K. Lenk, Problemgeschichtliche Einleitung, in: $K$. Lenk (Hrsg.), Ideologie - Ideologiekritik und Wissenssoziologie, 3. Aufl. 1967, S. $18 \mathrm{ff}$.

42) Vgl. die Nachweise bei $K$. Lenk, aaO. (Anm. 41). 
Argumente haben also eine doppelte Funktion. Einerseits schaffen sie Problembewußtsein, sie erklären, was, wie man im Englischen so treffend sagen kann, „issue“, der Kern der Streitfrage ist. D. h., sie vermitteln die Interpretationsschemata, die aus dem unendlichen Fluß diffuser Erlebnisse das Relevante sichtbar machen. Dadurch erst werden Erlebnisse zu Erfahrungen. Andererseits relativieren Argumente die Interpretationsschemata, indem sie Tatsachen geltend machen, die mit diesen nicht oder nicht zulänglich erklärbar sind und wandeln die Schemata auf diese Weise um. Kurz: Argumente und Diskussionen ändern Meinungen meistens nicht unmittelbar und sofort, aber sie leiten langfristig die Erfahrungen, die ihrerseits Meinungswandlungen herbeiführen. Wenn man so die Einsichten der Ideologiekritik und der Gruppenpsychologie einbezieht, so wandelt sich das rationalistische Verständnis der Diskussion in ein dialektisches, wenn man unter Dialektik versteht: Verwirklichung des Naturrechts im Prozeß geschichtlicher Erfahrung.

Ihren dialektischen Gang in diesem Sinne nimmt die Geschichte auch ohne parlamentarische Demokratie, dann aber auf langwierigen und blutigen Wegen über Souveränität und Revolution, Bürgerkrieg, Diktatur und Terror. Der Sinn der parlamentarischen Demokratie ist, die geschichtliche Dialektik gewissermaßen an prozessuale Regeln zu binden, die ihr Freiheit geben und zugleich ihre Friedlichkeit gewährleisten. Die geistesgeschichtliche Grundlage der parlamentarischen Demokratie kann man mit Ernst Troeltsch ${ }^{43}$ ) in der gemeineuropäischen Naturrechtstradition finden, sofern man unter Naturrecht nicht einen feststehenden Normenkomplex versteht, sondern den geschichtlichen Prozeß dialektischer Rechtfertigung, die die relativ größte Chance der Verwirklichung der Gerechtigkeit im positiven Recht eröffnet.

Im Folgenden wird das demokratische Prinzip zunächst in Konfrontation mit der Idee der Volkssouveränität und sodann in Konfrontation mit der rationalen Repräsentationsidee beleuchtet.

\section{Art. 20 II GG und Volkssouveränität.}

1. Das Grundgesetz erkennt an, daß der pouvoir constituant beim Volk lag. Wie es in der Präambel heißt, „. . . hat das deutsche Volk in den Ländern . . . kraft seiner verfassungsgebenden Gewalt dieses Grundgesetz beschlossen".

43) E. Troeltsch, Naturrecht und Humanität in der Weltpolitik, Berlin 1923, abgedruckt in engl. Sprache in: O. Gierke, Natural Law and the Theory of Society I, Cambridge 1934, Appendix I, S. $201 \mathrm{ff}$. 
Der pouvoir constituant ist aber nunmehr im Grundgesetz aufgehoben: pouvoir constitué. Im Wege des Art. 79 kann das Grundgesetz geändert, aber nicht ersetzt werden. Eine neue Verfassung zu schaffen ist tatsächlich möglich, aber nicht verfassungsrechtlich vorgesehen. Die Möglichkeit der Verfassungsablösung ist eine Frage der Staatslehre, nicht des Staatsrechts.

Da das Grundgesetz als provisiorische Regelung bis zur Wiedervereinigung gedacht war, ist allerdings in Art. 146 vorgesehen, da $B$ dann das (ganze) deutsche Volk in freier Entscheidung eine es ablösende Verfassung beschließen kann. Man hat aus Art. 146 auf die Möglichkeit geschlossen, daß sich auch das "Volk der Bundesrepublik" eine neue Verfassung geben kann. Das ist nicht richtig. Eine Volksabstimmung über eine neue Verfassung im Gebiet der Bundesrepublik wäre ein revolutionärer Akt. Mit der Berufung auf Art. 146 will man dem Bedürfnis nach Legitimitätskontinuität scheinbar entgegen kommen, in Wirklichkeit die Legitimitätskontinuität aber durchbrechen $^{44}$ ).

Die Selbstbeschränkung der verfassunggebenden Gewalt in Art. 79 III, 21 II, 9 II, 20 IV kann eben nicht legal, sondern nur revolutionär überspielt werden. Diese Selbstbeschränkung ist freilich mit der rousseauistischen Vorstellung der Volkssouveränität nicht in Einklang zu bringen ${ }^{45}$ ). Demokratie als Prozeß der Rechtsverwirklichung erklärt sie zwanglos: eine in der neuzeitlichen Geschichte des westlichen Verfassungsstaats erreichte Stufe des Fortschritts wird festgehalten ${ }^{46}$ ).

Die verfassungsgebende Volkssouveränität gehört zwar für die meisten Franzosen seit der französischen Revolution zu einer mindestens einmal im Leben persönlich erfahrenen Realität.

44) $H$. Dichgans, Eine verfassungsgebende Nationalversammlung?, ZRP 1968, S. 61 ff.; dazu W. Schütte, ZRP 1969, S. 34. Vgl. ferner W. Thieme, Für eine Totalrevision des Grundgesetzes, ZRP 1969, S. 32 ff.; R. Dahrendorf, Der Volkswirt 1968, S. 16; Th. Eschenburg, „Die Zeit“ v. 28. 6. 1968, S. 5 und v. 5. 7. 1968, S. 7; H. Schäfer, Bedarf unser Grundgesetz einer Gesamtrevision, in: Aus Politik und Zeitgeschichte, Beilage zu "Das Parlament", vom 3.4.1968, S. 3 ff.; F. K. Fromme, "Totalrevision" des Grundgesetzes, in: „Zeitschrift für Politik", 1970, S. 87 ff.; U. Scheuner, Der Staat, wie wir ihn wünschen, Nach zwanzig Jahren Bundesrepublik, in: Politische Meinung, 1969, S. $19 \mathrm{ff}$.

45) Vgl. U. Scheuner, Festschrift für Kaufmann, 1950, S. 317 f.; W. Kägi, aaO. (Anm. 35), S. 132 ff.

46) Das ist der richtige Kern der herkömmlichen Formel von der "wertgebundenen Demokratie"; siehe $H$. Peters, Festschrift für Giacometti, 1953, S. 229 ff.; Dürig, in: Maunz-Dürig-Herzog, Kommentar zum Grundgesetz, RN 20 zu Art. 79; weitere Nachweise bei L. Roos, aaO. (Anm. 15), S. 169, Anm. 72. 
Deshalb steht sie in der französischen Ideologie sehr im Vordergrund. Für die Demokratie vorwiegend angelsächsischer Prägung gehört sie zu einer theoretisch bewußten Möglichkeit, die außer bei Staatsgründungen nur für besondere Ausnahmesituationen in Frage kommt. Vernünftig ist, den Ausnahmezustand zu vermeiden ${ }^{47}$ ) und nicht die Stabilität der demokratischen Verfassung durch unnötige Appelle an den pouvoir constituant aufs Spiel zu setzen.

2. Das Grundgesetz unterscheidet in Art. $20 \mathrm{II}$ zwischen Trägerschaft und Ausübung der Staatsgewalt und spricht dem Volke die Trägerschaft zu. Doch wird alle Staatsgewalt durch besondere Organe ausgeübt. Daß sie vom Volk ausgeht, besagt in diesem Zusammenhang: alle Organe unterliegen dem Anspruch, für das Volk, in seinem Interesse zu handeln $\left.{ }^{48}\right)$. Entscheidungskompetenz bedeutet Entscheidungsverantwortung.

Unterschiebt man dem demokratischen Prinzip des Grundgesetzes den rousseauistischen Begriff der Volkssouveränität, so folgt daraus zumindest eine durch die Verfassungsordnung eingeschränkte Universalkompetenz, also mindestens die Auslegungsregel: das Volk könne Entscheidungen treffen, soweit das GG das nicht ausdrücklich ausschließe. Die Volkssouveränität quillt dann in alle Grundgesetzlücken hinein.

Rule of law bedeutet demgegenüber Einbindung jeder $\mathrm{Ge}-$ walt in die Kompetenzordnung. Wie im juristischen Prozeß der Vertretene nicht statt des Prozeßvertreters handeln kann und auch nicht beliebig neben ihm, so auch im politischen Prozeß. Während Entscheidungskompetenz Entscheidungsverantwortung bedeutet, ist innerstaatliche Souveränität gerade durch den Ausschluß der Verantwortlichkeit gekennzeichnet. Deshalb hat auch das Volk nur die Kompetenzen, die sich aus dem Grundgesetz ergeben.

Im Hinblick auf Plebiszite ist eine Kompetenz zu Abstimmungen über die im GG vorgesehenen Fälle hinaus zu verneinen. Das ergibt sich eindeutig aus der genetischen Auslegung ${ }^{49}$ ). Die Grundgesetzväter waren der Ansicht, daß die Instabilität der Weimarer Verfassung durch die vielfältigen plebiszitären Möglichkeiten mitbedingt war. Wieweit diese Ansicht zu Recht bestand, ist eine historische und verfassungspolitische Frage. Für die juristische Auslegung ist entscheidend, daß die im GG vor-

17) Odo Marquard, Hegel und das Sollen, Philosophisches Jahrbuch 72 (1964) S. 103 ff.

48) Utbereinstimmend: K. Hesse, VVDStRL 17 (1959), S. $19 \mathrm{f}$.

${ }^{49}$ ) Wie vor allem F. K. Fromme: Von der Weimarer Verfassung zum Bonner Grundgesetz, 1960, S. 150 ff. belegt hat. 
gesehenen Abstimmungsfälle erschöpfend sein sollten. Der Einführung weiterer plebiszitärer Elemente in das Grundgesetz stünde das demokratische Prinzip aber nicht im Wege; sie ließe sich verfassungspolitisch aus diesem Prinzip durchaus rechtfertigen.

Die Frage, ob unverbindliche, aber offizielle und förmliche Volksbefragungen in zur Entscheidung anstehenden Sachen mit dem demokratischen Prinzip vereinbar sind, hat das Bundesverfassungsgericht im Atombewaffnungsfall offen gelassen ${ }^{30}$ ). M. E. ist die Frage zu verneinen. Denn liegt die Kompetenz zur Entscheidung der Sache bei einem Bundesorgan, so trägt dieses auch die Entscheidungsverantwortung. Das Organ könnte zwar rechtlich dem Ergebnis der Volksbefragung zuwider handeln. Damit würde es aber die Legitimität des Repräsentativsystems erschüttern. Das Volk könnte nicht verstehen, warum es dann befragt worden ist. Man wäre also praktisch genötigt, der Entscheidung zu folgen. Das aber hieße, sich der Entscheidungsverantwortung entziehen ${ }^{51}$ ).

3. Volksherrschaft manifestiert sich drittens im Prinzip der Gleichheit - nicht als Gegenprinzip zu Freiheit, sondern zu Privilegien: Recht auf Ungleichheit für alle, nicht nur für eini$\mathrm{ge}^{52}$ ). Aus Gleichheit folgt deshalb nicht z. B. Auflösung der Ämter- und Kompetenzordnung, sondern gleicher Zugang zu öffentlichen Ämtern und folglich eine verfassungsrechtliche Pflicht, Gleichheit der Bildungschancen herzustellen und zu bewahren.

Besonders wichtig, wenn auch erst jüngeren Datums, ist das allgemeine und gleiche Wahlrecht. Die Entwicklung dahin empfing im 19. Jahrhundert die wichtigsten Impulse aus der französischen Revolution. Der Schluß, daß es sich deshalb um einen Ideenkompromi $B$ zwischen rousseauistischer Volkssouveränität und Parlamentarismus handele, ist jedoch nicht berechtigt. Politische Selbstbestimmung folgt vielmehr konsequent aus der notwendigen Identität von Plädierenden und Entscheidungen selbst. Die Erfahrung der französischen Revolution förderte das Selbstbewußtsein und die politische Kraft, die nötig war, um diese Konsequenz gegen die hemmende Kraft der Bevorrechtigten durchzusetzen, aber nicht gegen die Herrschaft des Rechts, sondern gegen Privilegien.

50) BVerfGE 8, $104 \mathrm{ff}$.

51) a. A. Hamann, Das Grundgesetz, 2. Aufl. 1960, Anm. $36 \mathrm{zu}$ Art. 20.

s2) O. Marquard, Hegel und das Sollen, aaO. (Anm. 47), S. $103 \mathrm{ff}$., 113; Th. W. Adorno, Minima Moralia, S. 130 f. 
Zunächst hatte die englische Geschichte des Parlamentarismus die Voraussetzung dafür geschaffen, daß das oberste Entscheidungsorgan überhaupt ein aus Wahlen hervorgegangenes Parlament war. Das wichtigste Argument der englischen Juristen des 17. Jahrhunderts dafür war die unendliche Komplexität der entscheidungsfälligen Probleme, die den prozeßhaften Charakter des Entscheidungsvorgangs erfordert. Der Hobbes'sche Einwand, daß dabei ein anthropologischer Optimismus vorausgesetzt sei, verfehlte das Problem der Komplexität und mußte schon deshalb wirkungslos bleiben ${ }^{53}$ ). Zum anderen erwies sich dieser Einwand auch als in sich unschlüssig. Die Annahme, der Mensch sei böse, ausgenommen die Mächtigen in Staat, Wirtschaft und Militär, ist ja weder realistisch noch konservativ, sondern blo $\beta$ unbegründet. Die Entwicklung der Demokratie beruhte nicht, wie man so oft behauptet, auf der Annahme, daß der Mensch gut sei, sondern auf der Annahme, daß die Mächtigen auch nicht besser seien als andere Leute ${ }^{54}$ ) und obendrein der Verführung durch die Macht ausgesetzt ${ }^{55}$ ).

Ausschlaggebend für die ständige Verbreiterung des Wahlrechts wurden jedoch zwei Einsichten:

Einmal: common sense, politisches Urteilsvermögen, Gerechtigkeitssinn ist unabhängig von Besitz, Bildung und beruflichem Erfolg und durch alle Schichten des Volkes gleichmäßig verteilt, ebenso wie die Demagogisierbarkeit ${ }^{56}$ ). Die Wahrheit dieses Satzes hat die Geschichte oft erwiesen. Z. B. waren unter den Enthusiasten Hitlers Besitz und Bildung reichlich ver-

59) Vgl. M. Kriele, Die Herausforderung des Verfassungsstaates, 1970, Abschnitt 10.

54) Vgl. zur Idee des „common man" als Voraussetzung der Demokratie C. J. Friedrich, Demokratie als Herrschafts- und Lebensform, 1959, S. 37 ff., 47 ff.; L. Roos, aaO. (Anm. 15) S. 176 ff. mit weiteren Nachweisen.

55) L. Roos, aaO. (Anm. 15) S. 186 ff. (mit weiterer Literatur) spricht geradezu von "Institutionalisierung des anthropologischen Mißtrauens". Vermittelnd: $\boldsymbol{R}$. Bäulin in: Evengelisches Staatslexikon, 1966, Stichwort „Demokratie“, Sp. 280 f.

${ }^{36}$ )Als Wigard in der Debatte des Verfassungsausschusses der Deutschen Nationalversammlung über das Wahlgesetz im Januar 1849 bestritt, daB mit Besitz und Bildung bessere politische Urteilskraft einhergingen, erwiderte ihm Dahlmann: er glaube nicht, daß Herrn Wigard der Beweis gelungen sei, daß unter den Ungebildeten ebensoviel Bildung herrsche wie unter den Gebildeten und daß die $\mathrm{Ab}$ hängigen ebenso frei seien wie die Unabhängigen (Wilhelm Mommsen, Deutsche Parteiprogramme vom Vormärz bis zur Gegenwart, 1951 , S. 41 f.). Das verfehlte Wigards Argument und ist ein Beispiel für die advokatische Demagogie, mit der die Bildung ihre Privilegien verteidigte. 
treten, während mancher rechtschaffene Arbeiter die Wahrheit wußte. Das erforderliche Sachwissen setzt zwar ein Minimum an Volksbildung voraus. Allgemeine Schulpflicht ist deshalb ein zwingendes Erfordernis des demokratischen Prinzips. Aber angesichts der Komplexität übersteigt das Sachwissen ohnehin die Fassungskraft selbst der Erfahrensten. Der Wähler wird in der Regel nicht von Sacheinsichten motiviert, sondern von Vertrauen in die gleichgerichtete Beurteilung der Relevanzen und Prioritäten im großen und ganzen.

Sodann: Der Blick für die Unmöglichkeit der Neutralität wurde in dem Maße geschärft, indem sich im 19. Jahrhundert der Gegensatz zwischen Arm und Reich zuspitzte und die soziale Frage virulent wurde. Das Honoratiorenparlament wurde ideologiekritisch als Klassenparlament gedeutet. Empörung über soziale Ungerechtigkeit, Verbreiterung der Volksbildung und ein durch die französische Revolution gestärktes Bewußtsein gleicher Menschenwürde machte die Parole „one man, one vote" schließlich unabweisbar. Die ohnehin unausweichliche Identität von Plädierenden und Entscheidenden wurde vom Parlament auf die Wählerschaft ausgedehnt.

4. Volksherrschaft manifestiert sich ferner in den Prärogativen der Parlamente. Die regelmäßig wiederkehrende Wahl des Bundestages und der Landtage ist der Kern der demokratischen Legitimation. Die demokratische Legitimität aller anderen Staatsorgane ist durch sie vermittelt: einmal durch ihre unmittelbare oder mittelbare Abhängigkeit organisatorischer, personeller, budgetmäßiger Art und die rechtliche und politische Kontrolle.

Was die budgetmäßige Kontrolle angeht, so machen allerdings Planung und Gemeinschaftsaufgaben die Parlamente zwar nicht rechtlich, aber praktisch zu Vollzugsorganen von Entscheidungen, die auf der Ebene der Regierung und Verwaltung getroffen sind. Das Budgetrecht, angesichts der „festliegenden Ausgabeposition" ohnehin auf $10 \%$ des Haushalts geschrumpft, wird fast gänzlich ausgehöhlt ${ }^{57}$ ). Vorschläge zur Abhilfe laufen im wesentlichen hinaus auf Informations- und Mitspracherechte der Parlamente oder ihrer Ausschüsse bei der Beratung und Aufstellung der Pläne, auf Bewilligungsbedürftigkeit des Plans oder Ausbau der parlamentarischen Hilfs-

57) Zur Problematik vgl.: Stern-Münch, Kommentar zum Stabilitätsgesetz, 1967, 1. Teil Einführung, S. $55 \mathrm{~m}$. w. Nachw.; M. Abelein, Finanzplanung und Haushaltsrecht, ZRP, 1969, S. $242 \mathrm{ff}$. 
dienste $\left.{ }^{58}\right)$. Davon sind Linderungen, aber wohl kaum Lösungen des Problems zu erwarten.

Zum anderen vermittelt die Wahl die demokratische Legitimität der Gesetze ${ }^{50}$ ). Die Prärogative des gewählten Organs manifestiert sich vor allem in der Rechtsetzungsprärogative, also der Kompetenz, jede generelle Rechtsfrage im Rahmen der Verfassungsordnung an sich zu ziehen und für alle anderen Organe verbindlich zu entscheiden. Deshalb gehören zum demokratischen Prinzip die Gesetzmäßigkeit der Verwaltung, die Unterworfenheit des Richters unter das Gesetz, die das demokratisch unerläßliche Korrelat seiner Unabhängigkeit ist, und das Verwerfungsmonopol des Bundesverfassungsgerichts.

Die rousseauistische Idee der Volkssouveränität tendiert $\mathrm{zu}$ einer Umdeutung der Rechtsetzungsprärogative zu einem Rechtsetzungsmonopol. Praktische Folge ist das Verbot konkurrierender Rechtsgewinnung. Die Beschränkung der Verwaltung auf Gesetzesvollzug, auch im Bereich der Leistungsverwaltung, wird postuliert. Die juristische Methodenlehre wird auf Gesetzesauslegung reduziert, die ganze Theorie der Rechtsgewinnung auf ein Prokrustesbett von Postulaten und Fiktionen gespannt. Hier besonders zeigt sich: das Problem Prärogative oder Monopol der parlamentarischen Rechtsetzung - das ist nicht eine Frage der Option, sondern der Einsicht in das Wirkliche und Mögliche ${ }^{00}$ ).

88) Vgl. die Vorschläge von Abelein, aaO. (Anm. 57) S. 244; U. Scheuner, Verfassungsrechtliche Probleme einer zentralen staatlichen Planung, in: J. A. Kaiser (Hrsg.), Planung, Bd. 1, 1965, S. 67 ff.; zur demokratischen Kontrolle der Planung vgl. $R$. Herzog, Stichwort „Planung“, in: Evangelisches Staatslexikon, 1966, Sp. 1524 ff.; zur Notwendigkeit der Planung im demokratischen Staat bereits $K$. Mannheim, Diagnose unserer Zeit, 1952, S. 11 ff.

s9) Zur Legitimationsfunktion der Wahlen vgl. u. a. N. Gehrig, Parlament-Regierung-Opposition, 1969, S. 78; von Nitzsche, Stichwort "Wahlen", in: A. Görlitz, Handlexikon zur Politikwissenschaft, 1970, S. 458 ff.; W. Piepenstock, ZRP 1969, S. 159 ff.; ferner HamannLenz, Grundgesetz für die Bundesrepublik Deutschland, 3. Aufl. 1970, S. 356.

"o) Zum Begriff „Rechtsetzungsprärogative“ vgl. M. Kriele, „Theorie der Rechtsgewinnung", 1967, S. 60 ff. Die Unterworfenheit des Richters unter das Gesetz ist mit der Annahme, daB es kein Rechtsetzungsmonopol, sondern nur eine Rechtsetzungsprärogative geben könne, nicht im mindesten infrage gestellt, wie behauptet worden ist. Auf die „Frage, ob der Richter gegenüber dem Gesetz grठ̋ßere Freiheit haben sollte . . . kann es nur ein entschiedenes Nein geben: der Richter ist dem Gesetz unterworfen. Dieses Prinzip aufweichen, bedeutet, die gesetzgebende Gewalt ihrer Prärogative berauben, und die rechtlichen Dezisionen der Willkür des Richters und dem dunklen Einfluß unkontrollierbarer interessierter Milieus zu überliefern. Kurz, es bedeutet Preisgabe der Prinzipien von Ge- 
5. Staatsbürgerliche Einflußrechte. Die zwischen den Wahlen liegende, vom Volk ausgehende Mitwirkung an der Meinungs- und Willensbildung durch Parteien, Verbände, öffentliche Meinung, Petitionen ist nicht nur zur Vorbereitung auf die Wahl wesentlich. Die Staatsorgane werden von ihr angeregt, informiert, kontrolliert und im großen und ganzen im Einklang mit den Meinungen des Volkes gehalten, Meinungsfreiheit vorausgesetzt.

Besondere Probleme wirft in diesem Zusammenhang die Konzentration der Presse auf. Das Bundesverfassungsgericht ist $\mathrm{zu}$ Recht davon ausgegangen, daß Meinungs- und Pressefreiheit nicht nur die individuelle Freiheit schützt, sondern unerläßlich für die Demokratie überhaupt ist ${ }^{01}$ ). Diese Feststellung ist näher dahin zu konkretisieren, daß diese Unerläßlichkeit im Hinblick auf drei Gesichtspunkte besteht, nämlich:

a) demokratische Meinungsbildung,

b) demokratische Kontrolle und

c) demokratische Legitimität - ein Element das unter dem Gesichtspunkt des Art. 5 verhältnismäßig wenig berücksichtigt wird.

Die Legitimität, d.h. die innere Akzeptierung der demokratischen Rechtsordnung vom Volk, hängt aus mindestens drei Gründen von der Meinungsfreiheit $a b^{62}$ ):

1. Das als ungerecht Empfundene muß öffentlich artikuliert werden können, damit sich nicht Empörung aufstaut, die in Widerstand oder Revolution treibt.

2. Es muß eine reelle Chance bestehen, daß die öffentliche Diskussion das Regelungsbedürftige heraussondert und abgewogener Entscheidung zuführt. Auf dieser Chance beruht sowohl die Hoffnung auf Besserung als auch das Vertrauen darauf, daß das schon Entschiedene im großen und ganzen annehmbar ist.

waltenteilung und Demokratie usw." (aaO. S. 64 und öfter). Das in der "Theorie der Rechtsgewinnung erörterte Problem ist die Frage, ob, wieweit und unter welchen Bedingungen sich in Gesetzen und anderen Rechtssätzen praktische Vernunft verwirklicht und was daraus für die Methodenlehre folgt. Unaufgeschlossenheit für diese Fragestellung führte gelegentlich zu Mißverständnissen und Unterstellungen.

11) BVerfGE 10, 118, 121; 12, 205, 259 ff.; 20, 162, 174 f., vgl. ferner $U$. Scheuner, VVDStRL 22, 1 ff.; $H$. Ehmke, Festschrift für Arndt, 1969, S. 84 ff.; M. Kirn, ZRP, 1970, S. 102 ff. m. w. Nachw.

62) Siehe hierzu Th. I. Emerson, Toward a General Theory of the First Amendment, The Yale Law Journal, 1963, 1. Halbbd., S. $72 \mathrm{ff}$.; H. Ridder, Meinungsfreiheit, in: Die Grundrechte, Handbuch der Theorie und Praxis der Grundrechte, Bd. 2, 1954, S. 243 ff. 
3. Die Gründe für getroffene Entscheidungen müssen vermittelt werden, weil sonst querulatorische Emotionen die Verfassung zerstören können ${ }^{63}$ ). Querulanten sind Verlierer im gerichtlichen oder administrativen Verfahren, denen die Entscheidung unbegreiflich ist und die deshalb die Motive des Entscheidenden verdächtigen. Im politischen Prozeß werden zwangsläufig breite Bevölkerungsschichten zu Verlierern und neigen entsprechend zu revolutionären oder reaktionären Ressentiments. Wenn diese sich nicht durch Information und Nachdenklichkeit auflösen, können sie so sehr an Breitenwirkung und Intensität gewinnen, daß sie die Legitimität der Verfassungsordnung zerstören können. Der Hugenbergkonzern hat, ohne je unmittelbar für die NSDAP zu plädieren, wesentlich dazu beigetragen, die Legitimitätsgrundlage der Weimarer Demokratie über die Belastungsgrenze hinaus zu erschüttern.

Das Problem der Pressekonzentration muß unter allen diesen Aspekten unabhängig von der politischen Richtung und presseethischen Verantwortung Springers und Bauers beurteilt werden. Der demokratische Staat unterscheidet sich vom absolutistischen dadurch, daß er nicht auf die Tugend und Einsicht des Machthabers, sondern auf rechtliche Institutionen vertraut. Deshalb kommt es auch weder darauf an, ob sich ein kurzfristiger Einfluß auf das Wahlverhalten, noch ob sich konkrete Meinungssteuerung durch den Konzernherrn erweisen läßt $\left.{ }^{04}\right)$. Entscheidend ist die Wirkungsmöglichkeit durch parteiische Personalpolitik. Diese Möglichkeit schafft unangemessene Macht über Wahlen und damit über Parlamente, Regierungen und Staat und Staatsform insgesamt. Die Staatsorgane handeln zwar im Einklang mit den Meinungen des Volkes. Was das Volk aber meint, hängt weitgehend von den wahren, halbwahren, unwahren und vorenthaltenden Informationen ab. Wirtschaftliche Verfügungsmacht über Information ist ein undemokratisches Privileg, mit Tendenz zu einer neuen Art von Souveränität.

Wie Herzog hervorgehoben hat, geht die liberale Formulierung der Pressefreiheit von der Voraussetzung eines liberalen Wirtschaftsmodells aus, das die Herstellung einer bunten Pluralität der Meinungen von dem "Selbstregulierungsmechanis-

63) N. Luhmann, Legitimation durch Verfahren, 1969, S. 234 ff. („ableiten der Enttäuschung in Bahnen, die der Struktur nicht schaden").

o4) So aber R. Herzog in Maunz-Dürig-Herzog, Grundgesetz, RN 180 zu Art. 5. 
mus Markt" erwartet $\left.{ }^{049}\right)$. Der Wegfall dieser Voraussetzung ist aus wirtschaftlichen und technischen Gründen anscheinend unaufhaltsam. Wenn das zutrifft, so ist es nicht nur eine als möglich zu erwägende, sondern eine bereits bestehende „Pflicht des Staates, Gefahren abzuwehren, die einem freien Pressewesen aus der Bindung von Meinungsmonopolen erwachsen können ${ }^{\text {"65) }}$. Private Rundfunk- und Fernsehanstalten sollen nach den Erklärungen ihrer Befürworter dem Verfassungserfordernis der Pluralität Rechnung tragen. Der Einbau pluralistischer Elemente in Privatunternehmen ist also prinzipiell möglich. $\mathrm{Daß}$ er aber politisch kaum noch durchsetzbar ist, zeigt, daß der Staat übermächtigen Einzelnen fast ausgeliefert ist.

6. Offentlichkeit $\left.{ }^{60}\right)$ des Beratungs- und Entscheidungsprozesses ist kein Absolutum, sondern ein dem demokratischen Prinzip dienendes Prinzip. Aus dem Sinn des demokratischen Prinzips ergibt sich die Auswahl der Form der Öffentlichkeit, für die es eine breite Skala von Möglichkeiten gibt. Sie reicht von Formen unmittelbarer Demokratie über akklamierende oder schweigende Zuhörerschaft, über Berichterstattung durch Wortlaut- und Beschlußprotokolle, Beschreibung des wesentlichen Gangs der Verhandlungen, nachträgliche Begründungspflicht, Aufhebung der Vertraulichkeit generell oder in einzelnen Punkten, bis zu genereller oder ausnahmsweiser Erlaubnis der Akteneinsicht.

Offentlichkeit dient der Repräsentation durch Transparenz der Entscheidungen, nicht aber der unmittelbaren Teilhabe am Entscheidungsproze $\beta$, wie die Theoretiker der Volkssouveränität meinen ${ }^{87}$ ). Deshalb lassen sich mitberatende oder auch akklamierende Zuhörerschaft aus dem demokratischen Prinzip des Grundgesetzes nicht rechtfertigen, sondern sind mit ihm unvereinbar.

64a) R. Herzog, aaO. (Anm. 64); ähnlich F. Kïbler und S. Simitis, Presse und Wettbewerb, JZ 1969, S. 445 ff. (448).

05) BVerfGE 20, 162, 176.

${ }^{\circ 6)}$ Hierzu: W.Martens, Offentlich als Rechtsbegriff, 1969; J. Habermas, Strukturwandel der Offentlichkeit, 2. Aufl. 1965; P. Haeberle, Struktur und Funktion der Offentlichkeit im demokratischen Staat, in: Politische Bildung, 1970, Heft 3, S. 3 ff.; R. Smend, Zum Problem des Offentlichen und der Offentlichkeit, in: Gedächtnisschrift für Walter Jellinek, 1955, S. 11 ff.; U. K. Preuss, Zum staatsrechtlichen Begriff des Offentlichen, 1969.

67) Eine normative Verbindlichkeit der „öffentlichen Meinung“ wird in der heutigen Staatslehre (statt vieler: H. Krüger, Allgemeine Staatslehre, 1964, S. 453) und Politologie (ausführlich dazu: L. Roos, aaO., Anm. 15, S. 228 ff.) allgemein abgelehnt. J. Habermas, aaO. (Anm. 66), S. 242 ff. spricht der verbandsmäßig organisierten Offentlichkeit eine weitgehende politische Kontrollfunktion zu. 
Die Transparenz des Entscheidungsprozesses zwingt zur Rechtfertigung der Entscheidung und erhöht damit die Chance der Verantwortbarkeit vor dem common sense, festigt ihre demokratische Legitimität und kann wichtig für ihre Interpretation werden. Diese Gründe, so gewichtig sie sind, sind aber mit Gegengründen abzuwägen:

Die Sachlichkeit der Diskussion kann beeinträchtigt werden durch Verführung zu effekthaschender Rhetorik, durch Rücksicht auf partikulare Interessen oder diffuse Emotionen (Reden zum Fenster hinaus), durch Scheu vor dem Wagnis der Artikulation unausgereifter Erwägungen. Deshalb ist eine Differenzierung etwa zwischen Offentlichkeit der Plenarverhandlung und Nichtöffentlichkeit der Ausschußverhandlung sinnvoll. Die Offentlichkeit der Verhandlungen der Bundestagsausschüsse kann vom demokratischen Prinzip des Grundgesetzes her sinnvoll sein, ist aber nicht gefordert.

Außerdem kann die Rücksicht auf außenpolitische, militärische, betriebliche oder private Interessen Vertraulichkeit erfordern.

Das demokratische Prinzip fordert öffentliche Beratung nur im gewählten Repräsentationsorgan des Volkes, im übrigen lediglich öffentliche Rechtfertigung der Entscheidung. Das kann, aber muß nicht durch Transparenz auch der Beratung geschehen. Da diese Transparenz aber die rechtfertigenden Gründe am deutlichsten sichtbar macht, ist die Begründungspflicht nach der Regel verteilt: soviel Transparenz wie möglich, soviel Vertraulichkeit wie nötig ${ }^{a b}$ ). Angesichts gegenwärtiger Trends ist es aber angebracht $\mathrm{zu}$ betonen, daß oft gute Gründe die Vertraulichkeit nötig machen. Sich über sie hinwegzusetzen, ist rücksichtslose Mißachtung z. B. außenpolitischer Interessen, verfassungsrechtlicher Kompetenzverteilung oder privater Rechtsgüter und ist deshalb nicht Ausweis demokratischer Gesinnung, sondern im Gegenteil Verletzung demokratischer Konventionalregeln.

\section{Art. 20 II GG und Repräsentation.}

Nun einige Gesichtspunkte, die sich aus der Gegenüberstellung des demokratischen Prinzips mit dem rationalistischen Repräsentationsbegriff ergeben.

1. Aus der Identität der Plädierenden und Entscheidenden erwächst der ethische Anspruch, der mit der Idee der Reprä-

68) Das wird in der politologischen Literatur oft zu wenig differenziert, vgl. die Ausführungen bei L. Roos, aaO. (Anm. 15) S. 223-239. 
sentation erhoben ist, nämlich auf sachliche und verantwortliche Meinungsbildung. Der Verwurzelung in Tradition, Leidenschaft, Vorurteil, Eigeninteresse soll soviel Vernunft wie möglich abgerungen werden. Der Anspruch geht also über das Standesethos des Rechtsanwalts, dem die Einseitigkeit erlaubt ist, hinaus, weil der Abgeordnete gewissermaßen zugleich Anwalt und Richter ist. Die parteiliche Einseitigkeit ist aber unausweichlich und kann durch den ethischen Anspruch nur gemäßigt und in Grenzen gehalten werden.

Sie ist angesichts der demokratischen Prozeßregeln auch erträglich und kann zur Wahrheitsfindung beitragen, ebenso wie der einseitige, ja polemische Anwalt vor Gericht der zutreffenden Sachverhaltsermittlung dienen kann - vorausgesetzt, daß die Gegenpartei uneingeschränkt ebenfalls zu Worte kommt, weil er nämlich jedenfalls alle für die eine Seite relevanten Gesichtspunkte herbeischafft. Doch könnte die prozessuale Sachverhaltsdiskussion oft selbst dann nicht zu Einigkeit führen, wenn es weder Entscheidungsfristen noch Beweisschwierigkeiten gäbe, weil verschiedene Parteien von verschiedenen Normhypothesen ausgehen und infolgedessen verschiedene Tatsachen relevant finden. Vor Gericht haben die Parteien oft verschiedene Versionen desselben Sachverhalts, auch wenn sie sich gewissenhaft an die Wahrheit halten, weil sie verschiedene Gesichtspunkte als relevant hervorheben. Noch mehr gilt das im politischen Prozeß, wo Interessebedingtheit und ideologische Prägung zu völlig verschiedener Sicht der Dinge führen können. Vernunft ist ihrem Wesen nach dialektisch und kann sich nicht anders verwirklichen als durch Parteien und Parteienkampf ${ }^{89}$ ).

2. Parteien haben nicht den Parlamentarismus in sein Gegenteil verkehrt und sind überhaupt dem repräsentativen Prinzip nicht entgegengesetzt $\left.{ }^{70}\right)$. Sie entstanden vielmehr konsequent aus den Strukturprinzipien des repräsentativen Parla-

09) In der Tradition der Rhetorik unterschied sich die juristische von der politischen Rhetorik nur darin, daß für den Juristen die Beurteilung geschlossener Sachverhalte, für den Politiker die Abschätzung künftiger Entscheidungskonsequenzen überwog und als typisch galt. Die Grenzen zwischen juristischer und politischer Rhetorik waren aber flüssig. Der wesentliche Bestandteil an Lehren war für beide Typen identisch und wurde meistens in einheitlichen Rhetorikschulen zusammen unterrichtet, vgl. Perelman, Traité de l'Argumentation.

70) So aber G. Leibholz, Der Strukturwandel der modernen Demokratie, 1952, S. $16 \mathrm{ff}$. 
mentarismus selbst ${ }^{71}$ ). In dem Maße, in dem die Wählerschaft zahlenmäßig wuchs und in dem die Sachprobleme komplexer wurden, bedurfte die Vermittlung zwischen Fraktion und Volk zunehmender Organisation ${ }^{72}$ ). Der Zwang zu organisierten Parteien entstand aus Gründen des praktischen Funktionierens und nicht etwa aus einem Ideenkompromiß zwischen Repräsentation und Identität. Es gibt keine parlamentarische Demokratie in der Welt ohne Parteiensystem, wohl aber ohne maßgeblichen Einfluß der rousseauistischen Denktradition.

$\mathrm{Da}$ es im dialektischen Rechtfertigungsproze $\beta$ kein neutrales Urteil geben kann, kann es ohnehin nur parteiliche Ansichten geben, unabhängig davon, wieweit sich Parteien zu politischen Organisationen verfestigt haben. Politische Parteien sind vergleichbar den Prozeßparteien vor Gericht, und die Gleichheit des Wortes „Partei“ ist weder historisch noch sachlich zufällig. Die primäre Funktion der politischen Parteien im politischen Prozeß ist das Plädieren. Der über die von den Parteien organisierten Wahlen ins Parlament gelangte Abgeordnete ist gewissermaßen Anwalt mit Generalvollmacht. Das freie Mandat des Abgeordneten ist historisch aus der Prozeßvollmacht des Anwaltes entstanden ${ }^{73}$ ). Seine Doppelrolle als Plädierender und Entscheidender wirkt freilich auf die Partei zurück und unterstellt sie dem Anspruch, ihr Plädoyer vor dem ganzen Volk rechtfertigen zu können.

3. Fraktionsbildung ist wegen der Komplexität der zur Entscheidung anstehenden Fragen unvermeidbar. Denn Entscheidungsbildung setzt voraus, da $B$ aus einer diffusen Vielfalt von Ansichten und Absichten durch Kompromisse und Diskussionen immer wieder Einigkeit darüber hergestellt wird, welche Probleme relevant, vordringlich, entscheidungsbedürftig und entscheidungsreif sind und in welchem Sinne sie vernünftigerweise entschieden werden sollten, kurz Einigkeit über Relevanzen und zeitliche und sachliche Prioritäten. Solche Einigkeit läßt sich nur aus Gruppenloyalität gewinnen, deren bester Kitt die Frontstellung gegenüber einem gemeinsamen politischen Geg-

71) Es ist streitig, wieweit man die Idee der Partei in das 17. Jahrhundert zurückverfolgen kann; fest steht, daß sie im 18. Jahrhundert in England allgemein anerkannt war, vgl. dazu $K$. Kluxen, Das Problem der politischen Opposition, 1956, S. 29 ff.

72) K. Hesse und G. E. Kafka, VVDStRL 17 (1959), S. 11 ff., 18 f., $53 \mathrm{ff} ., 55 ; A$. J. Rinck, Der verfassungsrechtliche Status der Parteien in der Bundesrepublik, in: Die moderne Demokratie und ihr Recht, Bd. 2, S. 305, $307 \mathrm{ff}$.

73) Hierzu Gaines Post, Plena Potestas and Consent in Medieval Assemblies, in: Studies in Medieval Legal Thought, 1964, S. 91 ff, 116; Ch. Miiller, Das imperative und freie Mandat, 1966, S. $125 \mathrm{ff}$. 
ner ist. Auch erfordern die meisten Fragen Spezialwissen und Sachverstand, die nur fruchtbar werden können, wenn die Arbeitsteilung und das ganze Geflecht von Solidarität, persönlicher Autorität und wechselseitigem Vertrauen funktioniert, was in aller Regel nur unter der Voraussetzung der Polarität von Mehrheit und Minderheit gelingt.

Für die Auslegung des Art. 38 I folgt daraus, daß Fraktionsloyalität mit dem repräsentativen Prinzip nicht in Widerspruch steht, soweit sie nicht durch verwerfliche Nötigungsmittel erzwungen ist ${ }^{74}$ ).

Unabhängigkeit von Aufträgen und Weisungen besteht zwar rechtlich nicht nur gegenüber partikularen und regionalen Interessen, sondern auch gegenüber Fraktion und Partei. Der Abgeordnete, der nur in begründeten Ausnahmefällen von der Fraktionslinie abweicht, respektiert aber damit die Funktionsvoraussetzung des Parlamentarismus. Zurückstellung abweichender eigener Meinungen ist auch mit der Gewissensunterworfenheit des Art. 38 I vereinbar, weil das Gewissen die weiterreichenden politischen Gesichtspunkte sowohl der Funktionsbedingung des Ganzen als auch der politischen Grundüberzeugung, auf der die Fraktionssolidarität beruht, in die Erwägungen einschließen muß. Zudem erhöht die Fraktionsloyalität die Unabhängigkeit des Abgenordneten, nämlich gegenüber partikularen und regionalen Interessen, deren Ansprüche mit dem Hinweis auf die Fraktionsentscheidung leichter zurückgewiesen werden können.

4. Die in jüngster Zeit wieder diskutierte gesetzliche Einführung des Mandatsverlustes bei Parteiwechsel würde m. E. Art. 38 I GG nicht verletzen ${ }^{75}$ ). Denn sie würde weder die Abhängigkeit des Abgeordneten von der Partei, noch von Aufträgen und Weisungen vergrößern.

Eine gewisse Abhängigkeit von der Partei besteht zwar für den Abgeordneten, der auf die Aufstellung als Kandidat einer Partei angewiesen ist. Aber diese Abhängigkeit bleibt beim

${ }^{74)}$ Vgl. E. Friesenhahn, VVDStRL 16 (1958), S. 24 f., m. w. Nachw.; P. Badura, Bonner Kommentar, Art. 38 RN 78; W. D. Hauenschild, Wesen und Rechtsnatur der parlamentarischen Fraktionen, 1968.

$\left.{ }^{75}\right)$ Vgl. M. Kriele, Mandatsverlust bei Parteiwechsel? ZRP 1969, S. 241 f. Die dort vorgenommene Differenzierung zwischen Listenmandat und Wahlkreismandat hält der Verf. nicht mehr aufrecht, weil auch die Wahl des Wahlkreiskandidaten fast immer ganz überwiegend durch seine Parteizugehörigkeit motiviert ist; in gleichem Sinn: F. F. Siegfried, Mandatsverlust bei Parteiausschluß, Parteiaustritt oder Parteiwechsel, ZRP 1971, S. 9 ff., a. A.: H. Trautmann, JZ 1970, S. 405 ff.; P. Badura, Bonner Kommentar, Art. 38 RN 79, neuestens: Schröder, ZRP 1971, $97 \mathrm{ff}$. und Kriele, ZRP 1971, $99 \mathrm{ff}$. 
Parteiwechsel erhalten, lediglich die Partei wechselt. Die Freiheit aber, seinem Gewissen zu folgen und die Partei zu wechseln, bleibt dem Abgeordneten auch dann, wenn mit dem Parteiwechsel der Mandatsverlust verbunden ist. Die Gegenmeinung setzt offenbar das verächtliche Bild eines Abgeordneten voraus, der lieber seine Gewissensentscheidung opfert, als für den Rest der Legislaturperiode auf seinen Sitz zu verzichten. Um was für eine "Gewissensentscheidung" muß es sich dabei handeln! Eine solche Auslegung fügt dem Schutz des Gewissens nichts hinzu. Sie ermöglicht und fördert aber die Mediokrität und Käuflichkeit der Abgeordneten. Sowohl die Abgeordneten als auch die Abgeordneteneinkäufer werden in Versuchung geführt, neue Abhängigkeiten werden geschaffen, das Ansehen des Parlaments wird erschüttert. Gerade der Mandatsverlust würde den Abgeordneten, der aus ehrlichen Gewissensgründen die Partei wechselt, vor falschem Verdacht schützen und seine Unabhängigkeit von der Partei festigen.

Auch eine Abhängigkeit von Aufträgen und Weisungen aus der Wählerschaft würde durch die Einführung des Mandatsverlustes nicht begründet. Denn die Wahl darf nicht mit Aufträgen und Weisungen verwechselt werden. Aufträge und Weisungen der Wählerschaft sind speziell. Die Wahlentscheidung aber wird von der generellen Linie der Partei bestimmt. Das gilt - den Fiktionen und Mythen zum Trotz - in aller Regel auch bei der sogenannten Persönlichkeitswahl. Bei der Listenwahl zumindest ist es zweifellos. Nur von abstrakter Warte aus kann man den Wähler deswegen tadeln; er verhält sich vielmehr systemgerecht und trägt der Funktionsweise der Fraktionen Rechnung.

Die Wahlentscheidung ist fast die einzige und jedenfalls wichtigste Kompetenz der Wählerschaft, die Basis der demokratischen Legitimität. Parteiwechsel des Abgeordneten heißt: diese Entscheidung nicht respektieren, sie nachträglich gegenstandslos machen, ja ins Gegenteil verkehren. Das ist verselbständigte Macht, Mißbrauch der Weisungsunabhängigkeit.

Demokratisch wäre die wechselseitige Respektierung: die Wählerschaft respektiert die Entscheidung des Abgeordneten zum Parteiwechsel, dieser respektiert die Wahlentscheidung der Wählerschaft durch Mandatsniederlegung. Die Entrüstung, mit der bisher Parteiwechsel von Abgeordneten bei Beibehaltung des Mandats von der Wählerschaft quittiert worden ist, zeigt, daß es sich dabei um eine jetzt schon im Volk geltende "Konventionalregel" handelt, die nur von einem rationalistischen Repräsentationsbegriff aus theoretisch in Frage gezogen werden kann. 
5. Es ist dies nur ein Beispiel für Konventionalregeln ${ }^{76}$ ) im Bereich des Verfassungslebens, die sich aus dem demokratischen Prinzip ergeben. Sie beanspruchen Verbindlichkeit, auch wenn sie vor Gericht nicht durchsetzbar sind. Die Stabilität der Demokratie hängt letztlich, wie wir in der Weimarer Republik erfahren haben, vom politischen Klima ab, also davon, wieweit undemokratisches Verhalten als unehrenhaft gilt.

Vom Standpunkt des rationalistischen Repräsentationsbegriffs aus müßten die Konventionalregeln Ähnlichkeit mit den Regeln des wissenschaftlichen Austausches haben, vom Standpunkt der pluralistischen Demokratietheorie aus müßten sie den Marktregeln vergleichbar sein. In Wirklichkeit ähneln sie eher den Regeln des juristischen Prozesses und laufen hinaus auf Respektierung von Parteirollen und Verfahrensmethoden des demokratischen Prozesses und damit auf Achtung der gemeinsamen Verfassungsbasis.

Es ist wichtig, daß das Verdikt „undemokratisch" jedenfalls aus offiziellem Mund nicht leichtfertig mißbraucht und abgenutzt wird. Andererseits muß es aber auch mit der nötigen Entrüstungsschärfe und Offentlichkeitsbreite dort angewandt werden, wo Konventionalregeln verletzt werden. Die Bezeichnung und Präzisierung dieser Regeln ist deshalb eine wichtige Aufgabe der Staatsrechtslehre. Diese muß sich dabei von folgenden Gesichtspunkten leiten lassen: die Regeln dürfen nicht überfordern, sie müssen nötig sein, um die Demokratie als Staatsform zu stabilisieren, und sie müssen, unabhängig vom konkreten Anlaß, der ihre Erforderlichkeit bewußt macht, unparteilich gelten können.

Beispiele für solche demokratischen Konventionalregeln sind neben der Forderung auf Mandatsniederlegung bei Parteiwechsel z. B. die Forderungen, daß keine Partei sich mit Begriffen identifiziert, die, wie Staat, Nation und Demokratie das politische Ganze bezeichnen, daß auch die parlamentarisch nicht repräsentierte Opposition bis zur Toleranzgrenze organisierter Verfassungsfeindlichkeit respektiert wird, daß die Minderheit in Ausschüssen und Wahlorganen anteilig repräsentiert wird, daß Rechtfertigung nicht durch Nötigung, Einschüchterung und Irreführung ersetzt wird, daß Vertraulichkeitsregeln nicht verletzt werden, auch wenn dies nicht strafbar ist.

70) $R$. Sohm, Die fränkische Reichs- und Gerichtsverfassung, Weimar 1871, 1911, S. XIV $f$. verwendet den Begriff „Konventionalregeln" für Verhaltensregeln, die für diejenigen gelten, die sich thnen unterworfen haben. 


\section{Demokratisierung}

\section{Politische oder verfassungsrechtliche Frage?}

Die verfassungsrechtliche Beurteilung der Demokratisierung der Gesellschaft setzt zunächst voraus, daß man sich über die Abgrenzung zwischen juristischer Verfassungsinterpretation einerseits und Kompetenz des demokratischen Gesetzgebers andererseits Rechenschaft gibt. Die Ansicht, daß die Stabilität der politischen Demokratie von der Demokratisierung der Wirtschafts- und Sozialordnung abhängen könne, war z. Zt. der Entstehung des GG verbreitet. Die Entstehungsgeschichte des GG erweist $a b e r^{77}$ ), daß man von einer verfassungsrechtlichen Absicherung wirtschafts- und sozialpolitischer Ordnungsmodelle bewußt abgesehen und ihre Ausformung dem demokratischen Gesetzgeber überlassen hat. Das BVerfG hat deshalb zu Recht den Schluß auf die wirtschaftspolitische Neutralität des GG gezogen. Im gleichen Sinne, aus gleichen Gründen und mit gleichen Einschränkungen ist das GG auch gesellschaftspolitisch neutral.

Ebenso wie man versucht hat, etwa die soziale Marktwirtschaft und mit gleicher Schlüssigkeit sozialistische Wirtschaftsmodelle aus dem GG abzuleiten ${ }^{78}$ ), liegt auch die Versuchung nahe, aus dem Demokratiebegriff und anderen Klauseln des GG gesellschaftspolitische Folgerungen zu ziehen, insbesondere das Erfordernis der Homogenität gesellschaftlicher Ordnungen mit der politischen Verfassung verfassungsrechtlich abzustützen. Das aber heißt: den Gegner solcher Forderungen als Gegner grundgesetzlicher Prinzipien hinstellen, ihn in den Bereich der Verfassungsillegitimität verweisen. Damit stellt man die Konsensgrundlage und die Friedensfunktion der Verfassung in Frage und radikalisiert den Parteienkampf. Das gleiche gilt selbstverständlich auch umgekehrt für den Versuch, gesellschaftliche Forderungen nach Demokratisierung gesellschaftlicher Bereiche verfassungsrechtlich für illegitim zu erklären. Die Kontroverse um die Demokratisierung bleibt der demokratischen Auseinandersetzung überlassen.

Das gilt mit zwei Einschränkungen:

Einmal: die gesellschaftspolitische Neutralität des Grundgesetzes ist ebensowenig wie die wirtschaftspolitische absolut.

77 Sörgel, Konsensus und Interessen, 1969.

78) H. C. Nipperdey, Die soziale Marktwirtschaft in der Verfassung der Bundesrepublik, 1954; $H$. Ehmke, Wirtschaft und Verfassung, 1961, S. 18 ff. stellt der Nipperdey'schen Wirtschaftsverfassung eine ebenso schlüssige verfassungsrechtliche Ableitung des Sozialismus gegenüber, um die Methode der Deduktion aus dem Grundgesetz ad absurdum zu führen. 
Aus dem Grundgesetz können sich unantastbare Prinzipien ergeben, die den Rahmen für die demokratische Auseinandersetzung abstecken. Eine Grenze der gesellschaftspolitischen ebenso wie der wirtschaftspolitischen Neutralität liegt da, wo die Demokratie als Staatsform gefährdet ist. Maßnahmen, die dazu geeignet sind, die Legitimität der demokratischen Staatsverfassung $z u$ bewahren und zu stärken, sind vom demokratischen Prinzip im Grundgesetz gerechtfertigt und, wenn sie dazu erforderlich sind, geboten.

Zur Kunst des Verfassungsinterpreten gehört es, die Erkenntnis der Grenze juristischer Zurückhaltung nicht $\mathrm{zu}$ verfehlen. Einerseits darf sich der Verfassungsinterpret unbeschadet seiner persönlichen politischen Ansicht als Jurist nicht mit umstrittenen ideologischen Konzeptionen identifizieren. Andererseits darf er nicht wirklichkeitsblind oder schüchtern mit Berufung auf die "weise Zurückhaltung" des Verfassungsinterpreten vor Erosion der demokratischen Legitimität oder gar der Verfassungszerstörung kapitulieren.

Zum anderen: eine Berufung auf das demokratische Prinzip im Grundgesetz, die verfassungsrechtlich verfehlt ist, braucht deshalb nicht auch in der politischen Rhetorik illegitim zu sein. Aus dem Grundsatz gesellschaftspolitischer Neutralität des Grundgesetzes ergeben sich keine Einwände dagegen, Bestrebungen als "demokratisch" zu bezeichnen, die z. B. auf Ausbau der Chancengleichheit, Verbreiterung der Bildung, Versachlichung der politischen Auseinandersetzung, Mitbestimmung in Unternehmen und anderen Organisationen, Funktionalisierung der Autorität, Erziehung zu Respekt und Toleranz etc. zielen. Es bleibt der freien geistigen Auseinandersetzung in der Demokratie überlassen, zwischen gesellschaftspolitischen Bestrebungen und dem Grundgesetz einen geistigen und geschichtlichen Zusammenhang herzustellen und politische Bestrebungen mit Tendenzen zu begründen, die sich auch im Grundgesetz niedergeschlagen haben. $\mathrm{Da} B$ sie zu Verfassungsrecht erstarken, ist nicht ausgeschlossen, setzt aber zumindest voraus, daß sie bewährt und nicht mehr umstritten sind und daß Konsens über ihre Ableitbarkeit aus grundgesetzlichen Prinzipien entstanden ist.

\section{Funktionale und politische Organisationen}

In idealtypischer Zuspitzung kann man funktionale und politische Organisationen unterscheiden ${ }^{79}$ ). In funktionalen Organi-

$\left.{ }^{79}\right)$ Dieser Organisationstypologie entspricht die Aufgabendifferenzierung: Programmiertes und programmierendes Entscheiden. Vgl. N. Luhmann, Zweckbegriff und Systemrationalität, 1968, S. 177: 
sationen sind die Zwecke im wesentlichen vorgegeben, z. B.: produzieren, handeln, verwalten, Interessen vertreten, erziehen, unterrichten, forschen, heilen. Gegenstand der Diskussion ist die Frage nach den geeigneten Mitteln. In politischen Organisationen stehen nicht nur die Mittel, sondern auch die Zwecke zur Debatte, die Rechtfertigung ihrer Selektion und ihrer zeitlichen und sachlichen Prioritätenordnung. Funktionalen Organisationen ist die Zweckrationalität zugeordnet, politischen die demokratische Dialektik des Meinungs- und Richtungskampfes. Die Chance der optimalen Zweckerreichung wird in funktionalen Organisationen möglicherweise, aber nicht notwendigerweise durch demokratische Organisationen erhöht. Das Ministerium z. B. erfüllt seine Zwecke besser, wenn es nicht nach dem Muster des politischen Ganzen demokratisch, sondern bürokratisch strukturiert ist. Die komplexe und arbeitsteilige Gesellschaft macht die Verteilung von Funktionen, Kompetenzen, Weisungsbefugnissen nötig, und nimmt auf diese Weise Sachverstand und Berufserfahrung in ihren Dienst.

Hingegen ist die Chance der Vernünftigkeit und Gerechtigkeit politischer Entscheidungen relativ am größten unter der Bedingung demokratischer Organisationsformen. Demokratische Struktur bedeutet mindestens, daß die Entscheidungssuprematie bei einem aus gleichen Wahlen hervorgegangenen Repräsentationsorgan liegt, wie bei der Selbstverwaltungskörperschaft oder dem Verein. Ob solche Strukturen vorgeschrieben werden können, ist eine Frage der Grundrechtsauslegung.

\section{Politische Organisationen}

Satzungsautonomie ist nicht nur als Bestandteil der allgemeinen Vertragsfreiheit, sondern auch speziell durch Art. 9 GG grundrechtlich geschützt. Zwingende Vorschriften über den Mindestinhalt von Satzungen, wie sie u. a. in den $\S \S 26 \mathrm{ff}$. BGB für eingetragene Vereine enthalten sind, sind aber dadurch nicht ausgeschlossen ${ }^{80}$ ). Solches zwingende Recht ist allerdings im Licht des Grundrechts auszulegen. Es wäre jedenfalls verfassungswidrig, wenn es den Wesensgehalt des Grundrechts antastete. Von Mindestregelungen über die demokratische

zum Demokratisierungspotential bei verschiedenen Entscheidungstypen siehe auch F. Naschold, Organisation und Demokratie, 1969, S. $62 \mathrm{ff}$.

$\left.{ }^{80}\right)$ a. A. wohl K. Hesse, VVDStRL 17 (1959), S. 39, der $\& 2$ Abs. 2 des Berliner Gesetzes über die Vereins- und Versammlungsfreiheit v. 29. 9. 1950 (VBl. S. 442), wonach Vereinigungen verpflichtet sind, Aufbau, und Willensbildung nach demokratischen Grundsätzen zu gestalten, für verfassungswidrig hält, da sich aus Art. 9 GG eine derartige Verpflichtung nicht ergebe. 
Struktur kann man das nicht sagen, wenn lediglich ein Rahmen abgesteckt wird, der der freien Satzungsgestaltung genügend Spielraum läßt und die funktionalen $\mathrm{Z}$ weckmäßigkeiten nicht behindert. Z. B. wären zwingende Vorschriften etwa über die Bestellung des Vorstandes durch die Mitgliederversammlung oder die kollegiale Verfaßtheit des Vorstandes zulässig, schon deshalb, weil sie bloß die körperschaftliche Struktur des Organisationstypus verdeutlichen würden ${ }^{81}$ ).

Nicht nur gesetzliche Einschränkbarkeit, sondern unmittelbar verfassungsrechtliche Eingeschränktheit findet sich ausdrücklich nur in Art. 28 I für Länder, Kreise und Gemeinden und in Art. 21 I 2 für politische Parteien - charakteristisch politische Organisationen.

Für Gewerkschaften hat man eine Eingeschränktheit der Satzungsautonomie im Hinblick auf demokratische Organisationsstrukturen daraus abgeleitet, daß die Gewerkschaften neben der Auseinandersetzung im Tarifbereich auch Einflußnahme auf die Staatsgewalt erstreben ${ }^{82}$ ). Das Faktum der Interessenvertretung gegenüber dem Staat allein macht freilich aus einer funktionalen noch keine politische Organisation im angegebenen Sinn. Doch funktionale und politische Organisationen sind Idealtypen. In der Wirklichkeit gibt es Zwischenstufen. Für die Gewerkschaften ist kennzeichnend die große Breite nach der Zahl der Mitglieder, nach der ideologischen Herkunft in der Einheitsgewerkschaft und nach der politischen Zielsetzung, die sich auf fast den ganzen Bereich des Arbeits-, Wirtschafts- und Sozialrechts erstreckt. Damit ist zugleich eine erhebliche politische Macht verbunden, die die Verfassungslegitimität wesentlich von der demokratischen Grundhaltung der Gewerkschaften abhängig macht. Das alles rückt die Gewerkschaften in einen Zwischenbereich zwischen zweckbestimmter Interessenvertretung und politischer Organisation. Deshalb erscheint eine Eingeschränktheit der Satzungsautonomie gerechtfertigt. Sie ergibt sich rechtlich aus der Analogie zu Art. 21 I 3.

Was hier am Beispiel der Gewerkschaften erörtert worden ist, gilt entsprechend für andere Organisationen, wie Arbeit-

81) Vgl. G. Hueck, Der Grundsatz der gleichmäßigen Behandlung Im Privatrecht, 1958, S. 45.

82) Vgl. H. Ridder, Zur verfassungsrechtlichen Stellung der Gewerkschaften 1960, S. 29; U. Scheuner, Der Inhalt der Koalitionsfreiheit, in: Weber-Scheuner-Dietz, Koalitionsfreiheit, 1961, S. 68, folgert aus der in Art. 9 Abs. 3 enthaltenen institutionellen Verankerung öffentlicher Aufgaben die Rechtspflicht zur „Erhaltung eines inneren demokratischen Aufbaus"; vgl. auch I. v. Münch, Bonner Kommentar, RN 149 zu Art. 9. 
Martin Kriele

geberverbände ${ }^{8 s}$ ), Vertriebenenverbände, Bauernverbände und dergleichen ${ }^{84}$ ).

\section{Hochschulen.}

Die sog. Demokratisierung der Hochschule ${ }^{85}$ ) hat bisher lediglich zum Einbau ständestaatlicher Organisationsmaximen geführt $\left.{ }^{\mathrm{Bo}}\right)$. Demokratische Struktur nach dem Prinzip „one man, one vote" ist glücklicherweise noch nicht einmal gefordert worden. Die ständischen Organisationsformen sollen u. a. einen Kooperations- und Rechtfertigungszwang erzeugen. Davon verspricht man sich einen Edukationseffekt. Autoritärer Anspruch und ihm korrespondierende Devotion, die bei Erreichung entsprechender Lebensstellung wiederum in autoritäre Gebärde umschlägt - diese dem Obrigkeitsstaat zugeordneten Verhaltensformen will man durch demokratische ersetzen: Respekt vor prinzipieller Gleichberechtigung und Reduktion der Autorität auf das funktional gerechtfertigte oder das der Person freiwillig zuerkannte Maß. Inwieweit geht es also um demokratische Bewußtseinsbildung, nicht um demokratische Institutionen $^{87}$ ).

Maßnahmen, die auf Legitimität des demokratischen Verfassungssystems zielen, können vom Demokratieprinzip des Grundgesetzes her zwar tendenziell wünschenswert sein. Sie können aber nicht verfassungsrechtlich gefordert sein. Denn es ist strittig und bleibt eine Frage der politischen Auseinandersetzung, ob die demokratiestärkende Wirkung eintreten wird,

83) U. Scheuner, aaO. (Anm. 82), S. 68; I. v. Münch, aaO.

84) Nach W. Besson, Aufgaben und Grenzen der Staatsführung in der modernen Demokratie, 1964 (dazu L. Roos, aaO. Anm. 15, S. 101 ff.) treten in der modernen, sozialstaatlichen (,nachbürgerlichen") Welt die Interessenverbände mehr und mehr in politischen Funktionen ein; damit wird das Problem ihrer Demokratisierung zunehmend akut.

85) Hierzu H. H. Rupp, Die Universität zwischen Wissenschaftsfreiheit und Demokratisierung, JZ 1970, S. 165 ff.; G. Roellecke, Wissenschaftsfreiheit als institutionelle Garantie?, JZ 1969, S. 726 ff.; H. H. Rupp und W. K. Geck, VVDStRL 27 (1969), S. $113 \mathrm{ff}$., $143 \mathrm{ff}$. Zur Entwicklung dieses Demokratisierungsgedankens vgl. Friedeburg u. a., Freie Universität und politisches Potential der Studenten, 1968, S. 69, 75, 242 f., 320 ff., 369 ff. und öfter.

80) W. Hennis, Demokratisierung, Zur Problematik eines Begriffes, 1970 , S. 16 ff. hält "paritätische Zusammensetzung" von Entscheidungsgremien im halbstaatlichen bzw. gesellschaftlichen Bereich dort für wünschenswert, wo „im Kern einer Institution der Ausgleich von verschiedenen Interessen steht" (Rundfunkräte, Schlichtungskommissionen für Tarifstreitigkeiten etc.).

87) Zur Hochschulverwaltung als funktioneller Amtspflichterfüllung (und nicht Ausbeutung von Feudalrechten) $H$. Schelsky, Abschied von der Hochschulpolitik, 1969, S. 32 ff. 
wieweit die Effizienz der Hochschule beeinträchtigt bleibt, wieweit man etwaige Effizienzbeeinträchtigung um des Edukationseffekts willen in Kauf nimmt. Diese Fragen kann nur der demokratische Gesetzgeber entscheiden.

Schließlich sollen die Mitwirkungsrechte einen Zwang erzeugen, die gesellschaftliche und politische Relevanz der Forschung zu bedenken und Problemstellungen zu rechtfertigen. So wünschenswert solche Reflexionen mitunter sein mögen, sie zu erzeugen kann nur Gegenstand freier wissenschaftlicher Kritik sein. Ein institutionalisierter Rechtfertigungszwang verletzt das Grundrecht der Freiheit von Forschung und Lehre in seinem Wesensgehalt. Zwar ist richtig, daß das Demokratieprinzip eine systematische Schranke für Grundrechte bilden kann. Es darf aber dann nicht zuvor im Sinne einer ideologischen Gesinnungsforderung umgedeutet werden. Das demokratische Prinzip schränkt Art. 5 Abs. 3 nicht ein.

\section{Wirtschaft}

Was die sog. Demokratisierung der Wirtschaft betriff $t^{88}$ ), so geht es neben dem Edukationseffekt um Kontrolle wirtschaftlicher Macht. Diese besteht in drei Richtungen: a) Marktmacht, b) politischer Einfluß, c) Herrschaft über die arbeitsrechtlich Abhängigen $\left.{ }^{88}\right)$. Die noch von Naphtali ${ }^{90}$ ) vertretene Konzeption, wonach Demokratisierung das geeignete Mittel zur Kontrolle von Marktmacht und politischem Einfluß sei, wird politisch kaum noch vertreten. Nur im Hinblick auf demokratische Teilhabe als Selbstzweck angesichts der Herrschaft über die arbeitsrechtlich Abhängigen spielt die Demokratisierungstendenz heute eine ernsthafte politische Rolle ${ }^{21}$ ).

88) Zu den Demokratisierungskämpfen der Nachkriegszeit vgl. $E$. Schmidt, Die verhinderte Neuordnung 1945-1952, 1970.

89) Hierzu: H. Deist, in: Wirtschaftliche Macht und Rechtsstaat, hrsg. v. Justizministerium des Landes Nordrhein-Westfalen und dem DGB, Landesbezirk Nordrhein-Westfalen, 1961, S. 15 ff.; $L$. Vaubel, in: Eigentum und Eigentümer in unserer Gesellschaftsordnung, 1960, S. 11 ff.; E. Benda, Industrielle Herrschaft und sozialer Staat, 1966, S. 17; vgl. auch $H$. Kronstein, Recht und wirtschaftliche Macht, ausgewählte Schriften, 1962, S. 93 ff.; O. Kunze, Mitbestimmung als Legitimationsproblem, 1970.

90) F. Naphtali, Wirtschaftsdemokratie (hrsg. im Auftrag des Allgemeinen Deutschen Gewerkschaftsbundes) 1928; hierzu E. Benda, aaO. (Anm. 89), S. 178 ff.; Vorläufer: Sidney und Beatrice Webb, Industrial Democracy, London, 1897.

91) Zur "demokratischen Teilhabe" vgl. I. Fetscher, Konkrete Demokratie - heute, Festschrift für Otto Brenner, 1967, S. 377 ff.; F. Scharpf, aaO. (Anm. 6) mit umfangreichen Literaturnachweisen auch aus der amerikanischen Politologie; F. Naschold, Organisation und Demokratie, 1969. 
In diesem Selbstzweckargument kommt weniger die institutionelle als vielmehr die individualrechtliche Seite des Demokratieprinzips zum Ausdruck. Denn solange wir an den Maximen des Gesellschaftsrechts und der Marktwirtschaft festhalten, läßt sich das wirtschaftliche Unternehmen nicht als demokratisch verfaßte Gemeinschaft organisieren. Dann bedeutet Demokratisierung der Wirtschaft Einbau gewisser Mitbestimmungselemente, die die soziale Abhängigkeit des Arbeitnehmers bis zu einem gewissen Grade ausgleichen. Selbst wenn man den am weitesten reichenden Mitbestimmungsforderungen entsprechen wird, so wird die Betriebsverfassung nur wenig Ähnlichkeit mit einer demokratischen Verfassung haben. Der Ansatzpunkt für die verfassungsrechtliche Prüfung der "Demokratisierung " unter dem Gesichtspunkt des Selbstzwecks kann deshalb nicht das Demokratieprinzip des Art. 20 sein, sondern es sind die Grundrechte oder auch die Sozialstaatsklausel. Da eine unmittelbare Drittwirkung der Grundrechte oder der Sozialstaatsklausel nicht anerkannt werden kann, folgt aus diesen Bestimmungen aber kein verfassungsrechtliches Gebot.

Dies eben - und damit möchte ich schließen - ist der Sinn des demokratischen Prinzips: wenn und soweit die gesellschaftliche Demokratisierung vernünftig und menschlich ist, muß sich das im Prozeß der offenen politischen Auseinandersetzung erweisen. 
Leitsätze des Mitberichterstatters über:

\section{Das demokratische Prinzip im Grundgesetz}

I.

Zum Typus parlamentarischer Demokratie.

1. Der Anschein, parlamentarische Demokratie im Sinne des GG sei ein Kompromiß zwischen den im Grunde unvereinbaren Prinzipien Volksherrschaft und Repräsentation, entsteht nur, wenn man Aspekte mit logischer Konsequenz ins Extrem treibt, statt sie aufeinander zu beziehen.

a) Der Volksherrschaft wird die rousseauistische Idee der Volkssouveränität unterschoben. Im Verfassungsstaat gibt es aber keinen Souverän.

b) Der parlamentarischen Repräsentation wird der Sinn der Wahrheitsfindung durch öffentlich diskutierende Abgeordnete unterschoben - meistens zu dem Zweck, den Wegfall dieser angeblichen "geistesgeschichtlichen Grundlage" des Parlamentarismus behaupten zu können.

2. Die parlamentarische Demokratie entstand aus der Suche nach den verhältnismäßig günstigsten institutionellen Bedingungen für die allmähliche Verwirklichung des Naturrechts im positiven Recht. Man ging davon aus, daß sich das Recht dialektisch nach prozessualen Regeln aus den im Volk situationsbedingt gemachten Erfahrungen der Unzulänglichkeit des Rechts fortentwickelt. Parlamentarische Demokratie ist geschichtlich und theoretisch zu begreifen aus der Ubertragung des Gedankens des gerichtlichen Prozesses auf den politischen Proze $\beta$ der Gesetzgebung. - Insofern ist Herrschaft des Volks Herrschaft des Rechts.

3. Staatswillensbildung ist Meinungsbildung, die in verbindliche Dezision mündet. Im Unterschied zum juristischen Proze $\beta$ kann es im politischen Proze $\beta$ keine neutrale Instanz geben, weil jeder Amtsinhaber zugleich Mitglied der Gesellschaft und als solches in Interessen, Ideologien, Traditionen verstrickt ist. Der Parlamentarismus zieht im Mehrheitsprinzip daraus die Konsequenzen der Identität von Plädierenden und Entscheidenden (nicht der Identität von Regierenden und Regierten).

6 Veröffentl. Dt. Staatsrechtslehrer, Heft 29 
II.

Zum demokratischen Prinzip im Grundgesetz.

4. Das Grundgesetz erkennt an, daß der pouvoir constituant beim Volk liegt. Er ist aber im Grundgesetz aufgehoben (pouvoir constitué). Eine Ablösung des GG durch eine neue Verfassung ist deshalb, außer im Falle der Wiedervereinigung (Art. 146), nicht legal möglich.

5. Das Volk ist Träger der Staatsgewalt (Art. 20 II 1). Daraus folgt die Verpflichtung aller Staatsorgane, stellvertretend für das Volk, in seinem Interesse zu handeln. Entscheidungskompetenz beinhaltet Entscheidungsverantwortung. Plebiszite über die im GG vorgesehenen Fälle hinaus und offizielle Volksbefragungen bedürfen der Ermächtigung durch Grundgesetzergänzung.

6. Demokratische Gleichheit ist nicht Gegenprinzip zu Freiheit, sondern zu Privilegien. Die Abschaffung aller Wahlprivilegien folgte aus der Unmöglichkeit der Neutralität im politischen Proze $\beta$ und aus der Erfahrung, daß politisches Urteilsvermögen und Demagogisierbarkeit (allgemeine Schulpficht vorausgesetzt) weitgehend unabhängig von Besitz, Bildung und beruflichem Erfolg sind.

7. Der Kern der demokratischen Legitimation ist die regelmäßig wiederkehrende Wahl des Bundestages und der Landtage. Sie vermittelt die demokratische Legitimität der Gesetze. Auch die demokratische Legitimität aller übrigen Staatsorgane ist durch sie vermittelt: einmal durch ihre unmittelbare oder mittelbare Abhängigkeit organisatorischer, budgetmäßiger Art und die rechtliche und politische Kontrolle, zum anderen durch Gesetzmäßigkeit der Verwaltung, Unterworfenheit des Richters unter das Gesetz (das demokratisch unerläßliche Korrelat der Unabhängigkeit) und das Verwerfungsmonopol des BVerfG. Rechtsetzungsprärogative des parlamentarischen Gesetzgebers bedeutet aber nicht Rechtsetzungsmonopol.

8. Mitwirkung an der Meinungsbildung durch Parteien, Verbände, öffentliche Meinung, Petitionen, Versammlungen usw. regt die Staatsorgane an, informiert, kontrolliert und hält die Entscheidungen im großen und ganzen im Einklang mit den Meinungen des Volkes. - Meinungsvielfalt im Pressewesen ist durch den Selbstregulierungsmechanismus Markt nicht mehr gewährleistet. Die Pressekonzentration stellt uns vor das klassische Problem des Verfassungsstaats: Vertrauen entweder in das Gute im Mächtigen oder in rechtlich-institutionelle Sicherungen. 
9. Offentlichkeit dient nicht unmittelbarer Teilhabe an der Entscheidung, sondern der Transparenz im Dienste des Rechtfertigungszwangs, der Legitimität und der Interpretationsfähigkeit der Entscheidung. Offentliche Rechtfertigung der Entscheidung ist immer, öffentliche Beratung nur im Plenum der Parlamente gefordert. In anderen Organen stehen der öffentlichen Beratung oft Gründe der Praktikabilität und der Rücksicht auf öffentliche und private Interessen entgegen. Das Demokratieprinzip fordert Abwägung nach der Regel: soviel Offentlichkeit wie möglich, soviel Vertraulichkeit wie nötig. Vertraulichkeitsverletzungen können mit dem demokratischen Prinzip nicht gerechtfertigt werden.

10. Parteien vermitteln Volk und Parlament. Sie entstehen aus den Strukturprinzipien des repräsentativen Parlamentarismus selbst, nicht aus einem Ideenkompromi $\beta$ zwischen Repräsentation und Identität. An Parteimeinungen ist der Anspruch zu stellen, daß sie vor dem ganzen Volk gerechtfertigt werden können.

Fraktionsloyalität als Regelfall ist Voraussetzung der Entscheidungsfähigkeit und erhöht die Unabhängigkeit des Abgeordneten von partikularen Einflüssen. Fraktionsdisziplin ist bis zur Grenze verwerflicher Nötigung mit Art. 38 I vereinbar.

11. Wahlentscheidungen orientieren sich in aller Regel ganz ïberwiegend an der Partei und nicht an der Person, und das ist auch systemgerecht. Parteiwechsel des Abgeordneten ist zu respektieren; aber der Abgeordnete verhält sich demokratisch, wenn er die Wahlentscheidung durch Mandatsniederlegung respektiert. Gesetzliche Einführung von Mandatsverlust bei Parteiwechsel würde Art. 38 I nicht verletzen.

12. Aus dem demokratischen Prinzip ergeben sich Konventionalregeln, die gerichtlich nicht durchsetzbar sind. Von ihrer Einhaltung hängt das politische Klima ab, innerhalb dessen der demokratische Verfassungsstaat nur lebensfähig ist. Ihre Verletzung ist „undemokratisch“. Sie fordern z. B. Verzicht auf parteiliche Identifikation mit Begriffen, die wie "Staat", "Nation" oder "Demokratie" das politische Ganze bezeichnen, Respektierung der Opposition (auch der parlamentarisch nicht repräsentierten) bis zur Toleranzgrenze organisierter Verfassungsfeindlichkeit, anteilige Beteiligung der Minderheit in Ausschüssen und Wahlorganen, Verzicht auf Vertraulichkeitsverletzungen, auch wenn diese nicht strafbar sind und ähnliches. 
III.

Zur Demokratisierung der Gesellschaft.

13. Das demokratische Prinzip im GG ist gesellschaftspolitisch neutral. Eine Grenze bilden gesellschaftlich bedingte Gefährdungen der Demokratie als Staatsform. Es kann berechtigt sein, politische Werbung für Demokratisierung (nicht verfassungsrechtliche Gebote) mit dem Hinweis auf geschichtliche Tendenzen zu begründen, die sich auch im GG niedergeschlagen haben. Solche dem GG entlehnten politischen Wertentscheidungen können u. U. zu Verfassungsrecht erstarken, wenn darüber Konsens entsteht.

14. Eine gesellschaftliche Organisation ist demokratisch strukturiert, wenn ihr oberstes Entscheidungsgremium aus gleichen Wahlen ihrer Mitglieder hervorgeht. Paritätische Mitwirkungsrechte sind nicht demokratisch, sondern ständisch. Eine politische Aufforderung dazu kann nur an den Grundrechten und der Sozialstaatsklausel, nicht aber am Demokratieprinzip legitimiert werden.

15. Politische Organisationen, die, wie Gewerkschaften, Arbeitgeberverbände usw. auf breiter mitgliedschaftlicher Basis an der Erarbeitung politischer Zielvorstellungen mitwirken, unterliegen dem Gebot innerer Demokratie aus der Analogie zu Art. 21 I 3. Anderen privatrechtlichen Organisationen kann innere Demokratie ohne Verletzung des Art. 9 I insoweit vorgeschrieben werden, als die körperschaftliche Struktur des Organisationstypus verdeutlicht wird. 


\section{Das demokratische Prinzip im Grundgesetz}

\section{Aussprache und Schlußworte}

Zacher (Diskussionsleiter):

$\mathrm{Zu}$ Beginn der Nachmittagssitzung darf ich zunächst besonders die erste Dame begrüßen, die unserer Vereinigung angehört: Frau Staff.

Zur Diskussion darf ich folgendes bemerken. Es ist gedacht, daß zunächst Herr Eichenberger einen Diskussionsbeitrag über die Problematik der Demokratie in der Schweiz geben wird, sodann Herr Walter aus österreichischer Sicht. Alsdann werden wir zur allgemeinen Diskussion übergehen. Sie sehen an der Tafel vier Aspekte aufgezeichnet, die etwa bei der Diskussion eingehalten werden sollen. Ich will sie auch noch einmal akustisch erläutern. Zunächst einmal soll erörtert werden: der Demokratiebegriff im allgemeinen und zwar auch historisch und vergleichend. Zugleich soll auch etwas gesagt werden zum rechtlichen Demokratiebegriff nach dem Grundgesetz. Als zweiter Punkt kommt, was uns allen sehr am Herzen liegt: das Verhältnis staatliche Demokratie und Gesellschaft und zwar in der Richtung von der gesellschaftlichen Ambiance zur staatlichen Organisation, aber auch umgekehrt von der staatlichen Demokratienorm zur Gesellschaft. Als Drittes sollen dann die Details der demokratischen Ordnung unter dem Grundgesetz erörtert werden: die positive Ausprägung, die die Demokratie im Grundgesetz gefunden hat. Und als letzter Punkt der Tagesordnung soll die supranationale und internationale Dimension der Demokratie angesprochen werden, die ja vor allem im Referat von Herrn von Simson zum Ausdruck gekommen ist. Ich darf damit die Beratungen eröffnen.

Eichenberger: Ich darf Sie kurz über einige Elemente des Themas aus der schweizerischen Sicht orientieren. Sie kennen die Neigung der Schweizer, ihre Demokratie als die praktisch bestmögliche Ausformung des demokratischen Prinzips für einen Kleinstaat zu halten, und angesichts ihrer fleißigen Fremdund Selbstkritik besteht auch eine latente Missionsbereitschaft selbst gegenüber Flächenstaaten, die mit mehr oder weniger Wohlwollen hingenommen wird. Trotz den vielen Eigenarten ihres Staats möchte die Schweiz doch auch wieder nicht gern 
als staatsrechtlicher Sonderling betrachtet werden, der ein Leben fernab von der bedrängenden weltweiten Demokratieproblematik im Windschatten führen könnte. In der Tat steht auch sie im windigen Wetter, in das die mit dem ausgedehnten Sozial- und Verwaltungsstaat konfrontierte Demokratie geraten ist und dem die Schweiz wegen des institutionellen Ausbaus und wegen der dichten Verflechtung der Demokratie mit der gesamten Sozialordnung ganz besonders ausgesetzt ist. Sie erlebt die Demokratieproblematik gleichsam breiter, intensiver, krisenhafter. Sie ist durch ihre Kleinheit, durch ihre relativ hochgradige Homogenität, durch den Zwang, die vielfältigen Minderheitenprobleme mit einer lebendigen Demokratie jeden Tag zu bewältigen oder besser: gar nicht aufkommen zu lassen, sowie durch Gunstbezeugungen der Geschichte existentiell demokratisch.

Wenn sie in normlogischer Utbertreibung mit Vorliebe als Referendumsdemokratie bezeichnet wird, so hat man sie noch nicht charakterisiert. Das Referendum macht weder das Ganze, noch das Zentrum, noch das letztlich Wesentliche der schweizerischen Demokratie in normativer und in politischer Hinsicht aus. Hans Huber hat dies wiederholt dargetan. Die Schweiz ist in der "verwirklichten Verfassung" (Konrad Hesse) eine halbdirekte Demokratie im Sinne der französischen Typenlehre, die auf dem kräftigen Unterbau einer Repräsentativverfassung Elemente der unmittelbaren Demokratie übernommen hat und in welcher der politische Prozeß in einem spezifischen und hochkomplexen Miteinander von Behörden und Volk abzuwickeln ist. (Das auszeichnende „Miteinander“ hat Herr Friesenhahn an der Berliner Staatsrechtslehrer-Tagung als allgemeines Phänomen aufgewiesen und gerade für die Schweiz wissenschaftlich und praktisch in hohem Maß fruchtbar gemacht). Grundrechte hegen und stützen diese Demokratie.

Die institutionellen Schöpfungen der schweizerischen Demokratie waren das Werk des 19. Jahrhunderts, denen das 20. Jahrhundert beinahe nichts mehr beigefügt hat. Die erste Bundesverfassung von 1848 schuf einen repräsentativen Gesetzgebungsstaat, in dem das Volk auf Parlamentswahlen und die Verfassungsgebung beschränkt war. Abgeschwächte Rezeptionen der Volkssouveränitätslehren versetzen das Parlament als sogenannte oberste Gewalt in eine Suprematie. Ihm oblagen die Wahl einer stabilisierten Regierung, die dichte Kontrolle der vermeintlich auf den Vollzug zurückgebundenen Exekutive und die exklusive Legiferierung. Die Totalrevision von 1874, die den demokratisierenden Bewegungen in den Kantonen 
nachfolgte, und eine Partialrevision von 1891 führten das fakultative Gesetzesreferendum und die Verfassungsinitiative ein. Ein Ausläufer von 1921 forcierte die Volksbeteiligung im fakultativen Referendum für langfristige Staatsverträge, eine Institution, die nur zweimal benutzt wurde und der gegenwärtig eine Modeströmung eine fragwürdige Verstärkung zu verschaffen trachtet. Die Aktivbürgerschaft hat, in Erahnung ihrer Grenzen und der eigenen Gefährdungen durch demagogische Manipulationen, zweimal die Volkswahl der Bundesregierung verworfen, ferner die Volksinitiative für einfache Gesetze abgelehnt. Die Gliedstaaten freilich gingen angesichts ihrer Kleinheit weiter. Das Volk wählt die Kantonsregierungen, wodurch dem Kantonsparlament das schlagkräftigste Instrument der Gewaltenhemmung und der Realisation von Verantwortlichkeit aus den Händen geschlagen wurde. Die Kantone kennen die Gesetzesinitiative, zu einem großen Teil das obligatorische Gesetzesreferendum und ein Verwaltungsreferendum vorzüglich als Finanzreferendum. Die fünf verbliebenen Landsgemeinden, oft als reale Volksherrschaften gepriesen, sind nur ganz beschränkt deliberierende, zum Teil nicht einmal dezidierende Versammlungsdemokratien, und ihre bloße einmalige Einberufung im Jahr nimmt ihnen vollends den Hauch eines Abbilds athenischer Volksherrschaft. Hingegen ist die Versammlungsdemokratie in den vielen mittleren und kleinen Gemeinden Wirklichkeit; hier bietet sie oft die erquickende Bestätigung, daß im Rahmen bescheidener öffentlicher Aufgaben das Volk sachlich-politische Gestaltungskräfte unmittelbar erfolgreich aktivieren kann.

Richtete das 19. Jahrhundert die demokratischen Institutionen ein, ist das 20. Jahrhundert dasjenige tiefgreifender Verfassungswandlungen, der Ausbreitung von ungeschriebenem Verfassungsrecht und der Ausbildung einer Art von konstitutionellen Konventionalregeln.

Nun durchziehen aber sonderbare Zwiespältigkeiten das Verfassungsleben. Hans Huber hat die Situation in seinem Berliner Vortrag 1963 und in seiner letztjährigen Bonner Ansprache über das Gesetzesreferendum gültig dargelegt. Ich begnüge mich der knappen Zeit wegen auf wenige Erscheinungen: In der Staatspraxis werden Funktionen und Zusammenspiele den ungeheuren und unabsehbaren Ansprüchen des Leistungsstaats zögernd, aber doch unaufhaltsam angepaßt. Führung des Staatsganzen aus gesamtheitlicher Sicht, Effektivität von Leitung und Verwaltung, Koordination und Planung an den schwerfälligen verfassungsmäßigen Verfahren vorbei, rationa- 
lisierte Kontrollprozeduren statt der punktuellen und impulsiven Pseudokontrollen durch eine okkasionelle öffentliche Meinung - dies sind immer lauter erhobene Forderungen. Stille so gut wie sichtbare, plötzliche so gut wie zähflüssige Reformen richten sich allmählich daran aus. In der reflektierenden Diskussion hingegen, in der öffentlichen Erörterung und sogar in wissenschaftlichen Verfassungsinterpretationen werden Wandlungen noch nicht allgemein anerkannt. Man hält an Leitbildern oder an Vor-Verständnissen fest, als sei Rousseau noch mitten unter uns und hätte Tocqueville nicht gelebt und gedacht. Vorstellungen der realen Volkssouveränität, die Gleichsetzung von hypothetischem und empirischem Volkswillen werden immer wieder aufgefrischt. Die identitäre Demokratie fasziniert. Die vorgegebene Volkseinheit wird wie selbstverständlich erwartet, die Richtigkeitsproblematik, wie sie kürzlich Hans Ryffel dargelegt hat, wird übergangen, der Pluralismus, obwohl in praxi recht tauglich vollzogen, z. B. in einer qualifizierten Kompromißfähigkeit, die eine teils gelobte, teils verfemte „Konkordanzdemokratie“ (Richard Reich) befördert, wird selbst im wissenschaftlichen Raum oft als Ubel verworfen. Aus der Vorstellung der identitären Demokratie werden mit rascher Hand Folgerungen deduziert, so für das Parlament, z. B. seine nominelle Uberhöhung über die Exekutive unter gleichzeitiger Funktionshemmung im Milizsystem der Abgeordneten, für die Rückbindung der Justiz, für die Beibehaltung, ja, Ausweitung der Volksrechte, obwohl diese der Funktionstauglichkeit des vehement geforderten Leistungsstaats in die Quere kommen. Der immer wieder drohende Zug zur Erziehungstyrannis und der etwa von Werner Kägi unentwegt signalisierte Hang der öffentlichen Meinung zu einem gewissen demokratischen Absolutismus können durch die Verfassung selbst nur beschränkt verbaut werden. Uberhaupt folgt der schweizerische Staatsrechtler gerne der abschließenden These des Erstreferenten, die er auf folgenden Satz ausweiten möchte: Das Verfassungsrecht kann offenbar gerade die bedrängendsten Zeitfragen, z. B. Planung, hohe Effektivität, reale Kontrollen in demokratischen Prozeduren, noch nicht lösen, obwohl breite Schichten und viele Anhänger einer neuerlichen Totalrevision der Bundesverfassung dies glauben möchten. Das bedeutet keineswegs, die Verfassung werde vor den neuartigen Aufgaben und Funktionen dauernd abseits stehen müssen. Man wird Entwicklung und Möglichkeiten sorgfältig beobachten und dann zugreifen, wenn die Fähigkeiten zur verfassungsmäßigen Erfassung und Gestaltung heranreifen. Unheimlich ist nicht die Verzögerung, sondern die Befürchtung, daß solche Heranreifung ausbleiben 
könnte. Die kapitale Frage bleibt, wie die Verfassung jetzt und morgen die Demokratie funktionsfähig zu machen vermag, wie die Demokratie im modernen Staat einzurichten sei.

In der Schweiz stehen folgende Gestaltungsfragen voran, für die die Staatsrechtslehre der Staatspraxis das Problembewußtsein vermehrt $\mathrm{zu}$ wecken sucht: Wo und in welchem Ausmaß können unmittelbare Mitwirkungsrechte des Volkes angesichts der wachsenden Staatsaufgaben sinnvoll eingerichtet bleiben? Dabei ist zweierlei zu bedenken: Volksrechte lassen sich politisch nicht verringern; also geht es allenfalls um Umformungen, um sie sinnvoll und wirksam zu erhalten. Sodann muß man sich mit der unausweichlichen, aber kaum erfaßten Tatsache auseinandersetzen, daß Demokratie nur bis zu einer gewissen Schwelle rational getragen und bestimmt werden kann, während ein beachtlicher Rest unabdingbar im emotionalen Bereich verharrt. Nächste Frage: Wie lassen sich die stark veränderte Presse und die Massenkommunikationsmittel zuhanden der direkt-demokratischen Einrichtungen ohne grundlegende Verfälschungen einsetzen, eine Frage, die für die Schweiz brennender wird als die nach der Rolle intermediärer Gewalten im direkt-demokratischen Prozeß. Weitere Frage: Wird die Repräsentationsidee noch zureichend begriffen und dann die Repräsentationskraft dem Parlamente zugemutet, oder anders gefragt: Wie soll das unentbehrliche Repräsentativelement verstanden und gestaltet werden? Folgende Frage: Darf das enorme Leistungsbedürfnis durch die Regierung endlich offen anerkannt und wie kann es in einer relativen Harmonie mit den Möglichkeiten und mit der Wirklichkeit von Milizparlament und einer von der Sachkunde per se abgetrennten Aktivbürgerschaft praktisch institutionalisiert und gesichert werden? Gibt es verbesserte Kontrollmöglichkeiten, die die tatsächlichen Entscheidungsprozesse ins Auge bekommen, ohne in perfektionistischen Kontrollvorgängen die behördliche Handlungsfreiheit zu ersticken? Wie können Grundrechte für die funktionsfähige Demokratie gedeutet und entwickelt werden? Und endlich: Ist Verantwortlichkeit - dieser Kernbegriff neuen Demokratieverständnisses - real $\mathrm{zu}$ machen, $d . h$. außer auf der moralischen auch auf der handfesten rechtlich-politischen Ebene in gesicherten Vorgängen zu vollziehen? - Sie sehen: Auch die Schweiz ringt mit der offenen Problematik der Demokratie, hoffend, immer wieder tragfähige Ausformungen zu finden für den in der Aufgabenfülle anscheinend fast unbegrenzten Staat, dessen forcierte Leistungsforderungen dem Demokratieprinzip hinderlich zu werden drohen. 
Walter: Meine Aufgabe liegt darin - nicht in Konfrontation zu den Referenten, sondern sie gewissermaßen ergänzend die spezifischen Züge der Demokratie in der Verfassungsordnung Osterreichs aufzuzeigen. Erlauben Sie mir, da ich ja aus einer stärker positivistisch aufgeladenen Atmosphäre komme, dabei zunächst vom Bundesverfassungsgesetz auszugehen.

Das österreichische B.-VG. beginnt mit einer Art Bekenntnis zum demokratischen Prinzip. Der erste Satz des Artikels 1 lautet: "Osterreich ist eine demokratische Republik", ein Satz, dessen Aufnahme in eine Verfassung wohl - wie es auch geschehen ist - kritisiert werden kann, weil der demokratische Charakter eines Verfassungssystems ja nicht durch einen dies behauptenden Satz der Verfassungsordnung hergestellt werden kann, sondern durch ihre demokratischen Einrichtungen. Dieser theoretischen Einsicht gemäß, daß nämlich im Art. 1 B.-VG. eine Selbstdeutung des erst $\mathrm{zu}$ deutenden Verfassungsrechtsmaterials liege, hat denn auch zu heftigen Einwänden gegen diese Bestimmung von Seiten des verfassungsrechtlichen Beraters der Staatsregierung Hans Kelsen geführt. Wenn ich etwas Anekdotisches beifügen darf, so ist es dies, daß Staatskanzler Renner schließlich die Bestimmung Kelsen gegenüber mit dem Hinweis als unabweislich gekennzeichnet hat, daß Kelsen theoretisch sicher recht habe, man in einer Verfassung aber eben einige schöne Sätze, die den Leuten gefallen, haben müsse.

Fragt man sich nun, was für eine Vorstellung von Demokratie der österreichische Verfassungsgesetzgeber des Jahres 1920 hatte, so scheint hierzu zunächst der zweite Satz des Art. 1 einen gewissen Weg zu weisen, indem er nämlich der Deklarierung des demokratischen Prinzips beifügt, daß das Recht vom Volk ausgehe. Damit wird durchaus im Sinne der später von Kelsen zum Prinzip der Demokratie geäußerten Gedanken - ich erinnere an das in erster Auflage 1920 erschienene Buch über Wesen und Wert der Demokratie - das demokratische Prinzip als ein bestimmtes Prinzip der Rechtserzeugung aufgefaßt; ein Prinzip der Rechtserzeugung - orientiert an der Freiheit des Einzelnen - das auf dem Grundgedanken beruht, daß die Rechtsunterworfenen mit gleichem rechtlichen Einfluß selbst das sie bindende Recht erzeugen sollen. $\mathrm{Da} \beta$ dieser Grundgedanke durch die Mittelbarkeit der Verwirklichung des demokratischen Prinzips beeinträchtigt wird, ist zuzugestehen, aber ich meine mit Herrn Kriele, daß man Volksherrschaft und Repräsentation durchaus aufeinander $\mathrm{zu}$ beziehen vermag, insbesondere wenn man die Bedeutung der Wahl kennt. Ich wollte 
zunächst damit zum Ausdruck bringen, da $\beta$ das Prinzip der Demokratie in der österreichischen Verfassungsrechtsordnung als ein formales, die Art der Rechtserzeugung betreffendes Prinzip aufgefaßt wird. Ich bin allerdings nicht der, wenn ich recht verstanden habe, vormittags vertretenen Meinung, daß mit der demokratischen Rechtserzeugung lediglich ein „Ausgleichsmechanismus" geschaffen sei oder lediglich Identität von „Plädierenden und Entscheidenden“, sondern daß doch ein sehr wesentlicher Wertgesichtspunkt hinter der demokratischen Mehrheitsentscheidung steht; nämlich die Freiheit wenigstens der Mehrheit, nach ihrem Gesetz zu leben. Nur darin, nicht aber in der Hoffnung, daß die Mehrheit recht hat - von Wahrheit möchte ich in diesem Zusammenhang gar nicht sprechen erscheint mir der demokratische Gedanke gerechtfertigt zu sein und so scheint man sich ihn vorgestellt zu haben. Ich glaube in diesem Zusammenhang, daß Herr Kriele den Nachweis auch nur einer Wahrscheinlichkeit, daß die Mehrheit recht hat, nicht wird führen können. Hingegen möchte ich betonen, daß in der Demokratie im Sinne des österreichischen Verfassungssystems sicherlich nicht die Festlegung etwa eines ganzen Wertungssystems, also eines ganzen Systems inhaltlich bestimmter Werte liegt. Diese weiteren grundlegenden Werte sind in anderen Baugesetzen des Verfassungsgefüges enthalten.

Diese anderen grundsätzlichen Prinzipien des österreichischen Verfassungsgefüges müssen angeführt werden, um die Stellung des demokratischen Prinzips aufzuzeigen. Unbestritten tritt neben dem demokratischen Prinzip das rechtsstaatliche Prinzip in der österreichischen Verfassung hervor; ebenso das bundesstaatliche Prinzip. Erachtet man das republikanische Prinzip als nicht schon im demokratischen Prinzip enthalten (wobei es auf die Frage der Begriffsbildung ankommt), dann müßte man auch dieses nennen. Und zu Recht hat Adolf Merkl immer wieder das sich besonders in den Grundrechten manifestierende liberale Prinzip der österreichischen Verfassungsrechtsordnung hervorgehoben. Auch der Gedanke der Gewaltentrennung - freilich nicht in seiner reinen Ausprägung kann als ein solches Grundprinzip angesehen werden. Ein Sozialstaatsprinzip kann der österreichischen Verfassungsordnung - entgegen andersartigen, dogmatisch aber unhaltbaren $\mathrm{Be}-$ hauptungen - nicht entnommen werden. Die anderen erwähnten Prinzipien muß man bei Erörterung des demokratischen Baugesetzes der österreichischen Verfassung - wie schon erwähnt - deshalb behandeln, weil sie das demokratische Prinzip begrenzen und erst alle Prinzipien gemeinsam den Grundgehalt des Verfassungssystems manifestieren. So schränkt etwa 
das bundesstaatliche Prinzip das demokratische Prinzip in gewisser Richtung ein, wenn man an die nicht vollkommen bevölkerungsproportionale Repräsentanz der Landesbevölkerung im Gesetzgebungsverfahren des Bundes denkt. Das liberale Prinzip schränkt das demokratische ein, weil es gewisse Freiheitsräume statuiert, in die auch im Wege demokratischer Gesetzgebung nicht eingegriffen werden kann; und das rechtsstaatliche Prinzip schließlich steht mit dem demokratischen insofern in einem gewissen Antagonismus, als es auch im unbestrittenermaßen demokratischen Staat bei bestehender demokratischer Legitimation der Organe innerhalb des Staatsgefüges autokratische Elemente gibt und geben darf. Damit soll nur angedeutet sein, da $B$ die österreichische Lehre das Verfassungssystem als durch mehrere sich verflechtende Baugesetze geprägt ansieht. Die aktuelle Relevanz dieser Betrachtung zeigt sich z. B. darin, daß man bei richtiger Betrachtung dem Ruf nach „Demokratisierung“, wie er heute auch in demokratischen Verfassungen modern geworden ist, entgegensetzen kann und muß, daß es eben noch andere Grundprinzipien des Verfassungssystems gibt, die Berufung auf einen Grundsatz von mehreren somit noch keine hinreichende Begründung abgeben kann. Immerhin muß man dem, was man bei uns "das Unbehagen in der Demokratie" genannt hat, auf den Grund gehen. Und dies scheint doch darin zu liegen, daB die Fiktion der Repräsentanz (man denke an das Vokabel „Volksvertretung“ und dazu an das freie Mandat) durchschaut wurde. Gewiß kann es keinen Ubergang zur unmittelbaren Demokratie geben, aber ein Ausbau der Institute der unmittelbaren Demokratie scheint doch ein möglicher Weg zu sein. Ich darf sagen, daß Osterreich hier in der Mitte zwischen der Verfassungsordnung der Bundesrepublik und der Schweiz steht, allerdings seine Einrichtungen der unmittelbaren Demokratie in einem sehr vorsichtigen Ausmaße ausgebaut hat. Die Einrichtung des „Volksbegehrens" hat sich immerhin als ein taugliches Instrument der Kanalisierung von Unbehagen erwiesen, wie sich beim Rundfunk-Volksbegehren und Schulzeit-Volksbegehren gezeigt hat.

Wenn der Art. 1 des österreichischen B.-VG. das demokratische Prinzip zum Ausdruck bringt, so meint er damit das demokratische Prinzip der Ausprägung der mittelbaren Demokratie, neben die freilich auch Elemente der unmittelbaren Demokratie treten und treten können und er meint die Verwirklichung der demokratischen Organisationsform, insbesondere im Bereiche der Gesetzgebung. Darum ist es so wichtig, wie Herr von Simson ja auch ausgeführt hat, daß die demokratische Gesetzgebung nicht abdankt und anderen Kräften das 
Feld überläßt. Ob in diesem Punkte Herr Kriele - ich erinnere an das Wort „bloße Rechtssetzungsprärogative“ des demokratischen Gesetzgebers - eine andere Auffassung vertrat, habe ich nicht ganz deutlich gesehen.

Die Erkenntnis, daß das demokratische Prinzip ein Baugesetz der österreichischen Verfassung ist, hat nun juristische Relevanz im Hinblick auf die Bestandsgarantie dieses Prinzips, nicht zwar im Sinne einer Unabänderlichkeit, wohl aber in Richtung auf eine erschwerte Abänderbarkeit. Art. 44 Abs. 2 B.-VG. bestimmt nämlich, daß gesamtändernde Bundesverfassungsgesetze einer Volksabstimmung bedürfen. Und die Lehre und Judikatur nimmt - wohl zutreffenderweise - an, daß unter einer Gesamtänderung der Verfassung nicht etwa eine Neuformulierung oder Neusystematisierung des Verfassungsstoffes zu verstehen ist, sondern ein Abgehen von den grundsätzlichen Prinzipien, die das Verfassungssystem prägen. Insofern ist das demokratische Prinzip also nur unter den erwähnten Voraussetzungen aus dem österreichischen Verfassungsgefüge zu entfernen. Es zu modifizieren - etwa durch gewisse Änderungen des Wahlsystems, durch Verschiebungen zwischen repräsentativer und unmittelbarer Demokratie - steht jedoch der einfachen Verfassungsgesetzgebung frei.

Es mag vielleicht überraschen, daß die demokratische Verfassung auch ein Abgehen vom demokratischen Prinzip ausdrücklich ermöglicht, aber das österreichische B.-VG. ist eben typischerweise nicht vom Gedanken der sogenannten wehrhaften Demokratie geprägt, wozu sich freilich Ansätze in dem in Verfassungsrang stehenden Art. 8 und 9 des Staatsvertrages von Wien 1955 finden, der auch deshalb interessant ist, weil er Osterreich zu einer "demokratischen" Staatsform völkerrechtlich verpflichtet, wobei freilich Demokratie schon eine viel unbestimmtere Bedeutung haben dürfte.

Mit diesen Hinweisen konnte die österreichische Verfassungsrechtssituation in bezug auf das demokratische Prinzip nur ganz allgemein skizziert sein; und dies in der Hoffnung, Sie nicht zu sehr von unserem eigentlichen Beratungsgegenstand weggeführt zu haben.

Schneider: Ich ergreife das Wort in einiger Sorge. Ist doch die Gefahr nicht auszuschließen, daß das, was ich sage, Ihnen verehrter Herr Kollege Hans Schneider - wie auch schon in die Schuhe geschoben wird. Das wäre mir überaus peinlich.

Ich möchte an einen Ausdruck anknüpfen, den Herr Eichenberger in seinem Bericht gebrauchte: den Ausdruck identitäre Demokratie. In beiden Referaten ist der Sache nach zwischen 
der richtigen und der unrichtigen, der wirklichen und der scheinbaren, der absolutistischen, der totalitären und der freiheitlichen, rechtsstaatlichen, im GG konzipierten Demokratie unterschieden worden. Die Grenzlinie kann meines Erachtens vom Ausdruck identitäre Demokratie her bestimmt werden. Die Momente, welche freiheitliche, rechtsstaatliche Demokratie konstituieren, weder das Prinzip der Gewaltenteilung, noch dasjenige der Repräsentation sind von der Basis der identitären Demokratie verständlich. Im Sinne der identitären Demokratie wird der Wille des souveränen Volkes nicht allein mit Recht und Gerechtigkeit, sondern auch mit dem Willen aller identifiziert und damit eine unfehlbare und unanfechtbare Instanz eingesetzt. Von dieser Instanz aus kann im Grunde nicht einmal die Funktion der Mehrheitsentscheidung, geschweige denn diejenige der Verfassungsgerichtsbarkeit begriffen werden. Das Risiko der Diskrepanz zwischen Recht und Macht, Instanz und Instanz bleibt außer Betracht. Herr Eichenberger hat auf die eminent praktische Bedeutung hingewiesen, welche dem Umstand zukommt, ob demokratische Institutionen im Sinne der identitären Demokratie interpretiert werden oder nicht.

Von dieser Basis aus eine Frage an Herr Kriele: Sind Sie nicht auch der Meinung, daß die Redensart von der Identität der Regierenden mit den Regierten ihren Grund allein in der Identitätsvorstellung hat, $\mathrm{da} \beta$ auf diese Redensart verzichtet werden müßte, wenn man die Demokratie in ihrem Sinne als Prozeß bzw. als ein Inbegriff von Prozessen begreift?

Kriele: Ich kann die Frage nur bejahen. Identität von Regierenden und Regierten gibt es nicht. $D$. h. freilich nicht, daß man die Folgerung Schumpeters ziehen müßte, Demokratie sei Konkurrenzkampf der Machteliten. Da wird es ins andere Extrem getrieben, und die rechtlichen Institutionen, die auch noch charakteristischerweise zur parlamentarischen Demokratie gehören, geraten wiederum aus dem Blick.

Schneider: Sie, Herr Kriele, sind der Auffassung, daß das Prinzip der Gewaltenteilung ,identitär " nicht verstanden werden kann. Ich bin darüber hinaus der Ansicht, daß dies auch für das Mehrheitsprinzip und für die Tatsache gilt, daß zwischen der "Auslese" der Aktivbürger und den übrigen Bürgern unterschieden werden muß. Würden Sie auch diese Konsequenz ziehen?

Badura: Das Thema „Das demokratische Prinzip im Grundgesetz" hat den Referenten zwei verschiedene, aber zusammenhängende, Aufgaben gestellt, nämlich einmal uns darüber zu unterrichten, was nach ihrer Auffassung die politische Idee 
„Demokratie“ sei, und dann uns zu sagen, was nach ihrer Auffassung im Grundgesetz für eine Art von Demokratie verwirklicht worden ist. Es ging also darum, Demokratie als politische Idee und als Verfassungseinrichtung zu unterscheiden, in Verbindung zu bringen und darzustellen.

Es war für mich überraschend, in wie selbstverständlicher Weise die Referenten von einem verhältnismäßig greifbaren Begriff von Demokratie ausgehen konnten, sei er nun staatsrechtlich, sei er politisch gedacht. Dazu gehört auch, daß Herr von Simson in seinen Thesen 1 bis 3 eine Art Minimalinhalt von Demokratie im Sinne eines ", formalen Ausgleichsmechanismus" vorgestellt hat und das Problem der unterschiedlichen Vorstellungen nur als eine Sache der Verwirklichung dieses so verstandenen demokratischen Prinzips bezeichnet.

Auf der anderen Seite finde ich es auch eigenartig, wenn Herr Kriele in seiner These 13 sagt, daß das demokratische Prinzip im Grundgesetz "gesellschaftspolitisch neutral" sei. Er hat zwar nicht erläutert, was der Ausdruck "gesellschaftspolitisch" bezeichnen soll, weil er ihn offenbar als nach der Umgangssprache eindeutig voraussetzt. Aber gleichgültig, welche genaue Bedeutung gemeint ist - ich kann diese These nicht für richtig halten. Zwar glaube ich auch, daß die demokratische Idee ein politisches Prinzip für ein bestimmtes verfassungsrechtlich geordnetes Verfahren der politischen Willensbildung darstellt. Aber darüber hinaus, nach ihrer Entstehung und Wirkungsweise, bezieht sie sich auf eine aus diesem Verfahren resultierende Bestimmung und Veränderung der Staatsaufgaben. Darin kann ich nicht etwas sehen, das "gesellschaftspolitisch neutral" wäre. Mit dieser Beurteilung scheint mir ein nennenswerter Teil der eigentlichen Schwierigkeit der hier gestellten Frage und zwar gerade in der Form, wie sie in der Gegenwart aufgeworfen wird, offen zu bleiben.

Das Problem der Demokratie ist mindestens ein zweifaches: Es geht um eine bestimmte Methode der Etablierung legitimer Herrschaft und um eine bestimmte Methode der Schaffung und Verwirklichung des Rechts. Ich finde es ganz richtig, wenn Herr Kriele in seiner These 2 die vielleicht etwas in den Hintergrund geratene Vorstellung unterstreicht, daß das demokratische Prinzip auch auf eine bestimmte Organisation der Rechtserzeugung abzielt. Damit ist zugleich anerkannt, daß die Rechtserzeugung etwas Politisches ist. Dies hebt einen zutreffenden Gesichtspunkt hervor, es bleibt aber bei Herrn Kriele mehr oder weniger beiseite, daß Demokratie außerdem eine Methode der Etablierung legitimer Herrschaft ist. Wenn es 
nur um diese beiden Elemente der Demokratie ginge, wäre es noch verhältnismäßig einfach. Es kommt jedoch noch hinzu, daß Demokratie - wie es ihre folgerichtigen Verfechter immer verstanden haben - ein evolutionäres und in gewisser Weise auch revolutionäres Prinzip ist, ein Prinzip, das niemals vollständig in den Institutionen einer bestehenden Verfassung aufgeht, sondern immer bestehen bleibt als ein Prinzip der Kritik und ein Prinzip des Weiterdrängens; in diesem Sinne gibt „Demokratisierung“, so sehr es sich um ein Schlagwort handelt, ein richtiges Moment der demokratischen Idee an. In diesem Sinne möchte ich Herrn von Simson in seiner These 11 verstehen, wo er von der "Verantwortung der lebenden Zeit" spricht, die eben die Verwirklichung der materiellen Inhalte immer wieder neu aufgibt.

Als Ausgangspunkt der Betrachtung des Problems der Demokratie scheint es mir richtig - Herr Schneider hat eben auf einen ähnlichen Punkt Wert gelegt -, daß die politische Idee der Demokratie und ihre Verwirklichung nicht von Staat, Recht und der Herstellung einer gerechten politischen Ordnung gelöst werden. Wenn man von einer ,konstitutionellen" Demokratie spricht, besagt dieses Adjektiv eigentlich etwas Selbstverständliches; denn Demokratie ist als eine Staatsform des Verfassungsstaates gedacht. Als eine Staatsform - das heißt als ein Prinzip in bezug auf eine politisch organisierte Gesellschaft, und als ein Prinzip des Verfassungsstaates - das heißt als ein Prinzip des Staates, der seinen politischen ProzeB an das Recht bindet. Trifft das zu, dann ist die unmittelbare Demokratie in der Tat nicht ein politisches oder staatliches Prinzip; denn die unmittelbare Demokratie läuft auf die Aufhebung von Staatlichkeit, von Politik, von Herrschaft überhaupt hinaus. Bei konsequenter Postulierung und folgerichtig durchdacht, ist unmittelbare Demokratie als Aufhebung von Staat verstanden worden, jedenfalls von Staat in der Gestalt, wie er in der Entwicklung des Verfassungsstaates institutionalisiert worden ist. Von Herrn von Simson würde ich gern hören, ob dieser Punkt zu den in seiner These 4 zitierten „Elementen des Unbezweifelten" gehört, sei es daß diese, was mir eigentümlich erschiene, nur „nützliche Konventionen" wären, oder aber vielleicht eine Bedingung überhaupt der Verwirklichung von Demokratie. Wenn Herr von Simson dann in These 9 vom „Aufbau der Freiheit in der Gesellschaft" spricht und wenn man den Zusammenhang von Freiheit und Staat betrachtet, kann dieses "Element" nur auf eine bestimmte Art von Staatlichkeit bezogen sein. 
Wenn man diesen Uberlegungen folgt, wird man dahin kommen müssen, Demokratie nicht so sehr als ein Verfahren der unmittelbaren Artikulation zu begreifen, sondern als ein Verfahren der Legitimation, der Kontrolle und der Kritik politischer Herrschaft, wie es ja auch von den Referenten in verschiedenen Hinsichten hervorgehoben worden ist. Damit setzt sich die Fragestellung in den Problemen der Repräsentation fort, denen man nicht ausweichen kann, weil die Formulierung dieser Frage und ihre Beantwortung - nämlich wie Demokratie als Herrschaftsform zu verstehen sei - die eigentliche Schwierigkeit der Verwirklichung und überhaupt der Schaffung eines demokratischen Staates betrifft.

In dem Begriff der Repräsentation, wie immer man ihn faßt, - und damit kommen auch der Parlamentarismus und die Möglichkeit des Parlaments unter modernen Verhältnissen in das Thema hinein - ist stets vorausgesetzt, daß die Gesellschaft als politische Einheit bereits besteht. Das ist auch paradoxerweise die Wahrheit Rousseaus, der die unmittelbare Demokratie verficht, dennoch aber immer von der existierenden politischen Einheit der Gesellschaft ausgeht, in der die „bürgerliche Religion" die Voraussetzung für die "Republik" ist, in der Demokratie verwirklicht werden kann. Aus dieser Prämisse der Repräsentation leiten sich weitere Konsequenzen für die Frage des Parteienstaates ab, die Erscheinungsweise der parlamentarischen repräsentativen Demokratie unter den uns bekannten Bedingungen. An dieser Stelle darf ich beiläufig erwähnen, daß mir die These 11 von Herrn Kriele, daß die gesetzliche Einführung von Mandatsverlust bei Parteiwechsel Art. 38 Abs. 1 GG nicht verletzen würde, mit der Garantie des freien Mandats nicht in Einklang zu stehen scheint. Der damit verfolgte Sinn der Trennung von Institution (Abgeordnetenmandat) und Partei würde damit praktisch verloren gehen.

Als letztes komme ich zum Punkt der Selbstverwaltung, der - wenn ich das richtig gesehen habe - in beiden Referaten verhältnismäßig abwehrend behandelt worden ist. Diese Beurteilung möchte ich nicht teilen. Wenn auch der Begriff der "Wirtschaftsdemokratie" ein politisches Schlagwort ist, das insofern falsch ist, als es die Bedeutung von "Demokratie“ über ihr eigentliches Anwendungsfeld hinaus erstreckt, kann man doch den Art. 165 WeimRVerf und die in ihm ausgedrückten Ziele und Einrichtungen nicht völlig von dem politischen Prinzip der Demokratie abtrennen. Demokratie, wie sie wirklich funktioniert und wie sie besonders im angelsächsischen Rechtsbereich stets als selbstverständlich verstanden wurde, ist mit 
der politischen Idee der Selbstverwaltung verbunden. Wegen dieses Zusammenhanges darf ich nur auf Thomas Jefferson verweisen. Es ist meiner Ansicht nach ein von der französischen Theorie beeinflußtes Vorurteil der kontinentalen und auch der deutschen Vorstellung von Demokratie, eine so scharfe Trennung zwischen Demokratie und Selbstverwaltung zu ziehen. Dabei ist mir bewußt, daß die Notwendigkeit der Einheit der politisch organisierten Gesellschaft und die Frage der Koordination der Selbstverwaltungseinheiten eine theoretische und praktische Schwierigkeit darstellt, die gerade von Kelsen - wie vorhin Herr Walter betont hat - deutlich gekennzeichnet worden ist. Dennoch würde ich es nicht für richtig halten, so scharf zu trennen. Es liegt gerade im Gedanken der Selbstverwaltung, darin eine "Aufhebung" im Sinne Hegels der Polarität von staatlicher Organisation und gesellschaftlicher Unmittelbarkeit zu sehen.

Zacher: Herr Badura, ich möchte zu Ihrem letzten Beitrag selbst etwas sagen. Die demokratische Situation der Selbstverwaltung hat zwei Seiten: nämlich die Spannung zwischen der partikularen Einheit und der ganzen Einheit, die bei Herrn von Simson ja auch im föderalen System zum Ausdruck gekommen ist; aber auch die demokratiegerechte Innenstruktur von Selbstverwaltungseinheiten. Und ich glaube, daß die $\mathbf{Z u}$ rückhaltung zum Letzteren besteht und zu erklären ist.

Häberle: Ich möchte zum Teil als Kritik an dem soeben von Herrn Badura Gesagten sowie zu manchen Thesen von Herrn Kriele folgendes vorbringen: Es geht mir stärker um den $\mathrm{Zu}-$ sammenhang von Verfassungstheorie und Demokratieverständnis nach dem GG. Heute erscheint mir nur eine konkrete demokratische Verfassungstheorie als möglich - jede Spielart des westlichen Demokratieverständnisses setzt bewußt oder unbewußt ein bestimmtes Verfassungsverständnis voraus. Das liegt um so näher, als Demokratie die Lehre von der "guten Staatsordnung" überhaupt geworden ist und als eine „Parallelität" in wichtigen Punkten zwischen dem Demokratieverständnis einerseits und der Verfassungstheorie andererseits besteht: einmal in bezug auf die Offenheit der Verfassung und die von beiden Herren Referenten herausgearbeitete Offenheit der Demokratie (von Simson - These 2, Kriele - These 8); ferner hinsichtlich der Bedeutsamkeit der Verfahren: die "relative Wahrheit" liegt heute im Verfahren, das erkennt sowohl die Verfassungstheorie wie die Diskussion zum Demokratieverständnis an; auch hier besteht zwischen den beiden Referenten ein Konsens; schließlich liegt eine Annäherung von 
Verfassungs- und Demokratieverständnis im Bereich dessen vor, was man als eine Art "Ethik des Kompromisses" in der Demokratie bezeichnen könnte und dem das Prinzip „praktischer Konkordanz" (Hesse) entspricht. Das zeigt, daß heute Verfassungstheorie von vornherein nur als demokratische Verfassungstheorie möglich ist. Die Fragen der "Staatlichkeit" interessieren mich recht wenig, da unsere demokratische Ordnung (nur) von der Verfassung konstituierte Ordnung ist.

Zuletzt eine kritische Bemerkung zu Herrn Kriele: Mir scheint, er hat das Volk zu weitgehend zur Abdankung gezwungen bzw. das Volk ist verloren gegangen oder abhanden gekommen. Er spricht in These 2 von "Herrschaft des Rechts" - mir wäre der Gedanke der Souveränität der Verfassung lieber, da die Verfassung als Ordnung der res publica nicht im Recht aufgeht. So sehr mich die Abschaffung der voluntaristischen Volkssouveränität rousseauscher Prägung überzeugt: ist nicht ein großer Teil der Problematik jetzt auf den Rechtsbegriff verschoben? Von der konkreten demokratischen Verfassungstheorie aus wäre das Volk als differenzierte Größe stärker in die Verfassung „einzubringen“, z. B. im Rahmen eines öffentlichen, demokratischen Teilhabeverständnisses der Grundrechte, wie dies das Bundesverfassungsgericht seit dem Lüthüber das Spiegel-Urteil bis hin zur Leserbrief-Entscheidung so eindrucksvoll von der Grundrechtsseite her tut, wobei freilich auf die Unsicherheit und das Demokratiedefizit in Entscheidungen zum organisationsrechtlichen Teil (z. B. im Volksbefragungs- und Schleswig-Holstein-Urteil) und neuestens wieder auf den zu unreflektiert verwandten, ideologieanfälligen Begriff der "streitbaren Demokratie" negativ hinzuweisen wäre. Auch sonst müßte gefragt werden, wie das Volk im Rahmen einer demokratischen Verfassungstheorie stärker als bei Herrn Kriele zu aktivieren wäre.

Roellecke: Herr Kriele hat sehr schön gezeigt, daß sich die Theorie der Demokratie - entgegen der Auffassung Herrn von Simsons - doch noch weiter entwickeln läßt. Ich freue mich, Herrn Kriele in allen wesentlichen Punkten zustimmen zu können. Nur in zwei Punkten, meine ich, hat er nicht ganz konsequent argumentiert. Der erste betrifft den Mandatsverlust bei Parteiwechsel. Darauf möchte ich hier nicht eingehen. Der zweite Punkt erscheint mir ungleich wichtiger. Er betrifft die Qualifikation der Mehrheitsentscheidung. In dieser Frage möchte ich weitgehend Herrn Walter folgen.

Herr Kriele behauptet auf der einen Seite, Mehrheitsentscheidungen seien wahrscheinlich richtiger als Entscheidungen 
einer Minderheit oder einzelner Personen. Auf der anderen Seite sagt er zutreffend: $\mathrm{Da}$ alle in irgendeiner Form am demokratischen Willensbildungsproze $\beta$ beteiligt seien, könne es in diesem Prozeß keine neutrale Instanz geben. Wenn das aber so ist, dann kann es auch keine Instanz geben, die objektiv: unabhängig von der Mehrheit, über die Qualifikation von Mehrheitsentscheidungen entscheiden könnte. Und wenn das so ist, dann ist es überhaupt unmöglich, Mehrheitsentscheidungen abstrakt-allgemein zu qualifizieren, das heißt, außerhalb des Verfahrens, das zu einer Mehrheitsentscheidung führt. Der Grad der angeblich objektiven Richtigkeit - wahrscheinlich oder absolut? - ist unter diesen Voraussetzungen unerheblich. Die Konsequenz wäre, daß nicht die sichere, wahrscheinliche oder mögliche Richtigkeit Mehrheitsentscheidungen legitimiert, sondern $\mathrm{da} \beta$ es für Mehrheitsentscheidungen nur eine Qualifikation geben kann: das rechtsstaatlich-demokratische Willensbildungsverfahren.

Marcic: Gerne hätte ich zur Theorie der Demokratie unter dem Aspekt ihres Vertrags- und Kompromißcharakters das Wort ergriffen. Es gälte, den eigenartigen Zusammenhang zwischen ihr und dem Vorrang des Gewohnheitsrechtes zu beleuchten, wie er sich namentlich in der Entwicklung des common law in England behauptet: Die Methode der Rechtserzeugung kraft Gewohnheit ist von Grund auf demokratisch; das Recht wird von unten nach oben unter Mitwirkung der Rechtsgenossen (des Volkes) hergestellt. Gewohnheitsrecht und Vertrag sind, wie Kelsen aufweist (Reine Rechtslehre ${ }^{2}$ 1960, S. 234 f., 284 f.; Allgemeine Staatlehre 1925, S. 232) die beiden Urgestalten demokratischer Rechtsschöpfung. $\mathrm{Da}$ die Zeit drängt, sehe ich mich genötigt, nur zu den lehrreichen Ergänzungsausführungen des Herrn Kollegen Robert Walter ein paar Anmerkungen vorzubringen.

1. Art. 1 der österreichischen Bundesverfassung (B-VG) spricht in seinem zweiten Satz - nicht, wie häufig zitiert, von der Staatsgewalt. Art. 1 B-VG lautet: „Osterreich ist eine demokratische Republik. Ihr Recht geht vom Volk aus“. Auf Drängen Renners ließen sich Kelsen und der Unterausschuß bestimmen, „die Gewaltenterminologie zu beseitigen und sie durch eine Rechtsterminologie zu ersetzen. Diese terminologische Anderung wurde in der ganzen Verfassung durchgeführt. Diese spricht nicht mehr, wie dies in anderen Verfassungen üblich ist, von gesetzgebender, vollziehender und richterlicher ,Gewalt', sondern von den bezüglichen Funktionen und Kompetenzen ... (Kelsen, Die Bundesverfassung vom 1. Oktober 1920. Hsg. von Froehlich, Merkl, Kelsen. 5. Teil: Die Verfas- 
sungsgesetze der Republik Österreich. Wien und Leipzig, 1922, S. 65). Diese bewußte Abkehr von der Gewalt, die sich in Osterreich vor einem halben Jahrhundert ohne "Kritische Theorie" und ohne "Neue Linke" vollzog, geschah nicht von ungefähr; sie hängt mit dem zusammen, was die Herren Kollegen Kriele und von Simson gesagt haben - es hat mich sehr beeindruckt - mit dem Gedanken der rechtsbeschränkten Demokratie. Dieser ist das Ergebnis eines Konzeptes, welches Demokratie und Rechtsstaat nicht gegeneinander ausspielt, vielmehr auf die von vornherein gegebene Einheit von Volkssouveränität und Rechtssouveränität baut. Dieses Verhältnis drückt sich positivrechtlich namentlich in den Grundrechten und in der Verfassungsgerichtsbarkeit aus.

2. Der zweite Satz des Art. $1 \mathrm{~B}-\mathrm{VG}$ gibt, zusammen mit Art. 9 B-VG, der dem Art. 4 der Weimarer Reichsverfassung entspricht, einen weittragenden Aspekt frei (Art. 9 B-VG: „Die allgemein anerkannten Regeln des Völkerrechts gelten als Bestandteile des Bundesrechts"). Hier öffnet sich die österreichische Rechtsordnung prinzipiell dem Völkerrecht. Von diesem Boden aus, der deutlich die Handschrift Verdroß', Merkls und Kelsens trägt, bestünde die Möglichkeit, sogar den Monismus im Sinne des Primats des Völkerrechtes für Österreich zu vertreten (Verdroß und Miehsler vertreten den gemäßigten Monismus ambivalent). Die Auffassung wird dadurch bekräftigt, daß der zweite Satz des Art. 1 B-VG nicht sagt "alles Recht", sondern präzise nur: „ihr Recht", nämlich das positive eigenstaatliche Recht der Republik Österreich (des Gesamtstaates) „geht vom Volk aus".

3. Ebenfalls auf Seiten des Herrn Kollegen Kriele stehe ich in der Frage der grundsätzlichen Wertung der Mehrheit. Die Hypothese der Richtigkeitsgewähr der Mehrheit setzt ihrerseits eine Hypothese voraus: Es ist die von Aristoteles klar aufgewiesene, von Rousseau übernommene und von Hegel wiederholte Annahme, daß die Mehrheit die Richtigkeit indiziert (und zwar nicht unfehlbar), weil es einen Geist, eine Vernunft gibt, an der die Menschen als Vernunftwesen partizipieren. Die Richtigkeit wird verifiziert, wenn die Mehrheit die Minderheit überzeugt, „überredet" hat. Natürlich kann man das Ideologie nennen; ich vermeine jedoch, daß für die Annahme einer solchen Bedingung der Richtigkeitsgewähr der Mehrheit sehr viel spricht.

4. Das nächste, das ich in Ergänzung zu Herrn Kollegen Walter erwähnen möchte, ist eine Eigenart der österreichischen Demokratie: Sie artikuliert das Prinzip der Demokratie nicht 
nur auf der relativ ranghöchsten Stufe der Gesetzgebung, sondern in ganz deutlicher Weise auch in der Ebene der Gerichtsbarkeit in Art. 91 Abs. 1 B-VG: „Das Volk hat an der Rechtsprechung mitzuwirken". Entscheidend für den Bereich der Vollziehung in ihrem Zweig als Verwaltung (Exekutive) ist Art. 60 B-VG, wonach das Volk kraft Abstimmung den Bundespräsidenten in dessen Amt beruft (Abs. 1), wozu die Möglichkeit tritt, ihn vorzeitig aus politischen Gründen plebiszitär abzuberufen (Abs. 6). Als besondere österreichische Eigenart für den Bereich der Verwaltung soll schließlich das so weitläufig ausgebaute System der Selbstverwaltung herausgekehrt werden.

5. In einem Punkt darf ich noch an Herrn Kollegen Walter anknüpfen: Er hat betont, daß Osterreich in seiner rechtlichen Verfügbarkeit nach Art. 44 Abs. 2 B-VG (wo es um das Verfahren der Gesamtänderung der Verfassung durch Eliminierung von Bauprinzipien geht) von völkerrechtswegen beschränkt ist; hiezu nannte Herr Kollege Walter ganz allgemein das demokratische Prinzip. Ich darf hiezu spezifizieren: Merkl (letztmals: Die Baugesetze der österreichischen Bundesverfassung, in: Die Republik Osterreich, hrg. v. H. R. Klecatsky, Wien 1968, S. 79 - 105) hat als erster die Aufmerksamkeit darauf gelenkt, daß wir völkerrechtlich nicht mehr frei seien, uns eine beliebige Demokratie zu wählen, daß wir vielmehr auf Grund von Art. 8, 6 und 1 des Staatsvertrages von Wien vom 15. Mai 1955 verpflichtet seien, am Typus der rechtsstaatlichen Mehrparteiendemokratie festzuhalten.

6. Zum Schluß möchte ich anmerken, daß der Präsident des österreichischen Verfassungsgerichtshofes, der sich kraft seines Amtes höchste Zurückhaltung auferlegt, Walter Antoniolli, der zugleich erster Ordinarius für Offentliches Recht an der Universität Wien ist, vor dem Zweiten Osterreichischen Juristentag in seinem Festvortrag die Gewaltentrennung als Element der Rechtsstaatlichkeit als unabänderliches Fundamentalprinzip ansieht, das sich sogar der Disposition des Bundesvolkes gemäß Art. 44 Abs. 2 B-VG entziehe (Antoniolli, Herrschaft durch Gewaltentrennung. In: Neues Forum XI/128, August 1964, S. 358). Faßt man unsere Verfassungsordnung so auf, dann kommen wir dem Art. 79 Abs. 3 GG sehr nahe.

Scholler: Der Herr Mitberichterstatter hat ausgeführt, daß es in der Demokratie Verlierer gebe. Nun gibt es offenbar auch Gewinner, aber diese Gewinner haben keine Souveränität. In dieser Umschreibung enthüllt sich etwas sehr präzises, nämlich, daß nicht nur das Denken in Identitäten, sondern daß auch 
die Vorstellung der Repräsentation des Gesamtvolkes durch die einmal Gewählten überholt ist, denn sonst könnte es ja keine Verlierer geben, abgesehen von den Kandidaten, die kein Mandat erhalten haben. Wenn also, wie Herr Walter sagte, die Repräsentation durchschaut worden ist - ich würde nicht so weit gehen, ich würde sagen, sie ist nicht mehr funktionsfähig, sie schafft nicht mehr den Integrationsprozeß - dann müßte man einen Schritt weitergehen. Wir brauchen eine Demokratie als Prozeßregelung, ohne diese Fiktion oder Identität, daß die einmal gewählte Mehrheit repräsentativ sei für das Gesamtvolk.

Meines Erachtens kann es auch ohne Schaden geschehen, wenn man Demokratie begreift als Prozeß, in welchem die Parteien eine gleiche Chance haben zu regieren oder regiert zu werden. Daraus folgt andererseits, daß die Gleichgewichte stärker ausgebaut werden müssen und vor allem, daß die Ausbalancierung der Regierung dadurch erfolgt, da $\beta$ man der Opposition, also dem Verlierer, Kompensationsmöglichkeiten gibt, z. B. im Rahmen der Massenkommunikationsmittel. Das geschieht heutzutage in der Verfassungswirklichkeit, aber ich würde es als notwendige Ergänzung dieses auszubalancierenden Prozesses der Verfassungswirklichkeit ansehen, daß vom Verfassungsrecht her die notwendigen Instrumente geschaffen werden.

Leibholz: Mir scheint, daß bei der Analyse dessen, was unter dem Demokratiegebot des Grundgesetzes zu verstehen ist, die spezifisch-demokratische und -liberale Komponente schärfer herausgearbeitet werden sollte, als dies geschehen ist. Dies ist um so notwendiger, als das Grundgesetz sich nicht zur Demokratie schlechthin, sondern einem bestimmten Strukturtypus dieser Demokratie, nämlich der freiheitlichen Demokratie, sowohl seinem materialen Gehalt wie seiner organisatorischen Struktur nach bekannt hat.

Demokratie als politisches Herrschaftsprinzip impliziert, daß das Volk sich selbst regiert, d.h., daß das Volk die oberste, universale und finale Entscheidungsinstanz ist, von der sich alle politische Auctoritas im Staate ableitet. Dieses Volk erscheint in der Demokratie als der Schöpfer der politischen Wirklichkeit und ist in der Ausübung seiner souveränen Gewalt durch keine anderen Regeln gebunden, als durch die, die es sich selbst bei der Ausübung seiner verfassunggebenden Gewalt gegeben hat.

Demokratischen Vorstellungen entspricht es weiter, soviele Bürger wie möglich an der politischen Willensbildung teilneh- 
men zu lassen. Je mehr Volk mobilisiert werden kann, um so mehr kommt man der Vorstellung nahe, daß das Volk als Ganzes in der politischen Wirklichkeit als real-handelnde Einheit in Erscheinung tritt. Die Gleichheit ist somit das Vehikel, mit dessen Hilfe - heute bedient man sich hierzu des Ausdrucks „Demokratisierung“ - „die Herrschaft des Volkes durch das Volk für das Volk" in der Demokratie gesichert werden soll.

Demokratisch ist hiernach das Mehrheitsprinzip, weil durch dieses erst die größtmögliche Anzahl der Aktivbürger das Gefühl erhält, nur dem eigenen Willen unterworfen zu sein. Bei einer solchen, auf die möglichst weitgehende Verwirklichung der Gleichheit gerichteten demokratischen Mehrheitsentscheidung kann es daher nicht - wie es bei einer liberalen Interpretation des Mehrheitsprinzipes der Fall sein würde - auf die inhaltliche Qualität, d. h. die sachliche Richtigkeit der Entscheidung ankommen. Unter demokratischen Gesichtspunkten ist es allein die Macht, die hinter der Mehrheit steht, die die Mehrheitsentscheidung rechtfertigt.

Die Referate lassen auch die Frage offen, wie eine in Freiheit vollzogene, demokratische Mehrheitsentscheidung unter dem Aspekt des Demokratiegebotes zu qualifizieren ist, soweit diese den Eigenwert und die Subjektqualität der menschlichen Person in Frage stellt, diese nur als Werkzeug und Objekt gelten läßt und zur Disposition der in ihrer Tendenz totalitär ausgerichteten Mehrheit stellt. Schon nach Marx und Engels sollte durch eine solche Mehrheitsentscheidung das Volk mit Hilfe freier Wahlen in die Lage gesetzt werden, sich in dieser Weise der Opposition zu entledigen. In unserem Jahrhundert hat diese Frage nicht nur theoretische Bedeutung. Es gibt westliche Staaten, in denen ein Drittel respektive ein Viertel der wahlberechtigten Bevölkerung totalitär ausgerichtet ist. Es sei ferner an die Ereignisse in den dreißiger Jahren erinnert, die zur Etablierung des nationalsozialistischen Regimes geführt haben. In Südamerika - man denke z. B. an die letzten Wahlen in Chile - liegen die Dinge nicht sehr anders. Ist man bereit, solche Entscheidungen, auch wenn man die besondere Problematik des Art. 79 Abs. 3 GG ganz außer acht läßt, unter dem westlichen Demokratiegebot als demokratisch zu bezeichnen? Wäre dies z. B. der Fall, wenn in einem kommunistischen Staat die Mehrheit in Freiheit sich zu seinem Regime bekennen würde?

Schließlich noch ein Wort zur Demokratisierung der Gesellschaft, die von dem Herrn Zweitreferenten zum Schluß seines Referates angeschnitten worden ist: 
Wir sind heute Zeugen einer Entwicklung, die in fortschreitendem $\mathrm{Maße}$ dahin tendiert, die Wirtschaft und andere ihrem Wesen nach unpolitische Bereiche unseres Lebens zu demokratisieren, d. h. der Herrschaft einer radikalen Egalité zu unterwerfen. Zur Erreichung dieses Zieles bedient man sich zum Teil sozialer Grundrechte oder - wie dies im Grundgesetz z. B. der Fall ist - des Bekenntnisses zum Sozialstaat. Der moderne Verfassungsstaat des Westens ist aufgrund dieser Entwicklung mehr und mehr zu einem sozialen Leistungs- und Wohlfahrtsstaat geworden. Bei dieser Sachlage erhebt sich die Frage, ob die vom Grundgesetz feierlich verbrieften Freiheitsrechte des Menschen auf die Dauer noch die Grundlage unserer freiheitlichen demokratischen Ordnung bleiben können. Freiheit und Gleichheit stehen nämlich in einem inneren Spannungsverhältnis zueinander. So wie die hemmungslose Betätigung der Freiheit zu einer unerträglichen Ungleichheit führen kann, kann eine fortschreitende Perfektionierung der Gleichheit im politischen und gesellschaftlichen Bereich dazu führen, die Freiheit, zu der sich das Grundgesetz ebenso bekennt wie zur Gleichheit, fragwürdig zu machen. Die weitverbreitete Vorstellung, als ob das Bündnis, das die westlichen Demokratien seit Jahrhunderten mit der Freiheit eingegangen sind, ein apriorisches Bündnis sei, das aufgehoben werden könne, ohne zugleich die Demokratie selber in Frage zu stellen, beruht auf einem Mißverständnis. Das Bündnis ist begrifflich nicht ein notwendiges, weil Demokratismus und Liberalismus an verschiedenen politischen Werten orientiert sind, der Liberalismus an dem Personsein des Menschen und der persönlichen Freiheit, der Demokratismus am Volk, das als ein ideelles Ganzes in der politischen Wirklichkeit sich manifestiert. Heute besteht die Gefahr, daß - je mehr die Gesellschaft demokratisiert wird - diese Demokratisierung auf Kosten der Freiheit und damit zugleich aller autonomen Lebensbereiche erfolgt, die ohne Freiheit ihren materialen Gehalt nicht zu entfalten vermögen. Man denke an die Universitäten, die Justiz, die Kirche, die einer verantwortungsmäßig gebundenen Freiheit bedürfen, um ihre Funktionen im gesellschaftlichen Bereich zu erfüllen, etwa der Wahrheit zu dienen, Recht zu sprechen, das Wort Gottes zu verkünden. Vergessen wir nicht, daß die freiheitliche Komponente unserer Demokratie heute zugleich für eine Wert- und Lebensordnung steht, die die divergente Mannigfaltigkeit des Lebens zu einem "personalen Ganzen“ zusammenfaßt, das anti-totalitär ausgerichtet ist. Die freiheitliche Komponente des Demokratiegebots des Grundgesetzes läuft Gefahr, unterminiert zu werden, wenn es nicht gelingt, der nach Perfektionierung 
drängenden, radikal-egalitären Entwicklung um der Erhaltung der Freiheit willen Einhalt zu gebieten.

Von Simson: Also den Gedanken haben wir - ich glaube für beide sprechen zu können - zum Teil natürlich ausgeklammert, einfach, weil das Thema lautete „Das demokratische Prinzip im Grundgesetz". Manches ist im Augenblick noch nicht so akut, daß wir ihm einen Teil von unseren sechzig Minuten widmen konnten. Ich wollte nur eines sagen: ich habe ja auf die Möglichkeit einer Kategorie der Willensbildung hingewiesen, die nicht dem Handeln einer Generation überlassen sein könne. Ich gebe $\mathrm{zu}, \mathrm{da} B$ ich dabei hauptsächlich die Werte der Natur als Beispiel angeführt habe. Aber es wäre wohl zu erwägen, ob auch Werte wie die Freiheit, bei denen der Wille einer einzelnen Generation nicht nur über die Verhältnisse der eigenen, sondern zugleich über die einer zukünftigen Zeit entscheiden würde, zur Disposition der jeweiligen Gegenwart stehen und ob eine Generation für diese Willensmöglichkeit eine demokratische Legitimation in Anspruch nehmen könnte.

Kriele: Darf ich zunächst etwas zu den letzten Ausführungen sagen, Herr Leibholz. Ich sprach nicht allgemein von „Demokratie", sondern von "parlamentarischer Demokratie“ (auch wenn ich „Demokratie" sagte). Ich meine damit den bestimmten Verfassungstypus, der sich in der Neuzeit zunächst in England entwickelt hat, der von dort nach Amerika tradiert wurde und von da zurückgewirkt hat nach Europa, der aber auch mittelbar in Kontinentaleuropa als kritischer Maßstab gewirkt hat. Im 18. Jahrhundert hat das englische Beispiel die Legitimitätsgrundlage des absolutistischen Staates in Frage gestellt. Der absolutistische Staat beruhte auf dem Gedanken der Souveränität und der Behauptung, die Alternative zur Souveränität seien Chaos, Bürgerkrieg und Religionskämpfe. Montesquieu und andere haben im 18. Jahrhundert gesagt, das sei ja gar nicht wahr, es gebe eine dritte Möglichkeit. Sie brauchten nicht zu theoretisieren, denn sie konnten auf ein Gegenbeispiel in der europäischen Wirklichkeit verweisen. England hat das ganze absolutistische System mit dem Gedanken der institutionalisierten Liberalität, die sich mit dem Parlamentarismus angelsächsischer Prägung verknüpfte, verunsichert.

Eine ganz andere Tradition ist die kontinentaleuropäische der demokratischen Umkehr des monarchischen Absolutismus. Man wehrte sich gegen den monarchischen Souverän, nicht indem man das Prinzip der Souveränität in Frage stellte, sondern indem man den königlichen Souverän ersetzte durch den Volkssouverän. Wenn man diesen Begriff der Demokratie einmal 
zur Voraussetzung macht, dann folgt natürlich, daß das Volk die Freiheit abschaffen kann, dann folgt überhaupt, daß Demokratie zu einem Gegenbegriff zu Freiheit werden kann.

Man ist sich einig darüber, daß der Parlamentarische Rat eine Demokratie westlicher Prägung wollte. Ich möchte das näher dahin konkretisieren: er wollte eine parlamentarische Demokratie vorwiegend (nicht ausschließlich) angelsächsischer Prägung. Hinzuzusetzen ist, daß diese angelsächsische Prägung auch inzwischen ins französische Verfassungsdenken und überhaupt in die ganze westliche Welt eingegangen ist, wie umgekehrt der Parlamentarismus mit plebiszitären Elementen und dem allgemeinen und gleichen Wahlrecht "demokratisiert" worden ist, ohne jedoch die Rechtsverfassung preiszugeben und der Volkssouveränität zu opfern. Die theoretischen Probleme, die Sie, Herr Leibholz, angeschnitten haben, entstehen, zugespitzt, dann, wenn wir primär angelsächsischen Institutionen die französische Ideologie unterschieben. Das gibt Reibungen, und diese Reibungen haben Sie in drei Punkten sehr charakteristisch aufgezeigt.

Damit zusammen hängt das Problem, das mich in der bisherigen Diskussion am meisten bewegt hat: Mehrheit! Warum eigentlich soll die Mehrheit entscheiden? Gewährleistet die Mehrheit die Richtigkeit der Entscheidung? Soweit, Herr Marcic, würde ich nicht gehen. Ich würde aber auch nicht sagen, Herr Walter, der Sinn des Mehrheitsprinzips sei nur, daß der Minderheit Freiheit bleibt. Die Wahrheit liegt in der Mitte. Die Mehrheitsentscheidung bringt unter bestimmten Voraussetzungen, nicht unbedingt, aber unter der Voraussetzung einer freien Diskussion, die relativ beste Chance der Verwirklichung der Vernünftigkeit oder Gerechtigkeit oder wie man vielleicht ruhig sagen sollte, des Naturrechts, mit sich. Der Gedanke ist ungefähr der: Wenn einer vor Gericht ungerecht verurteilt wird und er hat eine zweite oder dritte Instanz, dann ist die Wahrscheinlichkeit, daß sich die Wahrheit durchsetzen wird, etwas größer, als wenn es nur eine Instanz gäbe. Und wenn sich die Entscheidung im Einklang hält mit der ständigen Rechtsprechung, und wenn dieser Rechtsprechung in der öffentlichen Diskussion und speziell auch in der Diskussion der Rechtswissenschaft vorgearbeitet worden ist, und wenn ihr Gesetze zugrundeliegen, die der demokratische Gesetzgeber gebilligt hat, dann ist zwar immer noch keine Gewähr dafür gegeben, daß sie vernünftig ist, aber die Wahrscheinlichkeit ist größer. Wenn man das nicht annimmt, Herr Roellecke oder Herr Walter, dann würde ich fragen, warum argumentieren 
Sie als Rechtsdogmatiker? Doch weil Sie uneingestandenermaßen selbst davon ausgehen, daß Ihre Argumente eine innere Uberzeugungskraft haben, daß sie uns der Vernünftigkeit näherführen, daß sie uns Einsichten vermitteln. Wenn Sie diese Voraussetzungen nicht im Grunde selbst machten, dann wären Sie Naturwissenschaftler geworden und würden nicht in der "jurisprudentia“ mitwirken.

Der Gedanke der parlamentarischen Demokratie beruht auf einer Naturrechtstradition, die sich orientierte an Erfahrungen z. B. mit Humanisierung des Strafrechts und des Strafvollzuges, mit Beschränkung der Todesstrafe auf Kapitalverbrechen, Abschaffung der Folter usw. Im Anfang des 17. Jahrhunderts haben Leute wie Graf Spee oder Coke einen verzweifelten Kampf geführt, es hat an die zweihundert Jahre gebraucht, dann haben ihre Gedanken sich durchgesetzt. Solche Erfahrungen stehen dahinter, wenn man von "rechtlichem Fortschritt" sprach. Man nahm an, daß dieser rechtliche Fortschritt eine desto größere Chance hat, je größer die Freiheit des öffentlichen Plädierens ist. Wenn man argumentiert, dann mit der Absicht und dem Ziel, der Vernunft relativ näher zu kommen. Die parlamentarische Demokratie hat in erster Linie den Sinn, die Chancen der Vernunftverwirklichung zu vergrößern. Wenn man nicht mehr annimmt, daß es wenigstens tendenziell die rechtliche Verwirklichung von Wahrheit, Vernunft, Gerechtigkeit, Naturrecht geben könne, dann natürlich muß man demokratischen Institutionen, wie z. B. dem Mehrheitsprinzip, einen neuen Sinn unterlegen. Das führt dann aber zu keinen Erklärungsmöglichkeiten, die alles miterklären, was sonst noch zur parlamentarischen Demokratie gehört, wie Freiheit, Gewaltenteilung und alles, was Herr Schneider angesprochen hat, also die Verknüpfung von liberaler Rechtsstaatlichkeit mit Demokratie.

Münch: Die Referenten sind davon ausgegangen, daß im Grundgesetz nicht eine beliebige Demokratie, sondern eine ganz bestimmt geprägte Demokratie westlicher Auffassung zum Ausdruck gekommen ist. Man erinnere sich, welche Propaganda aus dem angelsächsischen Bereich für die Demokratie gekommen ist. Sie meinte eigentlich nichts anderes als den Rechtsstaat. Dort wird unter Demokratie sehr viel Rechtsstaat verstanden, und ich bin mit Herrn Leibholz der Meinung, daß das in den Referaten nicht genügend zum Ausdruck gekommen ist, obwohl es wichtig ist.

Demokratie als Organisationsprinzip ist nur ein Mittel, eines der Mittel, mit denen man einen Staat organisieren kann. Wir 
wissen auch, daß sich als solches die Demokratie nicht überall empfiehlt; im Balkan, in Südeuropa, in Lateinamerika, in den neuen Staaten hat sie sich nicht bewährt, es gehört also mehr dazu. In den alliierten Deutschlandplänen von 1944/45 ist Demokratie ein reiner Formel-Kompromiß.

Das rechtsstaatliche Element braucht man nicht in der Demokratie zu finden; es gibt rechtsstaatliche Elemente - darüber ist neuerdings geschrieben worden - auch im aufgeklärten Absolutismus und natürlich auch in den Europäischen Gemeinschaften.

Wie definieren wir unabhängig von unserer Verfassung die Demokratie? Ich würde vorschlagen: der Volkswille soll überall maßgebend sein; möglichst viele sollen an der Bildung des Volkswillens teilnehmen; der Volkswille wird nach dem Mehrheitsprinzip ermittelt. Demokratisierung der Gesellschaft wenn man sie ernst nimmt -, würde bedeuten, daß in jedem Lebensbereich, in dem wir stehen, der Wille einer Mehrheit bestimmend ist, da $B$ sich jeder einzelne nach dem Willen der Mehrheit fügen soll. Das ist, wie Herr Leibholz ganz richtig sagt, das Ende der Freiheit, denn dann wird jeder Andersfühlende, -denkende und -handelnde niedergewalzt und getötet.

Die Verbindung von Demokratie und Rechtsstaat ist problematisch, weil der demokratische Wille sich an den rechtsstaatlichen Schranken stößt. Die radikalen Demokraten erheben dann den Vorwurf, daß im Verfassungssystem Voraussetzungen stecken, die heute dem Willen der Mehrheit nicht mehr entsprechen. Dieser Widerstreit läßt sich nicht ganz auflösen. Ich halte es nicht für einen Vorwurf, daß in einer Verfassung Werte garantiert sind, Es gibt Werte, die so persönlichkeitsformend sind, daß derjenige, der sie angreift, zum Todfeind wird. Solche Vorurteile, meinetwegen auch Tabus, beseitigen zu wollen, ist naiv und beschwört die ernstesten Konflikte herauf.

Es ist kein Vorwurf gegen unser Verfassungs- und Staatssystem, daß Entscheidungen ohne eine direkt demokratische Prozedur gefällt werden. Das ganze demokratische Prinzip wird neuerdings durch das technokratische angefochten; man muß sehen, daß die ausgesprochen a-demokratischen Europäischen Gemeinschaften durchaus funktionieren. Insofern möchte ich Herrn von Simsons These 27 zustimmen. Sie mildert sich dadurch, daß, vermöge der allgemeinen Staatsaufsicht und der parlamentarischen Verantwortlichkeit in einer obersten Instanz die Demokratie kontrolliert wird - allerdings muß sie sich dann die Organe und Prozeduren schaffen, die solche Kontrolle sachgerecht leisten. 
Rudolf: Nur noch eine Bemerkung zur Mehrheitsentscheidung: Die Entscheidung der Minderheit ist nicht die einzige Alternative zur Mehrheitsentscheidung. Es gibt noch die Einstimmigkeit. Das Einmütigkeitsprinzip klingt zwar für das innerstaatliche Recht sehr utopisch, doch versuchen einige ostasiatische Staaten, es zu praktizieren. Grundsätzlich wird dort eine Angelegenheit so lange diskutiert, bis man eine Einigung erzielt hat. Der Streit um das japanische Hochschulgesetz von 1969 hat sich deshalb in erster Linie daran entzündet, daß man das Gefühl hatte, das Gesetz sei im Parlament nicht genügend diskutiert worden. Der Nachteil des Unanimitätsprinzips liegt auf der Hand: Die Gesetzgebung wird ineffizient.

Doehring: Ich möchte nur einen kurzen Moment meinem Unbehagen Ausdruck geben, daß hier über die Demokratie schlechthin diskutiert wird. Das alles ist historisch und rechtsphilosophisch außerordentlich interessant. Ich habe aber Schwierigkeiten über Demokratie konkret zu diskutieren, wenn es sich nicht um Demokratie nach Maßgabe einer bestimmten Verfassung handelt. Was Herr Leibholz gerade gesagt hat, hat mich daher angeregt, diesen Gedanken noch einmal $\mathrm{zu}$ betonen. $\mathrm{Er}$ fragt, ist Demokratie frei, sich selbst zu vernichten? Ich würde sagen, nach Maßgabe der einen Verfassung ja, nach Maßgabe der anderen Verfassung nein. Ich glaube, daß es eine allgemeingültige Antwort darauf nicht gibt. Deswegen meine ich auch, wenn man über unsere Demokratie spricht, sind es jetzt die Grenzen, die der Mehrheitsentscheidung und dem rechtserzeugenden System gesetzt sind, die uns konkret interessieren müssen. Wenn wir dann hier prüfen, welches Staatsverhalten zulässig ist, dann sind die Grenzen vom Grundgesetz mitgegeben. Daher meine Frage an die beiden Referenten: haben Sie nicht vielleicht etwas wenig Wert darauf gelegt, diese Grenzen zu zeigen? Sie haben das System beschrieben, aber diese Grenzen kamen mir etwas zu kurz. Um zur Frage von Herrn Leibholz zurückzukehren: unsere Verfassung jedenfalls kann unsere Demokratie nicht legal vernichten, aber unsere Verfassung kann auch nicht über fremde Rechtsordnungen, etwa diejenige der DDR, etwas aussagen. Diese ist nach ihren eigenen Maßstäben zu beurteilen.

E. Küchenhoff: „Ich möchte zunächst einige Thesen beider Referate zur Meinungs- und Willensbildung aufgreifen. Herr von Simson hat in Satz 2 seiner These 29 ausgeführt: „Der Wähler kann die Staatsführung im ganzen ersetzen, aber kaum noch im einzelnen beeinflussen." In These 36 hat er anscheinend zur Korrektur dieses Befundes „neue Formen der Partizipation 
und Kontrolle" gefordert, „wenn Demokratie und Freiheit sich retten sollen" und zu These 35 hat er $u$. a. die Forderung nach Presse- und Informationsvielfalt befürwortet. Ich möchte in diesem Zusammenhang darauf hinweisen, daß gerade durch die Massenmedien schon heute auch während der Legislaturperiode fortwährend auf die laufende Politik eingewirkt wird. Diese Mitwirkung hat Herr Kriele in These 8 zutreffend beschrieben. Er hat auch ausdrücklich gesagt, daß diese Mitwirkung an der Meinungsbildung nicht nur der Vorbereitung der Wahlen dient, sondern daß laufend auf die Politik Einfluß ausgeübt wird.

Dieser Einfluß ist genau wie der Einfluß der Wähler inhaltlich von dem Informationsstand der Bürger bestimmt. Der Informationsstand der Bürger hängt von dem Informationsverhalten der Massenmedien ab. Hier ist das Feld, in dem auch wir uns viel intensiver als bisher mit neuen Formen der Partizipation und der Kontrolle beschäftigen müssen. Nicht allein die Pressekonzentration, sondern vor allem die Verfälschung und Unterdrückung von Nachrichten sind eine große Gefahr für eine repräsentativ-demokratische Meinungsbildung. Die optimale Sanktion, nach der wir zu suchen haben, kann ganz sicher nicht im Strafrecht liegen, dessen Wirkungsmöglichkeiten auch hier begrenzt sind und dessen Abbau wir nicht entgegenfordern können. Die Ausnahme solcher Schreiberei, die Ausnahme von Nachrichtenverfälschung, Nachrichtenunterdrückung und auch Aufhetzung vom Pressebegriff im Grundrecht der Pressefreiheit, wie ich sie seit langem vertrete, reicht mir selbst nicht aus. Die Einführung einer öffentlichen Rüge der Verletzung publizistischer Wahrheitspflichten durch Landespressekommissionen, wie sie gegenüber nationalen und regionalen Monopolen im Gesetzentwurf von Peter Glotz gefordert wird, stößt noch auf die Schwierigkeit, daß sich für Nachrichtenverfälschung und Nachrichtenunterdrückung kaum ein abstraktallgemeiner Tatbestand wird formulieren lassen, der den Anforderungen rechtsstaatlicher Tatbestandsbestimmtheit entspricht. Doch dürfen wir vor diesen Schwierigkeiten nicht kapitulieren. Wenn wir nicht ein geordnetes Verfahren zur Behebung der offenkundigen Mißstände finden helfen, die sich insbesondere mit dem Namen Axel Springer verbinden, dann dürfen wir uns nicht wundern, wenn wir immer wieder mit ungeordneten Verhaltensweisen konfrontiert werden, die dann über Partizipation an der demokratischen Meinungs- und Willensbildung vielfältig hinausgehen. Jedenfalls ist die Wissenschaft vom Verfassungsrecht als auch Wissenschaft von einer repräsentativ-demokratischen Meinungs- und Willensbildung dazu aufgefordert, in wissenschaftlich-interpretativer Form im- 
mer wieder die gegenwärtigen Mißstände als Verstöße gegen das repräsentativ-demokratische Modell zu kritisieren.

Zum zweiten hatte ich mich zu Herrn Krieles Thesen über Parteienstaat und Mandatsverlust $\mathrm{zu}$ Wort gemeldet. Herr Kriele ist in seinen Thesen 10 und $11 \mathrm{sehr}$ zutreffend von einer stark parteienstaatlichen Bindung des parlamentarischen Mandats ausgegangen. Ich stimme ihm auch zu, wenn er sagt, daß nicht nur die Listen- sondern auch die Wahlkreiskandidaten in erster Linie als Kandidaten ihrer Parteien gewählt und daher den Wahlaussagen ihrer Parteien verpflichtet sind. Mir geht es aber zu weit, wenn Herr Kriele in These 11 Sätze 2 und 3 schlechthin sagt: „Parteiwechsel des Abgeordneten ist zu respektieren; aber der Abgeordnete verhält sich demokratisch, wenn er die Wahlentscheidung durch Mandatsniederlegung respektiert. Gesetzliche Einführung von Mandatsverlust bei Parteiwechsel würde Art. 38 I nicht verletzen." Erst recht ginge mir eine Streichung von Art. 38 I 2 aus dem Grundgesetz zu weit, wie sie kürzlich von Herrn Leibholz befürwortet worden ist. Eine solche generelle Regelung würde neben anderem den Fall übersehen, in dem nicht der Abgeordnete sondern die Partei von ihren Wahlaussagen abweicht, in denen der Abgeordnete aber aus Gewissensgründen bei seinen und seiner Partei Wahlaussagen bleibt und nach sorgfältigem Abwägen zu dem Ergebnis kommt, daß er seinen Wahlaussagen und damit seiner Mandats-Legitimation durch die Wahl nunmehr nur noch durch einen Parteiwechsel nachkommen kann.

Einen solchen langen Abwägungsproze $B$ habe ich im Falle des Münsteraner Bundestagsabgeordneten Peter Nellen aus unmittelbarer Nähe miterlebt. Und ich glaube, daß es so etwas auch bei anderen Ubertritten gegeben hat und weiter geben kann, auch zwischen anderen Parteien. Deshalb kann es kein totales und undifferenziertes Abgehen vom Prinzip des Art. 38 I 2 in seinem bisherigen Verständnis geben. Wenn der Abgeordnete, nicht aber die Partei seiner Vermittlungsfunktion für den Wähler treu bleibt, die Abgeordneter und Partei in der repräsentativen Demokratie haben, dann muß der Abgeordnete gerade nach dem Prinzip der parlamentarischen Demokratie sein Mandat behalten dürfen.

Geck: Ich möchte wie Herr Küchenhoff an den Leitsatz Nr. 29 von Herrn $v$. Simson anknüpfen. Bedenken habe ich bei der Formulierung: „Der Wähler kann die Staatsführung im ganzen ersetzen, aber kaum noch im einzelnen beeinflussen."

Die Annahme, daß den Wählern nur noch diese Pauschalmöglichkeit zur Verfügung steht, um politische Entscheidungen zu 
beeinflussen, erscheint mir als eine nach dem Grundgesetz und der politischen Wirklichkeit nicht gerechtfertigte Resignation, als eine Verengung unserer demokratischen Möglichkeiten. Ich möchte das an Hand von zwei Beispielen erläutern.

Nehmen Sie eine Partei, die unter bestimmten Vorstellungen angetreten ist, und bei der die Parteiführung und ein Teil der Bundestags- und Landtagsabgeordneten eine Richtung einschlagen, die sich von einem erheblichen Teil des Partei-Fußvolks und der Wähler dieser Partei entfernt. Derartige Wandlungen zeichnen sich in der politischen Diskussion in der Bundesrepublik mehr oder minder schnell ab. Sie bleiben nicht folgenlos, sondern führen zu Auseinandersetzungen in der Partei und in der Offentlichkeit. Sie haben in unserem föderalen System Folgen in Gemeinde- oder Landtagswahlen, vielleicht auch bei den Wahlen zum Bundestag. Dabei ist es nicht so, daß es nur ein Ergebnis, nämlich eine Entscheidung über das Sein oder Nichtsein dieser Partei bei der nächsten Wahl gibt. Es ist durchaus möglich, daß die Reaktionen lokaler Parteiorganisationen, vor allem aber größerer Wählerkreise, bei der Parteiführung, bei Abgeordneten und Ministern zu einer Korrektur des neuen Kurses führen und damit zu einer Beeinflussung von Parlament und Exekutive. Gerade das föderale System mit unterschiedlichen Wahlterminen und den Warnzeichen von Wahlen bietet hier manche Möglichkeiten. Die Beispiele aus der Gegenwart und der jüngeren Vergangenheit sind jedem Anwesenden bekannt.

Gestatten Sie mir noch ein Beispiel aus einem anderen Bereich, nämlich aus der Rechtsprechung. Sie ist an Gesetz und Recht gebunden und steht dennoch in manchen Bereichen in einer ständigen Beziehung zu politischen Vorgängen. Die Judikatur des Bundesverfassungsgerichts hat, wie wir alle wissen, die Entwicklung zu einem echten Demokratieverständnis in der Bundesrepublik, nicht zuletzt in der öffentlichen Meinung, gefördert. Es gibt Entscheidungen des Bundesverfassungsgerichts, die als Wegbereiter des freiheitlichen Rechtsstaates und der Demokratie der öffentlichen Meinung um Jahre vorausgingen. Wir haben aber auch hier eine Wechselwirkung von der öffentlichen Meinung auf das Gericht, von den Bürgern als Leserbriefschreibern, Zeitungsredakteuren, Fernsehkommentatoren, Richtern an unteren Gerichten, wissenschaftlichen Kritikern und - last not least - als Wählern. Lassen Sie mich als Beispiel aus einer nicht so "hautnahen" Umgebung zwei Formulierungen über die Rechtsprechung des amerikanischen Supreme Court verwenden. Die eine lautet: Wir leben unter einer Ver- 
fassung, aber was die Verfassung ist, entscheidet der Supreme Court. Die andere - hier interessantere - stammt von einem Satiriker und heißt: Der Supreme Court folgt den Wahlergebnissen. In den USA dürfte - auf lange Sicht betrachtet - die Wahrheit irgendwo in der Mitte liegen.

Wie steht es bei uns? Wir alle wissen, daß die sozialen, wirtschaftlichen und politischen Verhältnisse, aber auch die entsprechenden Vorstellungen der Umwelt - kurz gesagt der Zeitgeist - auf die Rechtsauslegung der Gerichte im allgemeinen einwirken und auch auf die Verfassungsinterpretation des unabhängigen höchsten Gerichtes der Bundesrepublik. Das Bundesverfassungsgericht kann der öffentlichen Meinung vorausgehen, es kann hinter ihr zurückbleiben, es kann sie aber nicht ignorieren. Die Möglichkeiten der Bürger zur indirekten Beeinflußung selbst der unabhängigen Rechtsprechung, die jedenfalls in ihrer Spitze z. T. der Staatsführung zuzurechnen ist, erscheinen mir also ebenfalls mannigfacher, als es Leitsatz 29 ausdrückt.

Herzog: Herr von Simson hat sich ausdrücklich dazu bekannt, daß die alte theoretische Unterscheidung zwischen Staat und Gesellschaft aufrecht erhalten wird. Ich stimme mit ihm in diesem Punkt überein, muß aber folgendes zu bedenken geben: "Staat" im ursprünglichen Sinne dieser Unterscheidung war der Monarch und der von ihm gelenkte bürokratische und militärische Apparat, während wir heute auch das Volk als Basis der Staatsgewalt unter diesen Begriff rechnen - und Gesellschaft im ursprünglichen Sinne war das Bürgertum, während wir heute auch diesen Begriff mit dem Volk gleichsetzen. Wenn ich recht sehe, lassen sich Staat und Gesellschaft heute daher nur noch insoweit unterscheiden, als es sich bei beiden um Willensbildungssysteme unter unterschiedlichen Verfahrensprinzipien handelt: auf der einen Seite Majorität und Amt, auf der anderen Seite die ungleich unkonventionelleren Formen der Willensbildung des gesellschaftlichen Lebens. Daher nun meine Frage an Herrn von Simson, für deren Beantwortung im Schlußwort ich dankbar wäre: Haben Sie Vorstellungen darüber, welche Art von „Kompetenzverteilung“ zwischen diesen beiden Modellen der Willensbildung heute besteht oder rechtspolitisch angebracht ist? Ich muß hier insbesondere darauf hinweisen, daß es zu eng ist, wenn die gesellschaftliche Willensbildung, von der ich eben gesprochen habe, immer nur vom Modell der Tarifautonomie der beiden Sozialpartner her gesehen wird. Schon dort tritt ja die Frage auf, wie es sich mit der Repräsentation und andererseits mit dem Schutz von Außensei- 
tern vor illegitimer Repräsentation verhält; Herbert Krüger hält z. B. eine solche Repräsentation von Außenseitern ohne weiteres für möglich, während ich für meinen Teil sie unter keinen Umständen akzeptieren würde. Halten wir uns aber vor Augen, daß es noch ganz andere gesellschaftliche Normen- und Herrschaftssysteme gibt, so erhält die Frage, inwieweit der Staat durch eine Art „Kompetenzverteilung“ zwischen Staat und Gesellschaft aus diesen Bereichen verbannt ist, vollends vitale Bedeutung. Es scheint mir zu wenig zu sein, wenn man sich zu der Unterscheidung zwischen Staat und Gesellschaft bekennt, ohne darüber in Ansätzen Auskunft zu geben.

Maurer: Nachdem in der Diskussion mehrmals die Grenzen der demokratischen Freiheiten angesprochen wurden, erlauben Sie mir, noch einmal kurz darauf einzugehen, obwohl sie in den Referaten selbst nicht direkt erörtert worden sind. In der Bundesrepublik sind diese Grenzen durch Art. 18, 9 II und 21 II GG bestimmt und geschützt, und damit scheint das Problem geklärt zu sein. Indessen haben diese Artikel ihre Bewährungsprobe noch nicht bestanden; es ist auch zweifelhaft, ob sie sie im Ernstfall bestehen werden. Der Zerfall der Weimarer Republik und die Entwicklung zum Jahre 1933 wären wohl auch durch solche Normen kaum aufgehalten worden.

Das Risiko, das in jeder Freiheit liegt, läßt sich nicht beseitigen. Wenn man mit staatlichem Zwang die demokratische Freiheit zu erhalten versucht, hat man sie schon bis zu einem gewissen Grad aufgegeben. Die freiheitliche demokratische Ordnung beruht auf der Utberzeugung oder auf dem Glauben, daß sie sich selbst erhalten werde. Sie kann nur dann bestehen, wenn sich die überwiegende Mehrheit der Bürger freiwillig zu ihr bekennt und für sie einsteht. Damit soll der Wert von Normen i. S. der Art. 18, 9 II und 21 II GG nicht unterschätzt werden; nur darf man nicht in ihnen die sicheren Garanten der freiheitlichen demokratischen Grundordnung sehen.

Es ist die Frage gestellt worden, wie es zu beurteilen sei, wenn sich in der DDR oder in anderen Ostblockstaaten die Mehrheit des Volkes gegen die Freiheit aussprechen sollte. Diese Frage wirft eine Vorfrage auf, nämlich die, ob in Wirklichkeit die Voraussetzungen für eine echte und freie demokratische Entscheidung gegeben sind. $\mathrm{Zu}$ diesen Voraussetzungen gehört vor allem auch, daß sich eine Opposition bilden und als Alternative anbieten kann, daß also das Volk zwischen der einen oder der anderen Möglichkeit wählen kann. Das ist derzeit in den Ostblockstaaten (noch) nicht der Fall. Wo aber mangels politisch-realer Alternative nur die Akklamation für das 
Bestehende bleibt (Slogan des Systems: "Wir oder das Chaos"), gibt es keine freie demokratische Entscheidung.

Kriele: Ich meine weder, daß die gesetzliche Einführung des Mandatsverlustes bei Parteiwechsel verfassungsrechtlich geboten, noch daß sie politisch erwünscht, wohl aber, daß sie zulässig wäre. Durch sie würde der Abgeordnete weder in seiner Gewissensentscheidung vergewaltigt, noch an die Partei gebunden. Wo ein Abgeordneter die Partei aus wirklichen Gewissensgründen wechselt - wie seiner Zeit der Abgeordnete Nellen - wird er das auch dann tun, wenn er für den Rest der Legislaturperiode auf sein Mandat verzichten muß. Es gibt aber Beispiele dafür, daß Abgeordnete sowohl die Partei als auch die Wählerschaft betrügen, indem sie für eine Partei und eine Wahlplattform kandidieren, zu denen sie innerlich gar nicht stehen, und sich dann, wenn sie gewählt sind, nach einem geeigneten Vorwand zum Parteiwechsel umsehen. Dem liegt eine Verwechslung von Mandat und Pfründe und eine Verachtung der demokratischen Funktion der Wahl zugrunde. Sollen wir dagegen wirklich wehrlos sein? Das scheint mir ein Mißverständnis von Sinn- und Wortlaut des Art. 38 I zu sein.

Ferner: der im Volk lebendige Sinn für demokratische fairness reagiert auf solchen Mandatsmißbrauch so empfindlich, $\mathrm{da} \beta$ es berechtigt erscheint, von einer Konventionalregel zu sprechen, die den Mandatsverzicht bei Parteiwechsel fordert. Diese Konventionalregel macht eine gesetzliche Regelung überflüssig, wenn sie resprektiert wird. $\mathrm{DaB}$ wir heute die Namen von gewissen Parteiwechslern nicht mit dem Wort "Gewissen" in einem Satz verbinden können, ohne einen Lacherfolg zu erzielen, ist für das Ansehen des Parlamentarismus fatal. Deshalb beruht der legalistische Einwand: eine Regel, die sich rechtlich zur Zeit nicht durchsetzen lasse, brauche nicht respektiert zu werden, nicht auf einem Verständnis für die Funktionsbedingungen des demokratischen Verfassungsstaates. Dieser ist auf die Respektierung der Konventionalregeln angewiesen.

Zacher: Ich glaube, wir sollten das Problem des Mandatsverlustes nach Möglichkeit jetzt ausklammern. Es ist ja nicht nur schon viel darüber gesprochen worden, sondern auch Tinte, auch höchstrichterliche Tinte darüber geflossen.

Kaiser: In beiden Referaten finde ich eine Akzentverschiebung von einer vorwiegend institutionellen Betrachtungsweise zu einer mehr den demokratischen Prozessen zugewandten Demokratietheorie. Herr von Simson spricht vom „Prozeß der Herstellung von Eindeutigkeit" und Herr Kriele sagt, die Ubertragung des Gedankens des richterlichen Prozesses hätte hier 
historisch eine Rolle gespielt. Dabei frage ich mich, ob für unsere gegenwärtige Lage nicht noch eine andere Art von Prozeß das Verfahren der demokratischen Willensbildung zunehmend prägt, nämlich Beispiel und Modelle industrieller Entscheidungsprozesse. Und in den betriebswirtschaftlichen Entscheidungstheorien - vor allem amerikanischer Provenienz feiert der Entscheidungsbegriff Triumphe wie das zuvor kein staatsrechtlicher Dezisionismus zustande gebracht hat.

Von so aktuellen Moden und Modellen mit Recht beeindruckt, hat das Bundeskanzleramt sich einer Verjüngungskur unterworfen, die, wie man hört, von Herrn Ehmke auf drei Jahre bemessen ist. Dazu hat es sich so strapaziöse Kurmittel verschreiben lassen wie operations research, Kybernetik und Systemtheorie. Hier wird also aus dem industriellen Entscheidungsverfahren alles mögliche an Managementvorstellungen in den demokratischen Entscheidungsproze $\beta$ übertragen, und wenn Herr Ehmke hier wäre, würde ich ihn gern fragen, was er mit dem Bundestag vorhat: Weniger danach, wer an der geplanten Datenbank Zugriffsrechte erhält, sondern vor allem wer über die zu speichernden Daten entscheidet.

Darf ich noch nach zwei Details des demokratischen Entscheidungsprozesses fragen? Das eine ist die Autonomie der Sozialpartner. Sie ist aus dem demokratischen Prozeß allein nur schwer zu rechtfertigen. Dabei wird durch die Entscheidungen der Sozialpartner überaus viel für uns alle mitbestimmt: in der konzertierten Aktion z. B. und vor allem durch die Ausübung ihrer Tarifhoheit. Meine Frage an beide Herren: Was ist Ihrer Auffassung nach das demokratische Leitbild, aus dem sich die demokratisch gebotene Einbindung der Sozialpartner in den demokratischen Proze $\beta$ normieren läßt?

Das zweite Detail ist das Erfordernis eines unverfälschten Informationsflusses. Herrn Walter danken wir die wichtige Ergänzung, daß sich dieses Postulat auch gegen ein öffentliches Monopol unter den Medien, nämlich gegen die öffentlichen Rundfunkanstalten wenden kann; aus den Erfahrungen mit dem Rundfunk-Volksbegehren in Österreich ergibt sich eindeutig und eindrucksvoll, wie wenig sich die Parteipolitisierung öffentlicher Medien verträgt mit der Funktion der Medien im Prozeß der demokratischen Meinungs- und Willensbildung.

Die Risiken, die sich aus der wirtschaftlichen Verfügungsmacht über Information ergeben können, würde ich, wohl im Unterschied von Herrn Kriele, dann hoch einschätzen, wenn Information knapp wäre. Nicht geringer erscheint mir in der Demokratie jedoch das Problem des oft beschriebenen, gewal- 
tigen Uberflusses an Information zu sein, dessen sich der einzelne Staatsbürger gar nicht mehr bedient und den er wohl auch gar nicht angemessen nutzen kann. - Schwer wiegt, daß Herr Küchenhoff den Massenmedien oder einigen unter ihnen Verfälschung und Unterdrückung von Meinungen vorwirft. Das bedarf natürlich empirischer Nachweise, und das dürfte in hohem Maße interessant werden.

Gern stimme ich der These von Herrn Kriele zu, daß im Bereich der öffentlichen Medien vom Markt eine optimale Selbstregulierung nicht mehr zu erwarten ist, wie übrigens in anderen Bereichen auch nicht, man denke nur an Kohle und Stahl. Das Gesetz gegen Wettbewerbsbeschränkungen ist das System der notwendigen Marktkorrektive.

Püttner: Ich möchte gerne zu den Aspekten, die die Referenten bei dem Begriff der Demokratie hervorgehoben haben, einen weiteren hinzufügen. Im Grundgesetz ist die Demokratie meiner Ansicht nach nicht nur als eine zentrale Demokratie angelegt, sondern stufenförmig aufgefächert und so verstanden, $\mathrm{da} B$ sie in einer gewissen Breite praktiziert werden soll, Breite nicht nur bei den Sozialpartnern, nicht nur in der öffentlichen Diskussion und in der innerparteilichen Demokratie, sondern vor allen Dingen auch in der Weise, daß es Volksvertretungen in den Ländern und auch in Kreisen und Gemeinden (nach Art. 28 Abs. 1 S. 2 GG) geben soll. So stehen im aktiven politischen ProzeB nicht nur die wenigen hundert Abgeordneten, sondern über hunderttausend Mandatsträger insgesamt. Ich halte dies für einen Unterschied, den man sehen muß, und ich meine, daß ein ganz wichtiges Wesensmerkmal der Demokratie unseres Staates in der dadurch bedingten Breite des demokratischen Prozesses liegt, zumal noch andere Elemente wie die funktionale Selbstverwaltung das System ergänzen. In dem Bereich der örtlichen und regionalen Demokratie finden wir im Augenblick gerade nicht den viel zitierten zunehmenden Demokratisierungsprozeß, vielmehr beobachte ich im Rahmen der kommunalen Gebietszusammenlegung eher das Gegenteil, nämlich daß die Mandatsträger zahlenmäßig verringert werden und damit die unmittelbaren Einflußmöglichkeiten, die oft noch gegeben waren, schrumpfen. Wenn man die Breite als ein Wesenselement der Demokratie ansieht, wird man darin einen bedenklichen Prozeß sehen müssen. Jedenfalls gehört diese Problematik unbedingt mit zum Bild der Demokratie.

Kopp: Ich möchte zurückkommen auf These 30 von Herrn v. Simson, wonach das mangelnde Demokratiebewußtsein die Wirksamkeit des demokratischen Prinzips beeinträchtigt. Ich 
glaube, daß gerade hier heute eines der Hauptprobleme der modernen Demokratie liegt, daß es nämlich bisher noch nicht in ausreichendem Maße gelungen ist, das Volk anzusprechen. Wie die Erfahrung bei uns, in der eigenen Geschichte, und vor allem auch in den Entwicklungsländern zeigt, kann eine Demokratie nur dort Erfolg haben, wo sie auch von einem weite Kreise erfassenden demokratischen Bewußtsein getragen wird. Gerade daran aber fehlt es bei uns und auch in manchen anderen Ländern heute noch zum Teil. Demokratie ist mehr als eine Summe von Spielregeln formeller Art. Sie setzt immer zugleich ein Mindestmaß an Bereitschaft voraus, sich für die Gemeinschaft einzusetzen, mit der Gemeinschaft zu denken, sich für das öffentliche Geschehen mit verantwortlich zu fühlen und aktiv an der Gestaltung dieses Geschehens mitzuwirken. Wo dieses Empfinden und diese Bereitschaft fehlen, besteht die Demokratie weitgehend nur der Form nach; sie stellt dann nur einen Mechanismus dar, mit dessen Hilfe Interessen ausgetragen werden, die mehr oder weniger partikuläre Interessen einzelner oder von Gruppen sind. Es fehlt aber an der gemeinsamen Grundlage und der Klammer, die das Ganze zusammenhält, und der Staat droht zum Spielball einiger weniger zu werden, die nur noch einer wenig wirksamen Kontrolle durch die öffentliche Meinung und durch die Erfordernisse periodischer Wahlen unterworfen sind.

Dies aber wirft notwendig die weitere Frage auf, die auch in den Thesen von Herrn von Simson, vor allem in These 36 bereits angeschnitten wurde, nämlich was getan werden muß, um die moderne Demokratie wirksamer zu gestalten. Wegen der begrenzten Zeit möchte ich hier nur auf einige Punkte hinweisen, die bisher noch nicht zur Sprache kamen. Außer einer gewissen Dezentralisierung der Staatstätigkeit, die die Entscheidungsprozesse noch näher an die betroffenen Bürger heranführt und ihnen die Möglichkeit gibt, die Dinge mehr aus der Nähe zu sehen und an ihrer Gestaltung und Ordnung mitzuwirken, sollte man meines Erachtens auch die Funktion eines modernen, rechtsstaatlich geordneten Verwaltungsverfahrens in diesem Zusammenhang nicht vergessen. Ich glaube, daß der demokratische Prozeß der Normsetzung notwendig einer Ergänzung bedarf im Bereich des Normenvollzugs. Auch hier darf die Demokratie nicht Halt machen. Auch der Vollzug der Gesetze kann in der Demokratie nicht mehr als einseitiger Vorgang verstanden werden, sondern bedarf zu einem gewissen Grad auch der aktiven Mitwirkung der betroffenen Bürger. Verwaltung und Bürger müssen sich auch beim Vollzug der Gesetze zusammentun und sich auf der Basis des geltenden Rechts ge- 
meinsam bemühen, auch im Einzelfall sachgerechte Lösungen zu finden. Dazu gehört insbesondere, da $B$ Lösungen nicht ohne vorherige Anhörung des Bürgers diesem von oben aufoktroyiert werden, sondern daß der Bürger im Rahmen eines geeigneten Verfahrens auch in seiner Verantwortung für das Ganze angesprochen wird und Gelegenheit erhält, an der Entscheidungsfindung mitzuwirken. Dazu gehört weiter aber auch, daß der Entscheidungsproze $\beta$ der Exekutive insgesamt transparenter gestaltet werden muß, für die unmittelbar Betroffenen wie auch für die breitere Offentlichkeit, damit eine Kontrolle der Verwaltung durch die Offentlichkeit, wie es dem Gedanken der Demokratie entspricht, möglich wird. In der Demokratie muß sich die Verwaltung gerade auch in ihrem Verhalten und durch dieses der Offentlichkeit gegenüber legitimieren. Das aber bedeutet unter anderem auch, daB die Entscheidungen der Verwaltung mit Gründen versehen sein müssen, wo sie nicht selbstverständlich sind. Nicht zuletzt spielt dabei aber auch die Akteneinsicht eine erhebliche Rolle. Ich darf vielleicht in diesem Zusammenhang an das Beispiel Schwedens erinnern, wo die allgemeine Aktenöffentlichkeit sowohl als eine Voraussetzung der Demokratie als auch gleichzeitig als eine wesentliche Folge davon angesehen wird.

H. Klein: Meine Herren! Ich möchte zwei spezielle Aspekte unseres vielschichtigen Themas, die hier angedeutet worden sind, ansprechen; ich kann sie natürlich nicht in ihren vielfältigen Verästelungen darstellen, aber vielleicht doch in einigen Beziehungen verdeutlichen.

Zunächst ist es das Verhältnis von Demokratie und Rechtsstaatlichkeit, das mich immer wieder beschäftigt. Herr von Simson hat ja die Rechtsstaatlichkeit als eine Vorgegebenheit jedes aktuellen politischen Wollens bezeichnet und hat damit wohl das gemeint, was uns auf den ersten Blick unproblematisch erscheint, daß nämlich die rechtsstaatlichen Elemente der Verfassung dazu bestimmt sind, der Ausübung der demokratisch legitimierten Staatsgewalt Schranken zu setzen. Aber dieses Selbstverständliche ist, wie sich bei näherem Zusehen zeigt, längst nicht mehr selbstverständlich. Vielmehr ist - vielfach unter Berufung auf die sogenannte Einheit der Verfassung oder auch die Notwendigkeit einer harmonisierenden Auslegung eine Art demokratischer Uberwältigung der rechtsstaatlichen Freiheit im Gange - eine Formulierung, die bekanntlich von Herrn Forsthoff stammt. Beispiele dafür sind Rechtsprechung und Schrifttum, insbesondere zur Auslegung der Meinungsund Versammlungsfreiheit, in hinreichender Zahl zu entneh- 
men. Im Hinblick auf die hier wohl von niemandem bestrittene eminente Bedeutung dieser Grundrechte für das Funktionieren der Demokratie werden - ich gebe nur einige Beispiele Beiträge zur Bildung der öffentlichen Meinung, Äußerungen und auch Demonstrationen in Angelegenheiten von öffentlichem Interesse vor solchen mit anderen Zielen und aus anderen Motiven privilegiert, die nach Art. 5 Abs. 1 GG gleichrangig nebeneinander gewährleisteten Freiheitsrechte werden unterschiedlich gewertet und gewichtet, die Schranken der Demonstrationsfreiheit je nach Art des mit der Demonstration vertretenen Anliegens verschieden bestimmt. Eine demokratie-bezogene Interpretation der Grundrechte, wie sie uns heute vielfach begegnet, führt also zu einer differenzierten Wertung der Motive des Freiheitsgebrauchs mit der Folge einer nach Art der Motivation unterschiedlichen Bestimmung des Freiheitsumfangs. Mir scheint, daß dies dem Gedanken der rechtsstaatlichen als einer für alle rechtlich gleichen Freiheit stracks zuwiderläuft. Die funktional-demokratische Auslegung der Grundrechte - wie ich es einmal nennen will - verfehlt die individual-rechtliche Intention der Grundrechte und trifft damit, glaube ich, den Rechtsstaat im Kern. Man braucht sich nur einmal auszumalen, da $B$ diese Interpretationsmethode auf das Grundrecht des Art. 5 Abs. 3 GG angewendet wird, so daß sich das $\mathrm{Ma} \beta$ der Wissenschaftsfreiheit des einzelnen nach dem Grade der öffentlichen oder demokratischen Relevanz seiner wissenschaftlichen Utberzeugung bestimmt!

Die zweite Uberlegung, die ich hier anstellen möchte, gilt dem Verhältnis von Demokratie und Selbstverwaltung und zwar insbesondere der Bedeutung, die in diesem Zusammenhang einem der fundamentalen Sätze unseres Verfassungsrechts, Art. 20 Abs. 2 Satz 1 GG, zukommt. Ich vermag diesen Satz nur dahin zu verstehen, daß alle öffentliche Gewalt in der Bundesrepublik, gleichviel von wem und wie sie ausgeübt wird, der unmittelbaren oder mittelbaren Legitimation durch das Volk, und zwar durch das Staatsvolk, d. h. also entweder das Bundes- oder das Landesvolk, bedarf. Wenn das so ist, dann ist aber Selbstverwaltung nur zu begreifen entweder als ein Stück nur von einem Teil des Volkes legitimierter öffentlicher Gewalt, als echte Autonomie und damit als Durchbrechung jenes verfassungsrechtlichen Fundamentalprinzips, als Ausnahme also, die von Fall zu Fall des Nachweises ihrer Zulässigkeit am Maßstab der Verfassung bedarf. Oder aber Selbstverwaltung ist zu begreifen als ein Stück vom Staat delegierter öffentlicher Gewalt mit der unabdingbaren Folge des Vorbehalts staatlicher Aufsicht, die zumindest Rechtsaufsicht sein 
muß. Ich halte diese zweite Auffassung für richtig, auch für den Bereich der kommunalen Selbstverwaltung, für die sich ja noch am ehesten die andere begründen läßt. Dafür spricht, daß die Gemeindeordnungen neben den Bestimmungen über die Rechtsaufsicht sämtlich auch Vorschriften enthalten, die eine effektive Verantwortlichkeit der Ratsmitglieder und sonstiger Ehrenbeamter gegenüber der Aufsichtsbehörde gewährleisten, wobei es sich um eine notwendige Bedingung einer wirksamen Rechtsaufsicht handelt. Verliert man diese immanenten Grenzen des Selbstverwaltungsprinzips aus den Augen, gefährdet man nicht nur die Demokratie, wie sie das Grundgesetz versteht, sondern wiederum auch das Prinzip der Rechtsstaatlichkeit. Denn wenn der Staat - eine Vorstellung, wie sie etwa in dem bekannten Buch von Ulrich Preuß über den staatsrechtlichen Begriff des Offentlichen begegnet - in eine Vielzahl autonomer, von jeglicher Aufsicht befreiter Gruppen zerfiele, die sich - wie sich am Rande versteht: auf der Grundlage vom Staat beschaffter Mittel - selbst verwalten, dann wäre ein rechtliches Chaos die unausbleibliche Folge. Daß Selbstverwaltung die Vorhaltung autonomer Entscheidungsräume impliziert, wie das Herr von Simson gefordert hat, wird durch diese Feststellungen nicht ausgeschlossen.

Auch hier zeigt sich also, um mich der österreichischen Bildersprache $\mathrm{zu}$ bedienen, daß man die Bausteine der rechtsstaatlichen Demokratie nicht beliebig miteinander vertauschen kann, ohne das Ganze zu schädigen.

Böckstiegel: Ich möchte mich kurz fassen, weil manches von dem, was ich anmerken wollte, in der bisherigen Diskussion schon gesagt worden ist. Ich darf anknüpfen an das, was Herr von Simson in seinen Leitsätzen 23 und 35 und Herr Kriele in seinem Leitsatz 13 als Problematik angesprochen haben. Es scheinen mir zwei Entwicklungen zu sein, die man mit unserem gegenwärtigen staatsrechtlichen Apparat, der versucht, demokratische Verfahren durchzusetzen, nicht sicher im Griff hat.

Die eine ist die Änderung der Gewaltenteilung im staatlichen Dezisionsprozeß, und zwar nicht der üblicherweise gemeinten unter den drei staatlichen "Gewalten", sondern der Gewaltenteilung zwischen den staatlichen Funktionsträgern und den nichtstaatlichen gesellschaftlichen Kräften und außerdem auch unter diesen gesellschaftlichen Kräften selbst. Die zweite Entwicklung ist jene, welche Herr Kaiser vorhin schon angesprochen hat. Der neue Weg der Entscheidung, der sich insbesondere im Bund, aber auch auf kommunaler Ebene und anderen Ebenen zeigt. Hier ist ein Einbruch industrieller Dezisionsme- 
thodik in den staatlichen Dezisionsproze $B$ festzustellen. Ich weise als Beispiel nur hin auf die insbesondere im Bundeskanzleramt entwickelten neuen Planungsmechanismen.

Man kann meines Erachtens nicht einfach über diese Entwicklungen hinweggehen und sagen, wir müßten ihre Ergebnisse hinnehmen. Aufhalten läßt sich dieser Prozeß zwar nicht, aber er muß berücksichtigt werden. Sonst führen die staatlichen Dezisionsprozesse zu Ergebnissen, die letztlich demokratisch nicht mehr legitimiert sind. Industrielle Entscheidungsprozesse werden heute optimiert mit der sogenannten Netzplantechnik. Ich glaube, was aussteht, ist der Netzplan für jede wichtige Staatsdezision. Ich möchte insofern etwas der allerletzten These von Herrn von Simson widersprechen, wenn er sagt, diese neuen gesellschaftlichen Entwicklungen sehe er zwar, zur Zeit sei aber noch nicht die Möglichkeit gegeben, sie in den Griff zu bekommen. Ich glaube, damit können wir uns nicht abfinden. Diese Entwicklungen gehen weiter und sie verhindern, daß das demokratische Prinzip - was immer man darunter genau verstehen mag - Maßstab aller Faktoren ist, die im Dezisionsprozeß eine erhebliche Rolle spielen.

Scheuner: Muß Demokratie eine unvernünftige Entscheidung ergeben?

Ich glaube, es geht um die Sicherung eines demokratisch legitimierten Entscheidungsverfahrens. Das demokratische Prinzip zwingt uns, verfahrensmäßig sicherzustellen, daß möglichst wenig Unheil durch unkontrollierte Entscheidungseinflüsse geschehen kann. Diese Sicherstellung scheint mir nicht möglich zu sein, solange man diese beiden neuen Entwicklungen, die ich hier nur angedeutet habe, nicht in dieses Verfahren einbezieht und dabei versucht, die ihnen entsprechenden Kontrollen einzurichten.

Brohm: Ich kann an den letzten Beitrag anknüpfen und möchte auf das Problem der Komplexität der sozialen Verhältnisse hinweisen. Sie hat zur Folge, daß wir heute wichtige Entscheidungen nur noch durch Sachverständige treffen können, weil Sachverständige allein imstande sind, die Folgen etwa wirtschafts- und sozialpolitischer Maßnahmen einigermaßen vorauszusehen. Die Schwierigkeit ist doch nun die, diese Notwendigkeit sachverständiger Entscheidungen mit dem demokratischen Prinzip zu koppeln. Schließlich bedeutet Demokratie im allgemeinen Verständnis "Mitwirkung“. Die Konsequenz der gegenwärtigen Situation, scheint mir, hat Herr $v$. Simson in Leitsatz 29 aufgezeigt: Die Möglichkeit einer Mitwirkung 
besteht heute nur noch darin, pauschale Urteile zu füllen. Der Wähler kann die Staatsführung ersetzen, aber kaum einzelne Maßnahmen beeinflussen. Herr Geck hat diesen Leitsatz etwas korrigiert und darauf hingewiesen, daß die Staatsführung oft auch in ihrer Willensbildung zu einzelnen konkreten Fragen durch organisierte Gruppen beeinflußt werde. Dieser Gesichtspunkt trifft aber im wesentlichen nur auf festgefügte Organisationen zu. Nichtorganisierte Interessen haben diese Möglichkeiten nicht. Mir scheint daher, daß wir nach Formen suchen mübten, in denen auch etwa ad hoc gebildete Gruppen ihre Bedürfnisse auf institutionellem Wege artikulieren und so die Willensbildung der Führungsspitze beeinflussen können.

Sattler: Gestatten Sie mir bitte, daß ich wegen ihrer großen Wichtigkeit doch noch ein paar Worte zu der Frage der Beibehaltung oder des Verlustes des Mandats im Falle des Parteiwechsels des Abgeordneten sage. Meines Erachtens ist es ein Irrtum anzunehmen, daß der Mandatsverlust im Falle des Parteiwechsels dem demokratischen Gedanken besser als die Beibehaltung des Mandats entspricht. Das wäre vielmehr nur dann der Fall, wenn das Volk bei den Wahlen wirklich eine bis ins letzte eindeutige Entscheidung über die künftige Gestaltung der Politik in allen ihren Einzelheiten treffen könnte. Unter dieser Voraussetzung wäre es sicher richtig, daß der Parteiwechsel des Abgeordneten den Verlust des Mandats nach sich ziehen müßte; denn dann würde der Abgeordnete sich mit dem Wechsel der Partei ja notwendig mit der klaren Wahlentscheidung des Volkes in Widerspruch setzen.

Tatsächlich kann das Volk ja aber bei den Wahlen immer nur eine Entscheidung sehr allgemeinen Charakters über den künftigen Regierungskurs treffen und muß die Ausführung dieser Entscheidung im einzelnen den von ihm gewählten Repräsentanten überlassen. $\mathrm{Daß}$ es dabei zu Meinungsverschiedenheiten darüber kommen kann, wie der Volkswille tatsächlich im einzelnen zu verwirklichen ist, ist ebenso natürlich, wie sich die Frage, wer im Falle der Entstehung solcher Meinungsverschiedenheiten mit seiner Auffassung im Recht ist, im allgemeinen nur sehr schwer, wenn überhaupt beantworten lassen wird. Infolgedessen ist es auch keineswegs sicher, dals sich der Abgeordnete, der die Partei wechselt, wirklich mit dem Volkswillen, so wie er bei den Wahlen zum Ausdruck gekommen ist, in Widerspruch setzt.

Aus diesem Grunde läßt sich schon unter dem Gesichtspunkt der Verwirklichung des bei den Wahlen unmittelbar geäußlerten Volkswillens der Mandatsverlust des die Partei wechweln- 
den Abgeordneten nicht oder jedenfalls nicht durchweg rechtfertigen. Ganz und gar zuwider läuft jedoch der Mandatsverlust als Folge des Parteiwechsels des Abgeordneten dem Interesse an einer möglichst weitgehenden Berücksichtigung des Volkswillens, wenn man die Dinge nicht unter dem Gesichtspunkt der Verwirklichung des bei den Wahlen unmittelbar geäußerten Volkswillens, sondern der mittelbaren Einflußnahme des Volkes auf die Gestaltung der Politik im Wege der öffentlichen Meinungsbildung betrachtet. Würde sich doch in dem Maße, in dem die Einführung des Mandatsverlustes als Folge des Parteiwechsels die Stellung der Abgeordneten gegenüber den Parteien schwächen würde, zugleich auch die Aussicht des Volkes auf eine Beachtung seiner Meinungsäußerungen zu einzelnen politischen Tagesfragen vermindern.

Wie groß oder wie gering man diese Aussicht unter den gegebenen Verhältnissen nämlich auch immer einschätzen mag, so sind allein auf Grund der Tatsache, daß sie sich alle vier Jahre der Wiederwahl durch das Volk als ganzes stellen müssen, die Abgeordneten doch auf jeden Fall diejenigen, die der Meinung des Volkes auch in der Zeit zwischen den Wahlen am ersten Rechnung zu tragen bereit sein werden. Ganz im Gegensatz zu dem, was seine Befürworter meinen, würde deshalb auch die Einführung des Mandatsverlustes als Folge des Parteiwechsels nicht auf eine größere Sicherung, sondern auf eine Verringerung der politischen Einflußmöglichkeiten des Volkes hinauslaufen, weil sie mit der Stellung der Abgeordneten die Stellung der geborenen Adressaten der laufenden Meinungsäußerung des Volkes entscheidend schwächen würde.

Häberle: Es hat mich am bisherigen Verlauf der Diskussion etwas überrascht, daß die von der "neuen“ oder - wie wir nun von Herrn $v$. Simson wissen - „betagten“ Linken vorgebrachten Argumente zum Demokratieverständnis bisher nicht zur öffentlichen Sprache kamen. Das nachzuholen fühle ich mich um so mehr ermutigt, als mich heute früh einer meiner Kollegen auf meine rote Krawatte (zum schwarzen Anzug!) aufmerksam machte.

Mir scheint, es sind sechs Gesichtspunkte, die wir berücksichtigen sollten, weil sie - vielfältig gefiltert - den Anstoß zu einem gewandelten Demokratieverständnis „unter" dem Grundgesetz gegeben haben. Ich meine jedenfalls, daß ich insofern den Kontroversen der letzten Jahre manche Einsichten verdanke. Diese Kritik „von links“ im Rahmen der Verfassung aufzunehmen, fällt um so leichter, als beide Referate eine eindrucksvolle Grundlage dazu gelegt haben und uns in den Stand 
setzen, mancher Herausforderung sicherer zu begegnen. Meines Erachtens ist an folgende Gesichtspunkte zu denken:

1. an die stärkere Betonung der Seite des Konflikts im demokratischen Willensbildungsprozeß, die eine wichtige Korrektur an manchen früheren, zu starken Harmonisierungstendenzen bedeutet, 2. an die verfassungsrechtliche Verortung der außerparlamentarischen Opposition im Grundrechts- und organisatorischen Teil der Verfassung (einschließlich ihrer Demonstrationsfreiheit) - eine Opposition, die mit der innerparteilichen und innerparlamentarischen vielfältig verschränkt ist, 3 . an die Forderungen nach einem Mehr an - freilich im einzelnen zu differenzierender - Offentlichkeit, 4. an die neu aufgerollte Pluralismus-Diskussion; hier hat man sich in Realanalyse die Frage zu stellen, wie pluralistisch unser verfassungsrechtlich gewollter Pluralismus wirklich ist, der gelegentlich zur bequemen Ausrede wird und nicht-repräsentierte Pluralgruppen übersieht; ich denke an die Nichtzulassung bestimmter Gruppen zur konzertierten Aktion, 5. an die stärkere Bewußtmachung der demokratischen Funktion des Minderheitenschutzes, den bei uns - ausgerechnet in einer parlamentarischen Demokratie - nicht selten das Bundesverfassungsgericht übernehmen muß, 6. an das Verständnis der Grundrechte auch als öffentliche Teilhaberechte und -freiheiten (z. B. die Ausbildungsfreiheit); dem wird der von Herrn von Simson angedeutete Partizipationsgedanke gerecht. All diese Aspekte verfassungsimmanent stärker zu berücksichtigen, hat mich die Kritik "von links" veranlaßt - so unterschiedlich sie im übrigen motiviert sein mag.

Dürig: Ich bitte um Nachsicht, daB ich noch einmal grundsätzlich werde; Sie wissen aber, das geht bei mir immer sehr kurz und schnell. Ich glaube nicht, daß wir im Demokratiebegriff ohne Einsatztat auskommen, nämlich ohne eine bestimmte Anthropologie. So leicht können wir nun den alten Rousseau auch nicht hinwegdiskutieren. Es geht doch um die Vorstellung, wie man's mit dem Menschen als solchem hält. Hat man eine pessimistische Auffassung vom Menschen: dumm, feige, böse, faul usw. müssen Sie zu anderen Verfassungsarchitekturen kommen; etwa zur „Erziehungsdiktatur" oder zu einem Politik-ZK, das allein im Besitz der Wahrheit und des Richtigen ist. Demokratie ist nur nach- und mitzuvollziehen, wenn man einen gewissen Optimismus dem Menschen gegenüber hat, wenn man letztlich "ens" und „bonum“ für vertauschbar hält. Natürlich ist da bei Rousseau viel Hymnik, Schwarmgeisterei und Realitätsdefizit. Aber auch wenn wir auf dem Teppich 
bleiben und beim realen Menschen nicht an geheimnisvolle Mutationen glauben, denken wir doch etwa schon beim demokratischen Mehrheitsprinzip bewußt oder unbewußt mit, daß der Mensch als solcher im Letzten irgendwie gut und vernünftig ist, daß es eigentlich nur so gerechtfertigt werden kann, weil so gesehen die "maior pars" der Quantität nach dann im Prinzip auch die "sanior pars" der Qualität nach ist.

Und ein Zweites. Weil wir in politicis als Realisten keine absoluten Heilslehren, keine Ausschließlichkeitsansprüche gelten lassen, denken wir in den westlichen Demokratien - in den Texten nirgends ausgesprochen - immanente Spielregeln der Korrigierbarkeit und Revozierbarkeit mit, die aber mehr sind als bloße Spielregeln, vielmehr durchaus zum Inhalt des Demokratiebegriffs gehören: $\mathrm{Da}$ wo eine Mehrheit vorhanden ist, wenn man nicht mit den berühmten $99 \%$-Wahlen lügt, auch eine Minderheit vorhanden ist. Daß die überstimmte Minderheit von heute die Chance hat, die Mehrheit von morgen zu sein. $\mathrm{Daß}$ es sich bei Wahlen - Herr Leibholz, Herr Maurer, das ist Ihr Problem der Alternative - um Auswahl mindestens unter zwei Möglichkeiten, etwa zwei Parteien, handeln muß. $\mathrm{DaB}$ nach der Wahl die überstimmte Minderheit als staatsrechtliche Größe, als Opposition anerkannt wird, womit nun der demokratische Machtauswechselungsvorgang von vorn beginnt, in dem keine Türen endgültig zugeschlagen werden.

Und hier habe ich nun drittens, mit Ihnen Herr Herzog, gerade bei dieser Korrekturmöglichkeit und dieser Revozierbarkeit eine präzise Sorge beim Demokratiebegriff. Wenn man nämlich im Demokratisierungsrausch erst einmal alle Lebensbereiche demokratisiert, potentiell öffentlich, politisch gemacht hat, wenn Staat und Gesellschaft deckungsgleich werden, dann, meine Herren, gehen mal wieder die Lichter aus. Dieser Vorgang ist nämlich nicht mehr revozierbar. Ich finde jedenfalls in derart durchsozialisierten Systemen dafür keinen historischempirischen Beleg. Sie können nicht einem derartigen totalitären System - und die totale Gesellschaft ist für mich genau so gefährlich wie der totale Staat, weil sie sich darüber hinaus nämlich nicht um machtteilende Zuständigkeiten kümmert gleichsam von rückwärts her und nachträglich wieder Freiheitsräume und ausgrenzende Grundrechte einziehen. So etwas hat noch nie geklappt und wird es auch nie geben.

Und ein Letztes zum Demokratiebegriff. Herr von Simson, es geht um den erregenden Aspekt in Ihrem Leitsatz 34. Hier erleben wir eine Schere, die immer größer wird. Es klang vorhin an, daß die supranationalen Organisationen oft autokra- 
tisch arbeiten. Ich würde sagen "technokratisch" und denke an die gesamte Technologie, die ganz anders verfaßt ist, als demokratisch auf Egalisierung tendierend. Die Technologie ist ganz präzise vertikal geschichtet, mit elitären Befehlssträngen von oben nach unten. Und auch das Team ist ja als solches nicht demokratisch, sondern eine Form der Arbeitsteilung, bei der einer der BoB ist. Und so erklärt sich wohl auch viel in der Mentalität unserer jungen Leute, mit denen wir es täglich zu tun haben. Es ist die Angst, da $B$ sie im Leben in ganz dezidierte Befehlshierarchien hineinkommen werden, sei es am Operationstisch, im Industriemanagement, im Cockpit, bei der NASALeitstelle oder wo immer Sie wollen. Und da sie wissen, daß wir technologisch nicht mit der großen Verweigerung zu den Lagerfeuern zurückkönnen, werden alle Schonräume, in denen scheinbar noch egalitäre demokratische Verfahren möglich sind, bis zum Exzeß ausgenützt. So wird etwa auch der Freiraum der Universität „durchdemokratisiert". Nur muß man sich allmählich darüber klar werden, daß die organisationsrechtlich überdrehte "moderne" Universität mit ihren legitimierten internen Gruppenkämpfen um "Macht" eine ständestaatliche Karrikatur der Demokratie ist. Daß also - und dies ist nun wirklich hier meine allerletzte Sorge - die Universität in der heutigen "demokratisierten" Form das Ziel des Einübens demokratischen Verhaltens diametral verfehlt. Anders gesagt: Was heute an der neuverfaßten Universität ausgetobt wird, ist ein Anschauungsunterricht, der bei $90 \%$ unserer Studenten die Staatsform der Demokratie insgesamt in Mißkredit bringt.

Ipsen: Was ich zu sagen habe, habe ich schon mehrfach gedruckt geäußert (Fusionsverfassung Europäische Gemeinschaften (1969) S. 58 ff.; Verfassungsperspektiven der Europäischen Gemeinschaften (1970) S. 14 ff.) - aber wer liest das schon? Deshalb sei es hier wiederholt.

Herr von Simson hat unter (7) drei Mittel zur Ubertragung des demokratischen Prinzips in die Staatswirklichkeit genannt und unter (21) bis (23) zum Mittel der Willensverteilung sehr zutreffend die Aufmerksamkeit auf die Frage gelenkt, ob und wie es praktiziert werden könne im zwischenstaatlichen Bereich der europäischen Gemeinschaften, auf die mit Ermächtigung des GG auch deutsche Hoheitsrechte übertragen seien. Aufmerksamkeit ist hierzu sicherlich geboten, zumal die Gemeinschaftsbefugnisse an Ausdehnung zunehmen und die Gemeinschaften sich auch räumlich ausdehnen können. Der Referent ist der Auffassung, es entspringe einer fundamentalen Uberzeugung, auch in solchen neu entstehenden Herrschaftstypen 
auf demokratische Bindung zu achten. Die Schlußthese (36) enthält dann zum deutschen Verfassungsrecht die Forderung, neue Formen der Partizipation und Kontrolle zur Bewahrung von Demokratie und Freiheit zu entwickeln, wozu das GG zwar keine eigenen Lösungen anbiete, denen gegenüber es aber offen sei.

Angesichts der Bedrohungen, denen das demokratische Prinzip in der Wirklichkeit heute ausgesetzt ist, darunter der unter (34) genannten der technologischen Entwicklung und der Vermassungsprobleme, fehlt mir zu der begründeten Forderung des Referenten nach neuen Formen in seinen Ausführungen ein Schuß „Konstruktivität" oder Therapie, die, wie ich glaube, gerade der europäischen Wirtschaftsintegration entnommen werden kann. In ihr sind nämlich Formen der Willensverschränkung praktiziert und erprobt worden, die auch innerstaatlich auf ihre Eignung und Verwendbarkeit überprüft werden sollten. Diese Erfahrungen sind zwar leider von deutscher politischer Wissenschaft bislang nicht aufgearbeitet worden. Darin sind uns Angelsachsen und Franzosen vorauf. Aber das befreit uns nicht von dieser Aufgabe. Ich meine einmal die Struktur der an Bedeutung zunehmenden Entscheidungsprozesse aus Sachzwang mit der Frage, ob auch sie demokratischer Rechtfertigung bedürfen oder auch nur zugänglich sind. Ich meine zum anderen die Willensverschränkung im Zusammenwirken von Kommission und Rat, der Kommission mit den großen Ausschüssen und auch mit der Versammlung. Ich meine endlich die Mehrgleisigkeit der politischen Gesamtwillensbildung durch das Zusammenwirken der Gemeinschaftsorgane mit den Mitgliedstaaten sowie die zur Entscheidungsvorbereitung abklärende Diskussion zwischen den nationalen Bürokratien und der Kommission - Formen föderaler Willensverteilung i. S. der These (26), aber hier auf einer höheren Stufe.

Wenn sich hier im Integrationsbereich neue Formen entwickeln, liegt es nahe, sie bei Eignung auch für die innerstaatliche Verfassungsfortbildung zu nutzen, während bisher im Schablonedenken struktureller Homogenität überwiegend angenommen wurde, es gehe nur darum, den überlieferten und, wie wir heute erkennen, reformbedürftigen - Mechanismus des Nationalstaates seinerseits auf die Gemeinschaftsverfassung zu übertragen.

Herr Kriele hat sinngemäß gesagt, das Problem des Verfassungsstaates liege darin, Vertrauen in die Güte der Mächtigen zu haben oder ihn durch institutionelle, rechtsstaatliche Sicherungen zu gewährleisten. Ich bin für die Sicherungen, 
und in welcher Weise das Gemeinschaftsrecht ihre Ausformung entwickelt und erprobt, sollte auch für unser Verfassungsrecht beachtet werden.

Kriele (Schlußwort): Ich bitte zu verstehen, daß ich aus Zeitgründen nur zu einigen ausgewählten Punkten Stellung nehmen kann und bitte mir zu glauben, daß die übergangenen Beiträge nicht weniger anregend, wertvoll und interessant für mich gewesen sind.

1. Die institutionelle Seite der Grundrechte. Herr Häberle, ich stimme Ihnen darin $\mathrm{zu}$, daß die Grundrechte nicht nur eine individualrechtliche, sondern auch eine institutionelle Seite haben. Insbesondere die Meinungsfreiheit dient nicht nur dem Schutz des Einzelnen, sondern ist unerläßliche Voraussetzung für das Funktionieren der parlamentarischen Demokratie und von daher zu interpretieren. Ich meine, Herr Klein, die gesetzliche Forderung, der Wissenschaftler müsse sich vor irgendeiner Instanz rechtfertigen, müsse die gesellschaftliche Relevanz seiner Forschung aufweisen, ist selbstverständlich eine klare Verletzung des Art. 5 Abs. 3. Die individual-rechtliche Seite des Grundrechts wird ja dadurch nicht ausgeschlossen, daß man den institutionellen Aspekt hinzunimmt.

Ein Beispiel dafür, wie wichtig dieser institutionelle Aspekt ist, ist die von verschiedenen Seiten angesprochene Pressekonzentration. Dazu möchte ich nur eine Gedankenhypothese zur Erwägung geben, die das Problem einfacher und plausibler machen kann: stellen Sie sich bitte vor, der ganze SpringerKonzern falle, etwa durch Erbgang, in die Hände eines Mannes, der so weit links von der Mitte stünde, wie Springer rechts von der Mitte steht, und der ihn durch Personalpolitik usw. zu einem Instrument seiner Richtung mache. Dann werden sich bei manchen die Zögerungen und Hemmnisse im Begreifen des Problems auflösen und sie werden leichter verstehen, wieso die Pressekonzentration ein so ernstes Problem ist.

2. Rechtsstaat: Ich möchte die traditionelle Unterscheidung von Rechtsstaat und Demokratie nicht mehr gelten lassen. Denn der traditionelle Rechtsstaatsbegriff gehört $\mathrm{zu}$ einem Rechtsdenken, das sich zu wenig für die Realisierungsbedingungen des Rechts interessiert hat. Im traditionellen deutschen Rechtsstaatsbegriff ist der Rechtsstaat vereinbar mit Absolutismus. Die materielle Rechtsidee wirkt als moralischer Appell an den Souverän, und gerade das, Herr Dürig, setzt voraus, da $\beta$ der Mensch gut ist, nämlich der Machthaber. Vertrauen in den Menschen zu haben, ist nicht der Grundgedanke der Demo- 
kratie, sondern des Absolutismus. Die Anhänger der alten, mit dem Absolutismus vereinbaren Rechtsstaatsidee sagten: „Der Mensch ist böse, ausgenommen die Mächtigen in Staat, Wirtschaft und Militär". Die Tradition der parlamentarischen Demokratie ging davon aus, der Mensch sei so etwas in der Mitte zwischen gut und böse, und die Mächtigen seien auch nicht besser als andere Leute. Deshalb müsse ihre Macht institutionell eingebunden werden, und deshalb dürfe es keinen Souverän geben. Und deshalb wird zur entscheidenden Frage nicht die nach dem Inhalt der materiellen Rechtsidee, den man in einem aus Prämissen abgeleiteten Naturrechtssystem darstellen könnte. Entscheidend wird vielmehr die Frage nach den Realisierungsbedingungen des Rechts. Die Naturrechtsidee in der parlamentarisch-demokratischen Tradition ist mit der Frage nach den institutionellen Realisierungsbedingungen untrennbar verknüpft. Von den demokratischen Institutionen erhoffte man sich erhöhte Chance der Vernünftigkeit des Rechts.

Das impliziert eine Fortschrittsidee, die sich natürlich auf das Rechtlich-Institutionelle beschränken muß. $\mathrm{DaB}$ wir neben dem rechtlich-institutionellen Fortschritt vielleicht aus technischen Gründen in Katastrophen steuern, ist eine andere Frage. Im Rechtlich-Institutionellen ist ein Fortschritt, meine ich, Herr Walter, erweisbar. Ich möchte die These aufstellen: Das Recht ist vernünftiger als die Leute. Wenn man unmittelbar plebiszitäre Demokratie einführen wollte, dann hätten wir sehr bald wieder die Todesstrafe und die Abschaffung der Kautelen, die das gerechte Verfahren für den Angeklagten garantieren usw. Dann genügte ein grausiger Mord, um die Emotionen lebendig werden zu lassen, die all das hinwegspülen, was in unserem Recht an Vernunft enthalten ist. Das Recht ist deshalb vernünftiger als die mehr oder weniger durchdachten Meinungen der Leute, weil es sich im Zusammenwirken so vieler Argumente und in ihrem wechselseitigen Abklopfen und im wieder neuen Entscheiden und Weiterdiskutieren immer von neuem erproben und bewähren muß. Die Chancen für Fortschritt im Recht gibt es überall, soweit es Geistesfreiheit gibt. Aber diese Chancen zu optimieren, das ist der Grundgedanke der parlamentarischen Demokratie.

3. Und ein dritter und letzter Punkt, den unter anderem Herr Maurer und Herr Kopp angesprochen haben: politische Kultur. Ich glaube auch, da $\beta$ institutionelle Sicherungen allein unsere Demokratie uns nicht erhalten können. Die Weimarer Republik ist ja nicht nur etwa daran gescheitert, daß wir keine Art. 79 III und 21 II hatten, sondern eine Demokratie mit nicht ge- 
nügend Demokraten. Und mir scheint, daß, was jetzt wieder auf uns zukommt an Aggressivität gegen unsere Demokratie, mit Moral nicht sehr wirkungsvoll zu beantworten ist. Denn die politische Kultur ist nicht eine Frage der Moral, sondern der Einsicht, die sich in eingelebten Konventionalregeln niederschlagen muß. Im Jahre 1923 veröffentlichte Carl Schmitt seine "Geistesgeschichtliche Lage des heutigen Parlamentarismus", deren wesentliche Grundgedanken heute bei der neuen "Linken“ wieder auftauchen. Im selben Jahr erschien ein kaum beachteter Vortrag von Ernst Troeltsch, in dem er die geistesgeschichtliche Grundlage der Demokratie kennzeichnete als die gemeineuropäische Naturrechtstradition. Sein Grundgedanke war, daß Deutschland aus dieser Naturrechtstradition seit der Mitte des vorigen Jahrhunderts herausgefallen ist. Man kann die "hundert finsteren Jahre" in Deutschland ziemlich genau festlegen, nämlich von 1849, dem Jahr des Zusammenbruchs der Hoffnungen auf Verknüpfung von Demokratie und Rechtsverfassung, bis 1949, dem Jahr der Schaffung des Grundgesetzes. In diesen Jahren sind wir in einen Strudel des Verlustes der Naturrechtstradition und damit in die politische Katastrophe geraten. M. E. ist das Problem der Legitimität und damit der Stabilität unserer Demokratie nicht eine Frage der moralischen Entrüstung, sondern eine Frage der Vergegenwärtigung der wirklichen geistesgeschichtlichen Grundlage der parlamentarischen Demokratie. Und damit möchte ich Ihnen danken.

Von Simson (Schlußwort): Frau Kollegin, meine sehr verehrten Herren! Ich werde mich in der Ausdehnung meines Schlußworts zu beherrschen wissen, da ich einen Blick auf die Uhr geworfen habe und auch finde, daß viele Fragen, die zur Diskussion gestellt worden sind, doch so tief gehen, daß sie sich nicht innerhalb eines Schlußwortes zusammenfassend behandeln lassen.

Ich möchte nur ein paar Fragen beantworten, die direkt gestellt worden sind. Einmal möchte ich auf Herrn Roelleckes sehr richtige Bemerkung antworten, daß die Theorie der Demokratie natürlich nicht ausreichend entwickelt ist in dem Sinne, daß dazu nichts Neues mehr zu sagen wäre. Da war ja auch schon das Referat von Herrn Kriele der lebendige Gegenbeweis. Ich wollte nur sagen: soweit die Abgrenzung der Demokratie von der Nichtdemokratie in Frage kommt, verfügen wir über ausreichende Grundlagen, um uns nicht weiter verunsichern zu lassen. Wir wissen ganz genau heute, was Demokratie im Verhältnis zur Nichtdemokratie ist. Wie sie in posi- 
tiver Ausgestaltung sein könnte und wie weit sie nicht $\mathrm{zu}$ verwirklichen ist, darüber sind natürlich sehr, sehr viele Zweifel zulässig.

Was Herrn Gecks Beitrag angeht, so ist mir zwar bewußt, daß man in dem Rahmen einer Diskussion nicht ablesen soll. Ich werde aber trotzdem meine Antwort darauf ablesen und Ihnen sagen, was ich dazu geschrieben habe, nämlich: "Geck hat recht!" Natürlich! Bloß kam es mir auf das Prinzip an, das ich Ihnen auch nicht anders als prinzipiell darstellen konnte. Daß das aber nur mit Ausnahmen der erwähnten Art zutrifft, darüber kann gar kein Zweifel sein. Das hat ja Herr Küchenhoff auch schon hervorgehoben.

Die eigentlich schwierigste Aufgabe wurde mir gestellt von Herrn Herzog, wenn er verlangte, ich solle die Abgrenzung zwischen gesellschaftlich multipler und staatlich eindeutiger Betätigung präzisieren. Ich gestehe Ihnen ehrlich, daß ich mir nicht zutraue vor diesem Gremium mit der nötigen Präzision und mit der nötigen durchdachten Klarheit jetzt eine solche Abgrenzung darzubieten. Ich weiß sogar nicht einmal, ob ich im stillen Kämmerlein schon genügend dazu überlegt hätte, um selber eine solche Abgrenzung vornehmen zu können. Ich muß Ihnen also die Antwort schuldig bleiben. Ich kann jetzt nur sagen: im Prinzip sehe ich die Dinge so, da $B$ die autonomen Bereiche nach unten hin gesellschaftlich organisierte Bereiche sind, sich also aus einer gesellschaftlichen Betätigung zu einer Individualität zusammenkristallisieren. Das Resultat gesellschaftlicher Teilprozesse tritt dann in den Gesamtprozeß als teilnehmende Größe ein. Das ist eine Denk- und Erscheinungsform, die aus der Naturwissenschaft uns längst bekannt ist und neuerdings in die Soziologie übertragen wird; ich darf da vielleicht ein Buch erwähnen, es heißt "Les Dieux et les Rois" von Jacques Rueff (Jacques Rueff, Les Dieux et les Rois, Regards sur le pouvoir créateur, Paris, 1967), das mit einem vielleicht etwas übertriebenem philosophischen Anspruch überzeugend diese Konfiguration hervorhebt.

Auf Herrn Kaisers Frage nach den Tarifpartnern und ihrem Verhältnis zur staatlichen Kontrolle kann ich nur wiederholen, was ich schon anzudeuten versucht hatte. Ich glaube, daß gewisse Autonomien im Tätigkeitskreis der Tarifpartner tatsächlich in den Bereich der Staatsverantwortung eingreifen können; z. B. in die Konjunkturpolitik, die eben doch, wenn sie verantwortlich geplant werden soll, vom Staat geleitet werden muß. Das bedeutet, daß diesen Institutionen ein Spielraum angewiesen werden muß, und nicht eine volle Betätigung er-- 
laubt sein kann. Mestmäcker hat vor einigen Jahren einen sehr bemerkenswerten, von mir allerdings sachlich nicht gebilligten Aufsatz geschrieben (Wirtschaft und Verfassung, in: DOV, 1964, S. 606 ff.), in dem er glaubt, diesen Spielraum der zivilrechtlichen Auslegung überweisen zu dürfen, die eben vorgenommen werden müsse im Sinne der Staatszwecke. Ich glaube eher daran, daß hier ein verfassungsrechtlicher Leerraum besteht, der ausgefüllt werden müßte, daß also z. B. die Tariffreiheit doch ausdrücklich eingeschränkt werden sollte, und zwar mit dem Ziel, daß nicht in privater Entscheidung Wirtschaftsfakten geschaffen werden können, welche die Beeinflussung der Konjunktur durch den Staat vereiteln. Wenn man die Notwendigkeit einer staatlichen Konjunktursteuerung bejaht, dann muß man m. E. auch diese Einschränkung der Tarifautonomie durch den Staat bejahen. In den Niederlanden ist eine solche Einschränkung auch kürzlich erfolgt, in England bemüht man sich darum.

Was schließlich Herrn Ipsen angeht, so ist er leider weggegangen, wenn auch mit einer entschuldigenden Bewegung mir gegenüber. Ich wäre natürlich sehr versucht, meinen Freund Philipp Möhring hier nachzuahmen und zu sagen, ich hätte meinen Lösungsvorschlag deshalb nicht gebracht, weil ich Herrn Ipsen nicht durch den vollen Einsatz meiner Geisteskräfte bloßstellen wollte. In Wirklichkeit beruht aber meine Askese darauf, daß ein solcher Vorschlag weit über das Thema hinausginge. Wir haben ja heute als Thema „Das demokratische Prinzip im Grundgesetz" und da müßte ich mich, was Zukunftsmöglichkeiten betrifft, auf knappe Andeutungen beschränken. Auch damit würde ich aber jetzt den selbstgesetzten Spielraum überschreiten, und so will ich mich bescheiden und mich nur mit herzlichem Dank von Ihnen verabschieden.

Zacher: Meine Damen und Herren! Erlauben Sie mir einige subjektive Schlußbemerkungen. Für mich war unter all dem Bedeutsamen was heute gesagt worden ist, der bewegendste Satz der von Herrn Kriele, daß Demokratie Herrschaft des Volkes durch Herrschaft des Rechts ist. Ich glaube, das ist wirklich die beste Formel, auf die Demokratie als auf Dauer angelegtes Herrschaftssystem gebracht werden kann. Von daher verstehen wir auch, daß eine Demokratie, die überleben will als Demokratie, rechtsstaatliche Elemente impliziert. Und wir sehen, daß eine Demokratie nicht freigegeben werden kann von diesen Bindungen, sich durch die Herrschaft des Rechts zu verwirklichen, weil sie sonst verbrennt, sich verzehrt, explodiert oder auch nur einen Tag lang existiert, um sich wieder aufzu- 
geben, um mit dem Beispiel von Herrn Leibholz zu sprechen. Möge Herrschaft des Volkes Herrschaft des Rechts bleiben!

Ich darf nun Ihnen allen danken und auch noch einmal Herrn Walter und Herrn Eichenberger für Ihre Beiträge. Vor allem aber glaube ich, schulden wir alle herzlichen Dank den beiden Referenten dieses Tages. 
